\title{
A MEDIATION ANALYSIS OF SPIRITUALITY, WELLBEING, AND ACADEMIC PERFORMANCE IN FIRST-GENERATION \\ AND LOW-INCOME COLLEGE STUDENTS
}

\author{
A Dissertation \\ presented to \\ the Faculty of the Graduate School \\ at the University of Missouri
}

In Partial Fulfillment

of the Requirements of the Degree

Doctor of Education

by

\section{CHRISTOPHER BEGGS}

Dr. Barbara N. Martin, Dissertation Supervisor

MAY 2020 
dissertation in practice, C. Beggs

(C) Copyright by Christopher Beggs 2020

All Rights Reserved 
The undersigned, appointed by the dean of the Graduate School, have examined the dissertation entitled

A MEDIATION ANALYSIS OF SPIRITUALITY, WELLBEING, AND ACADEMIC PERFORMANCE IN FIRST-GENERATION AND LOW-INCOME COLLEGE STUDENTS

Presented by Christopher Beggs a candidate for the degree of doctor of education moreover, hereby certify that, in their opinion, is worthy of acceptance.

\author{
Dr. Barbara N. Martin
}

Dr. Sandra Hutchinson

Dr. David Kreiner

Dr. Carolyn P. McKnight 


\section{ACKNOWLEDGEMENTS}

First, to my mom, thank you. You never got to do anything like this because you took care of us since you were young and you did so by yourself. Our achievements are your achievements, we cannot and will not forget your lessons, love, and sacrifice for us.

To 1-B, I have never been on a more functional team in my life. Chris, Alizabeth, Trisha, and Brooke, you made me un-hate teamwork. You've got a friend in me.

To Frau Mellem, when I dropped out of high school, you told me you still expected me to make a contribution. Here is one, thank you.

To Shelley, we met on interview day and were instant friends. You do good work and take risks that make me envious. Thanks for being that cohort friend I could say things to that were unflattering and you did not judge me for them.

To Dr. David Kreiner, who talked me out of structural equation modeling that I had scribbled on a napkin, thank you. You have always been generous to me and others. Your reputation is earned.

To Drs. McKnight and Hutchinson who took time to review and provide feedback on this work, you keep integrity in this field.

To my wife, Meredith, who let me borrow her computer when I refused to buy another one, who would take the boys to their grandmothers so I could work, who would listen to me complain and celebrate this, who promised me a Tesla when this is done, who helps me finish things I start, thank you.

To my boys, Max, Ben, and (soon) Sam. Dad did this now so he did not have to do it later. Do favors for your future selves. 
To Dr. Martin. Who knew my educational life would start and end with you? How fitting and how lucky am I? I appreciate the guidance -- day or night - the stories, and most of all, the support to study this topic. From Kindergarten to Doctorate, I hope to make you proud.

To first-generation and low-income students, going first isn't easy and you won't have everything you need. Keep going.

To students who did not finish high school or are in some other ways considered a dropout, you still still get to decide how your story will go. 


\section{Table of Contents}

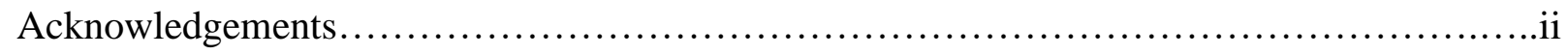

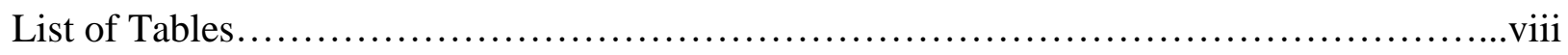

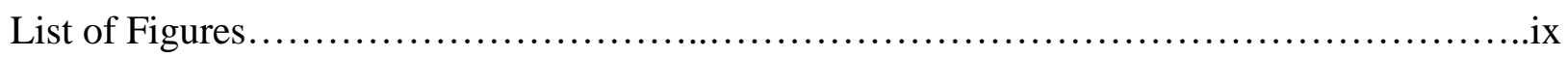

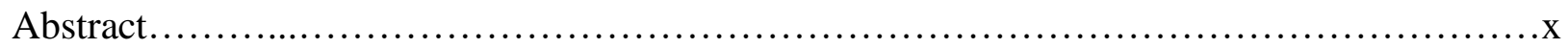

INTRODUCTION TO DISSERTATION $\ldots \ldots \ldots \ldots \ldots \ldots \ldots \ldots \ldots \ldots \ldots \ldots \ldots \ldots \ldots \ldots \ldots \ldots \ldots$

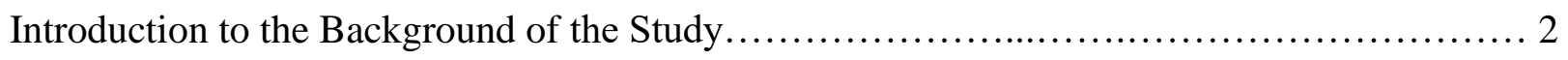

Statement of the Problem............................................................

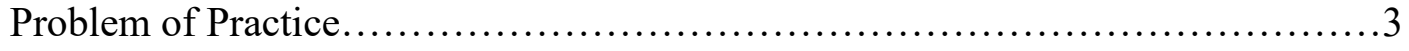

Existing Literature Gap.............................................4

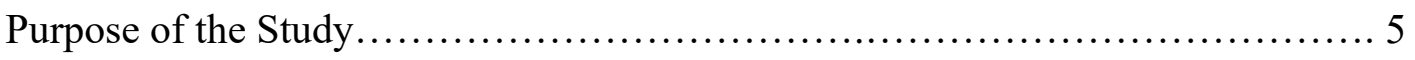

Research Questions and Hypotheses................................... 7

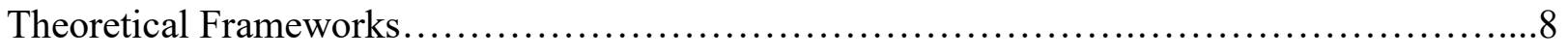

Spirituality.................................................................. 9

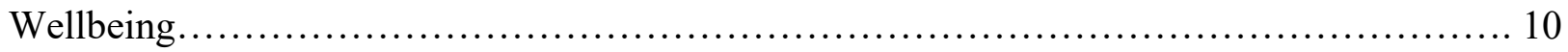

Faith Development Theory and Parks' Criticism........................... 11

Astin's Input-Environment-Outcome Model.............................. 12

Conceptual Framework: Chickering and Reisser's Seven Vectors of Development.............12

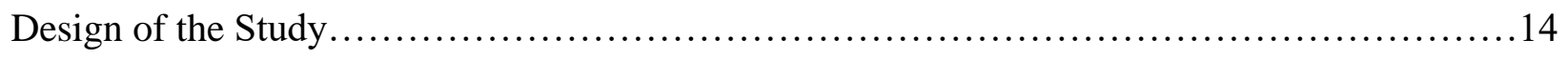

Study Setting .....................................................

Participants.......................................................... 15

Data Collection, Quantitative Analysis, and Survey Protocol.....................15

Limitations Assumptions, and Design Controls..............................20 


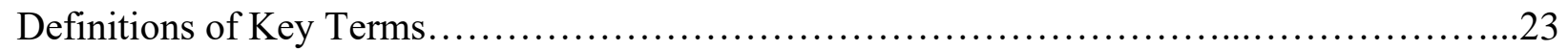

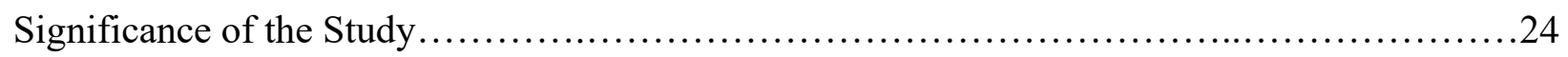

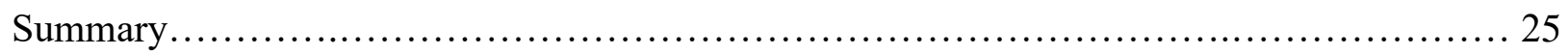

PRACTITIONER SETTING FOR THE STUDY ........................................... 26

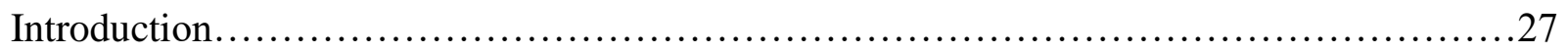

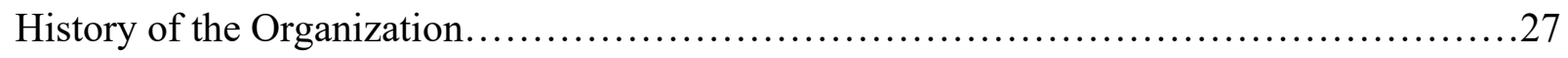

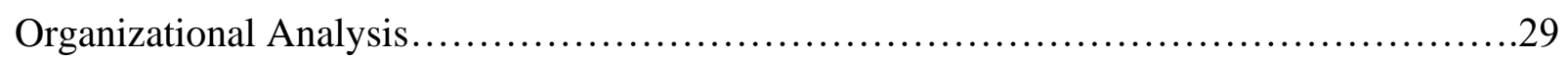

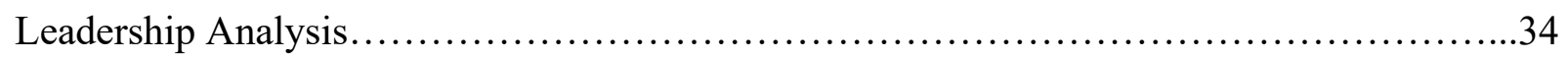

Implications for Research in the Practitioner Setting .......................................36

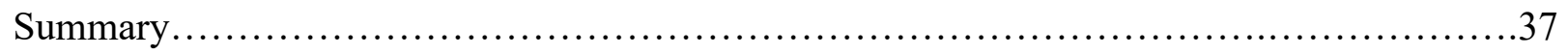

SCHOLARLY REVIEW FOR THE STUDY ........................................... 38

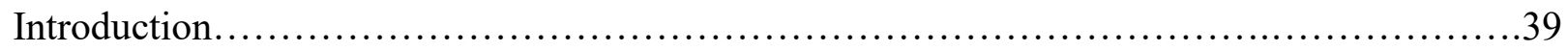

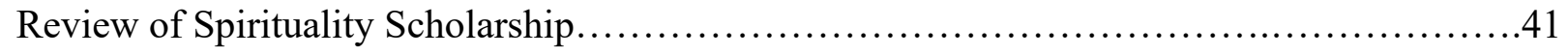

Spirituality and College Students........................................42

Review of Wellness and Wellbeing Scholarship......................................... 45

Spirituality and Wellbeing................................................46

Hedonic and Eudaimonic Wellbeing........................................46

Wellbeing for First-Generation and Low-income Students.................... 48

Seligman's PERMA Framework for Wellbeing ..........................................49

Review of College Student Development Theory Scholarship...............................49

Perry's Epistemological Development ..................................50

Faith Development Theory..........................................................................50

Park's Faith Development Model......................................................................52

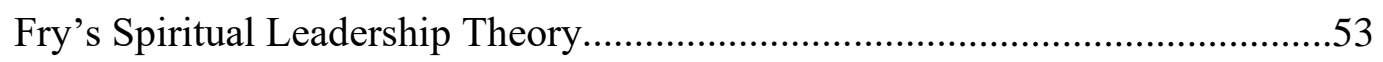

Astin's Input-Environment-Outcome Model.........................................................54 
Love and Talbot's Five Processes of Spiritual Development............................55

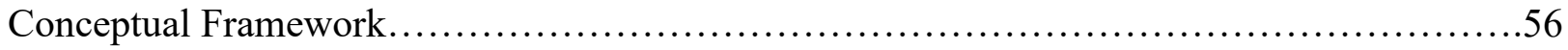

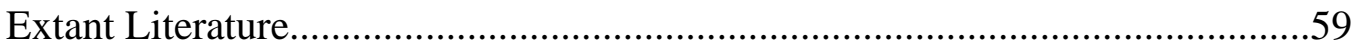

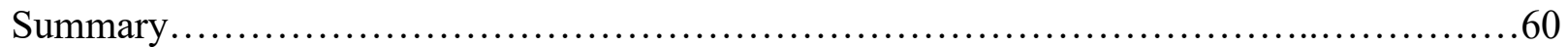

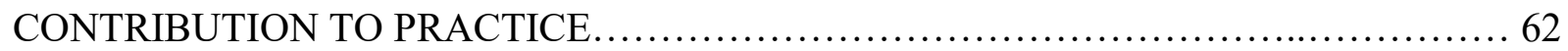

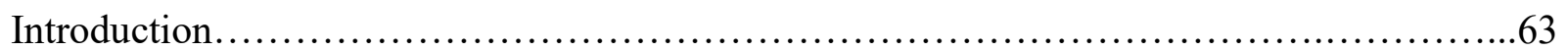

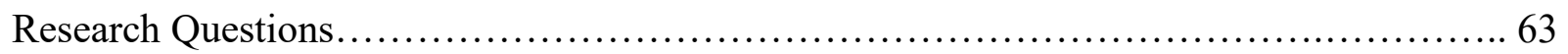

Connection to Conceptual Framework.................................6 63

Participants and Data Collection....................................64

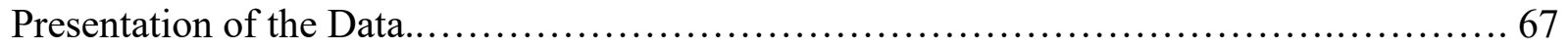

Research Question One.........................................................69

Research Question Two..........................................................76

Research Question Three......................................................... 77

Research Question Four...................................................... 78

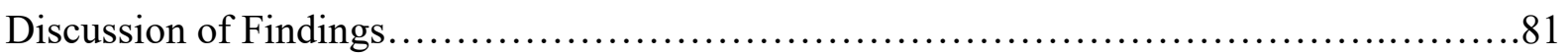

Conclusions...................................................................... 86

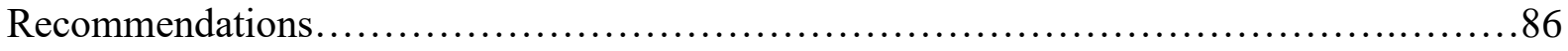

Website Infographic........................................................ 89

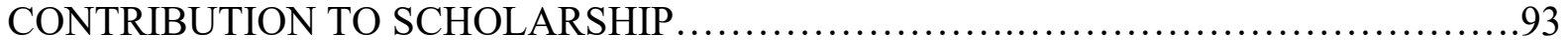

Submission letter.............................................................. 94

Journal Manuscript.......................................................95

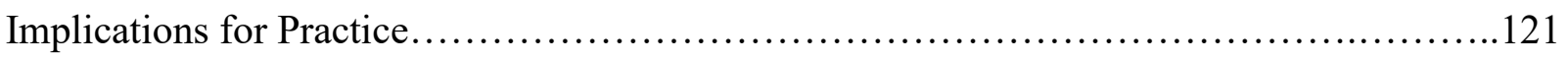

Implications for Research................................................. 122

Journal References......................................................... 123

SCHOLARLY PRACTITIONER REFLECTION .................................... 132 
REFERENCES.............................................................. 135

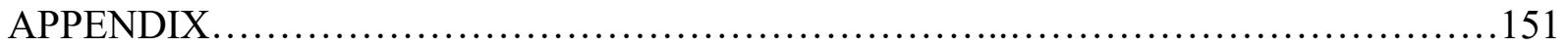

APPENDIX A..................................................................... 152

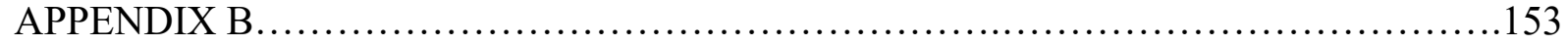

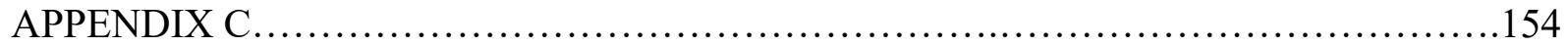

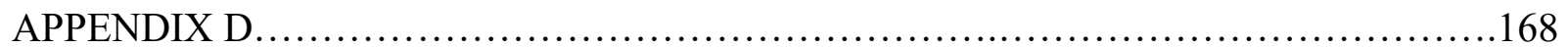

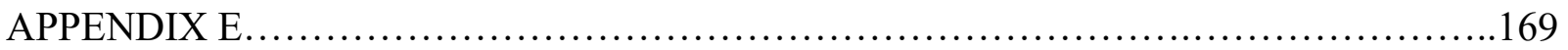

Vita...................................................................... 170 


\section{LIST OF TABLES}

Table

1. Principle Components Analysis: Total Variance Explained..........................18

2. Factor loadings........................................................... 19

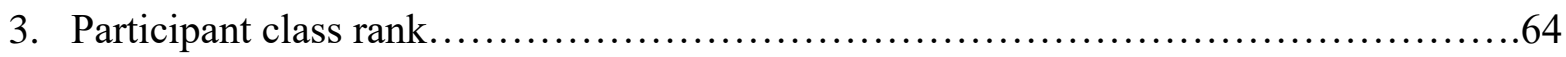

4. Participant classification by sex and/or gender................................65

5. Participant classification by First Generation Status..............................65

6. Participant classification by Low Income Status...............................66

7. Participant classification by First Generation and/or Low Income Status...............66

8. Participant classification by First Generation and Low Income Status................66

9. Descriptive statistics for relevant variables...................................67

10. Descriptive statistics for items related to spiritual salience........................68

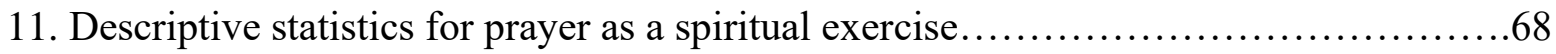

12. T-Test: Spirituality First Gen vs Non- First Gen..............................69

13. T-Test: Spirituality Low-income vs Non- Low-income.........................71

14. T-Test: Psychological Wellbeing (PERMA) First-gen vs non-first-gen.................72

15. T-Test: Psychological Wellbeing (PERMA) Low-income vs non-low-incom............72

16. Correlations Matrix---Spiritual Factors and Psychological Wellbeing..................76

17. Correlations Matrix---Spiritual Factors and Academic Performance.....................77 


\section{LIST OF FIGURES}

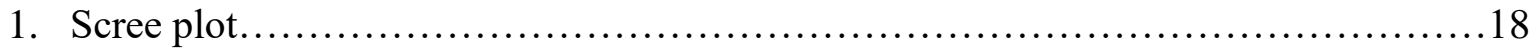

2. Mediation model Spiritual Crisis and Change, Wellbeing, and Academic Standing....79

3. Mediation model Prayer,Wellbeing, and Academic Standing ..................... 80 


\begin{abstract}
Mental health and attainment gaps comprise dual crises on today's college and university campuses, especially for first-generation and low-income students. Despite the common history and heritage of spirituality and religious foundations of America's colleges and universities, current norms and preferences have rendered candid discussions of spirituality to be, at best, passé, and, at worst, regressive. Despite extensive literature linking spirituality with psychological wellbeing, little is known as to what relationship, if any, spirituality has with psychological wellbeing and academic performance, particularly among first-generation and low-income students. This study uses a cross-sectional survey design.

This study was conducted at a public, regional, Midwestern institution within an hour's driving radius of the Kansas City metropolitan area. Data were collected through a survey, rendering 135 participants. Quantitative analysis found that there was no statistical difference between first-generation or low-income students and their peers in spirituality or wellbeing, that spirituality that is or once was salient to the student was correlated with and predicts psychological wellbeing, that there was a relationship between psychological wellbeing and academic performance in specific circumstances, and that there was an indirect effect between spirituality and academic performance in the presence of psychological wellbeing.

These data provide insight into the nature of the relationship between spirituality, wellbeing, and academic performance among college students and present implications for practitioners and researchers alike.
\end{abstract}




\section{SECTION ONE}

\section{INTRODUCTION TO DISSERTATION}




\section{Introduction}

From the inception of Harvard College in 1636 until 1819 when Thomas Jefferson founded the University of Virginia, every college in America was religiously affiliated and spiritual development was foundational in the curriculum (Brubacher, 2017; Rudolph, 1962). Over time, institutions became more secular and fostering spiritual development of students became all but absent from public colleges and universities (Chickering, Dalton, \& Stamm, 2015; Rudolph, 1962; Roberts, Turner, \& Turner, 2000). However, college students remain perennially interested in spiritual matters, with the majority claiming religious affiliation (Kosmin, Cragun, \& Navarro-Rivea, 2009).

This schism between student interest and institutional offerings happens alongside two concurrent crises in higher education: the mental health crisis and the achievement gap between historically underserved students and their peers (Markowitz, 2017;Wolverton, 2019).This difference between public universities and the students they support creates a problem of practice for emerging adults, particularly for first-generation and low-income students whose academic outcomes lag behind their peers despite their growing representation on college campuses (Katrevich \& Aruguete, 2017; McCarron \& Inkelas, 2006; Perna, 2015).

\section{Background of Study}

The researcher contends that the lack of recent discussion of spiritual development among first-generation and low-income college students is worthy of investigation. For this study, first-generation students are students whose biological parents did not receive a bachelor's degree (U.S. Department of Education, 1996). Low-income students are defined as those who qualify to receive a Federal Pell Grant, which is need-based financial aid for individuals in lowincome environments (Federal Student Aid, 2019). Researchers have been considering the 
problems of retention and achievement of academically at-risk students for decades (Duckworth, Peterson, Matthews, \& Kelly, 2007; Rendón, Jalomo, \& Nora, 2000; Strayhorn, 2012; Tinto, 1975). Researchers have also noted how first-generation and low-income students differ from peers in terms of college preparation, support, and experience (Thayer, 2000). Poverty has limited many students' prior access to quality instruction in pre-college experiences (Hughes, Stenjem, \& Newkirk, 2007). Further, low socioeconomic status students are less likely to have planned for expected and unexpected collegiate experiences that can disrupt timely academic progress to degree completion (Cabrera \& La Nasa, 2001).

Researchers (Williams, Smiley, Davis, \& Lamb, 2018) have considered various risk factors of being first-generation and low-income, primarily through identifying cognitive and non-cognitive student characteristics among peers who are successful and the lack or inconsistency in displaying those skills among the population in question (Adebayo, 2008; Schwartz, 2000; Williams, Smiley, Davis, \& Lamb, 2018). The rationale is, therefore, that once risk factors are identified, practitioners can develop interventions to mitigate their impact in an effort to increase outcomes among these students. The pursuit in uncovering these differences between first-generation and low-income students and their peers, as well as the differences between successful and non-successful students within this group, drives this inquiry.

\section{Statement of the Problem}

\section{Problem of Practice}

While first-generation and low-income students are growing in enrollment across public institutions in the United States, academic outcomes have not improved alongside enrollment gains (Perna, 2015). A notable and persistent degree achievement gap exists between firstgeneration and low-income college students and their peers (Pascarella, Pierson, Wolniak, \& 
Terenzini, 2004; Tinto, 2012). Theorists have contended with the student attrition phenomenon, suggesting models that may describe critical areas of needed support or intervention (Pascarella \& Terenzini, 2005, Tinto, 2006). Further, there is growing national concern for college students' mental health (Auerbach, et. al., 2018). First-generation and low-income students face common and unique wellbeing challenges. For example, first-generation and low-income students often encounter greater problems related to financial stress, academic adjustment, and family-related conflict when compared to their peers (Lippincott \& German, 2007).

Psychiatric problems have impeded students' abilities to complete college on a national scale (Breslau, Lane, Sampson, \& Kessler, 2008). Evidence supports a positive relationship between mental health and retention (Kitzrow, 2009). One central question in this inquiry is whether spirituality has any relationship to wellbeing and mental health for first-generation and low-income students. Public colleges and universities are virtually secular, despite $78 \%$ of college-aged students claim religious affiliation (Kosmin, Cragun, \& Navarro-Rivea, 2009). The researcher seeks to discover if this phenomenon is also observed within student subpopulations that are more likely to be first-generation and/or low-income. Stewart (2009) noted "spirituality is a key factors in the lives of Black college students as part of a cultural heritage passed down through generations" (p.255). When surveying the problem nationally, the wellbeing and academic performance of first-generation and low-income students presents a problem of practice for institutions of higher education in the United States.

\section{Existing Literature Gap}

Though multiple studies have examined the factors and characteristics of either firstgeneration or low-income students, few have considered students who are both first-generation and low-income as a population, though a relationship between both characteristics is well- 
documented (Engle \& Tinto, 2008; Thayer, 2000). There is a notable literature gap regarding the inner experiences of first-generation and low-income students, despite first-generation students representing nearly $50 \%$ of all college students since the beginning of the 21 st Century (Choy, 2002). While psychological and other medical literature have linked positive measures of personal wellbeing with spirituality, few studies have investigated whether a student's spirituality is related to general student wellbeing and performance (Adams, Bezner, Drabbs, Zambarano \& Steinhardt, 2000). If a relationship exists, this link may illuminate areas to support students in an attempt to address growing mental health challenges on college campuses (Astin, Astin, \& Lindhold, 2011; Bruffaerts, Mortier, Kiekens, Auerbach, Cuijpers, Demyttenaere, Green, Nock \& Kessler, 2018; Daaleman \& Frey, 2004; Davis, Kerr \& Kupius, 2003; Walker \& Dixon, 2002).

Prior attention to non-cognitive factors like grit and growth mindset as predictors for academic success in at-risk student populations may seem unrelated to spiritual resources (Duckworth, 2007; Dweck, 2008). However these behaviors might also be explained or mediated by inner, spiritual, or value-based realities of college students. While Low and Handal (1995) suggested a link between students' inner spiritual resources and their positive adjustment to college, there is a lack of recent studies investigating this phenomenon, especially among firstgeneration and low-income students.

\section{Purpose of the Study}

The purpose of this study is to determine if the spirituality of first-generation and lowincome students is different from their peers and whether or not there is a relationship between these students' spirituality and their psychological wellbeing and academic performance. If psychological wellbeing is a critical component necessary to promote academic achievement, 
and if spirituality is a critical component of psychological wellbeing, then an investigation into whether a relationship exists between these phenomena is warranted. If fostering the spiritual development of students has become forgotten or taboo, perhaps practitioners should reconsider the usefulness of a foundational educational practice in American higher education.

Much of the research concerning the experiences of first-generation and low-income students has focused on the cognitive and non-cognitive resources of these students (Adebayo, 2008; Muraskin \& Lee, 2004). While Adams, et.al (2000) discovered relationships between spirituality and wellness through rigorous quantitative methods, few have used such methods in considering these phenomena among first-generation and low-income students, explicitly. Religion and spirituality have been popular but difficult topics to define in the literature (Hood, Hill, \& Spillka, 2018). Scholars have considered the diversity of experiences related to spirituality and religion, even considering the terms both synonymously and distinctly, to describe the human search for meaning and significance (Clark, 1958; Miller \& Martin, 1988; Zinnbauer, Pargament, Cole, Rye, Butter, Belavich, Hipp, Scott \& Kadar, 1997). Some have considered college student's subjective use of religiousness to include conventional behaviors like church attendance or while others have included more conceptual attitudes related to altruistic beliefs (Pargament, Sullivan, Balzer, Van Haitsma, \& Raymark; 1995)

One survey of over 100,000 college students at over 200 colleges and universities found that $76 \%$ of students were searching for meaning and purpose in life (Astin, Astin, Lindholm, \& Bryant, 2005). Zinnbauer's (1998) work on Christian religious conversion sought to make distinctions between religious conversion and incremental changes in religiousness among Christian college students. While, Mattis (2000) described spirituality as being multidimensional including an understanding of transcendence, connections with the divine, living according to 
values, and internalizing values/beliefs. What remains unknown is to what degree, if any, does spirituality function in the lives and collegiate experiences of first-generation and low-income college students?

\section{Research Questions}

This present study has four research questions:

RQ 1: Are there differences in spirituality between first-generation and low-income students and their peers at a public Midwestern university?

RQ 2: Is there a relationship between spirituality and psychological wellbeing among first-generation and low-income students at a public Midwestern university?

RQ 3: Is there a relationship between spirituality and academic performance among first-generation and low-income students at a public Midwestern university? RQ 4: Does spirituality predict academic performance when mediated by psychological wellbeing among students at a public Midwestern university?

Guided by the literature, four hypotheses emerge:

H1: First-generation and low-income students are more spiritual than their peers at a public Midwestern university.

$\mathrm{H} 2$ : There is a positive relationship between spirituality and wellbeing among firstgeneration and low-income students at a public Midwestern university H3: There is a positive relationship between spirituality and academic performance among first-generation and low-income students at a public Midwestern university. H4: Spirituality is a predictor for academic performance when mediated by psychological wellbeing. 


\section{Theoretical Frameworks}

Several theoretical and conceptual frameworks are relevant to this study. To capture the robust, multi-decade scholarly conversation regarding spirituality, Clark's (1958) foundational work in the psychology of religion, Zinnbauer's (1998) investigation into the spiritual conversions of college students, Pargement's (2001) consideration of the relationship between psychological coping and religion, and many co-authored works seeking to provide clarity and consensus on definitions of spirituality and religion were reviewed (Hood, Hill, \& Spillka, 2018; Zinnbauer, Pargament, Cole, Rye, Butter, Belavich, Hipp, Scott \& Kadar, 1997).

Similarly, the concept of wellbeing is well-addressed in the literature. Hettler's (1984) wellness model which first introduced spirituality as a dimension of wellbeing. Ryff's (1989) Six Factor Model of Psychological Wellbeing lent prominence to hedonic wellbeing as a pole in the wellbeing spectrum. Additionally, Seligman's (2011) PERMA model further iterated upon the groundwork laid by past theorists, shifting to include eudemonics wellbeing, which is concerned with meaning-making, as opposed to feelings of happiness, as a measure of life satisfaction.

Finally, given that the units of analysis for this study are college students, the extensive range of college student development, and other lifespan theory was brought to bear in the scholarly review. Starting with Fowler's (1981) Faith Development Theory, which may explain how faith is formed in community to help develop one's reality and making meaning on one's life, consideration moved to Astin's (1993) Input-Environment-Outcome Model which may explain how students internal realities, such as spirituality, interact with the college environment and affect college outcomes. Considered were other theorists given their topical relevance and potential to inform this inquiry. While several other frameworks informed key definitions, helped shape variables, and informed hypotheses, Chickering and Reisser's (1993) Seven Vectors of 
Development was ultimately selected as the conceptual framework for this inquiry. A rationale is provided later in this section.

\section{Spirituality}

While spirituality is of abundant interest to scholars across various disciplines, there is no consensus on its definition. Miller and Martin (1988) use spiritualty and religion interchangeably, while Pargament (2001) argued that spirituality may not even have a religious component. Clark (1958) focused spirituality as experienced through conversion experiences. Mattis (2000) suggested that spirituality, similar to wellbeing, may be multidimensional. Despite a lack of scholarly consensus, the Higher Education Research Institute (2004) did discover one majority finding: $80 \%$ of college students are personally interested in spirituality.

While little is known regarding what relationship, if any, exists between spirituality and first-generation and low-income student experiences, the relationship between wellbeing and spirituality in the general college student population is documented (Daaleman \& Frey, 2004; Fehring, Brennan, and Keller, 1987; Klasses \& Greken, 2017; Kress, Newgent, Whitlock, and Mease, 2015; Nelms et.al, 2006). Walker and Dixon (2002) were some of the first to consider how spirituality might impact academic behavior in minority students, many whom are firstgeneration and low-income (Engle \& Tinto, 2008).

Responding to the lack of scholarly consensus of what spirituality may be, Hood, Hill, and Spillka (2018) synthesized scholarly spirituality literature to produce a definition that is inclusive and contains measurable language, promoting further inquiry. They suggest, at its core, spirituality is born out of aspects of the interplay of internal and external factors that come with how one makes or finds meaning for his or her life (Hood, Hill, and Spillka, 2018). As a 
definition, it is inclusive both of a religious and non-religious understanding of spirituality, which aligns with what we know about how college students spirituality is as a concept (HERI, 2004). This framework, born out of rich synthesis, is what guides and defines spirituality for this study.

\section{Wellbeing}

Wellbeing, similar to spirituality, has also garnered much interest and discussion among scholars. The challenges impacting college student wellbeing, particularly for students who are first-generation or low-income, are well-documented in college student counseling, student development, and retention literature ( Padgett, Johnson, \& Pascarella, 2012; Pascarella \& Terenzini, 2005; Stephens, Brannon, Markus, \& Nelson, 2015; Strayhorn, 2006; Wang \& Castaneda-Sound, 2008). Punctuating perennial challenges is the growing mental health crisis across college campuses in the United States (Auerbach, et. al, 2018; Bruffaerts, et. al, 2018; Markowitz, 2017; Wolverton, 2019).

Hettler (1984) was the first to explicitly highlight how spirituality may impact wellbeing, particularly in college students. Hettler and Diener (1984) contributed the concept of subjective wellbeing (SWB) which particularly focused on one's emotional or hedonic experience. Ryff's (1989) Six Factor Model for Psychological Wellbeing (PWB) was also predominant in the literature, and included more existential, or eudaimonic, experiences. Later, Seligman (2011) would attempt to reconcile the apparent differences between SWB and PWB with his PERMA framework which includes both hedonic and eudaimonic components. Seligman's (2011) framework, distinct for its inclusivity and intuitiveness, is the selected framework for wellbeing for this study. 


\section{Faith Development Theory (1981) and Parks' (2000) Criticism}

Fowler $(1981,1991,2006)$ was one of the first to attempt to describe how and why spiritual understanding may develop across the lifespan with Faith Development Theory (FDT). Fowler's framework has four functions: lending life both understanding and sense of direction, connecting people in ways that promote shared loyalty, connecting people to the greater community, and helping people "face and deal with the challenges of human life and death, relying on that which has the quality of ultimacy in their lives" (Fowler \& Dell, 2006, p. 36). While not the first theorist to consider the inner lives or ultimate concerns of emerging adults, FDT explained how this might occur within the college community (Pascarella \& Terenzini, 2005).

Many have contributed to or noted the limitations of FDT. Streib (2001) contended FDT, as a framework, over-relies on cognitive development at the neglect of other situational or environmental factors that affect how one interacts with the ultimate concerns of life. While not analyzing FDT directly, others noted critiques similar to Gilligan's (1977) that there may be moral developmental differences between men and women, which might not have been captured in Fowler's early analyses due to the bias inherent in a predominantly male sample. Parks (1986; 2000) both critiqued and expanded upon Fowler in her framework. While still using the term faith, her frame included an understanding of spirituality that may be non-religious or lack dogma (Parks, 2000). Parks (2000) also critiqued the "cognitive and stage-structure bias" similar to other theorists heavily influenced by the work of Jean Piaget (p.60). For these reasons, FDT, or any one of its theoretical derivatives, was not chosen as the guiding framework in this study. 


\section{Astin's Input-Environment-Outcome Model}

Astin's (1993) Input-Environment-Outcome (I-E-O) model described how internal student characteristics, including religious values/belief, might interact with the educational environment and the supports it does or does not provide. The model shows how pre-college factors, like students' spiritual outlook or religious upbringing, affect both their college experiences and ultimate outcomes. One study investigating the spiritual dimensions of first-year students used Astin's (1993) model to describe the religious behaviors and practices of students. The researchers found that while students' religious attendance and activity declined, their spiritual understanding continued to develop (Bryant. Choi, \& Yasuno, 2003).

While his model is not explicitly spiritual, Astin (2004) has called for growing emphasis on spiritual development within the liberal arts curriculum and participated in the creation of the College Student Beliefs and Values Survey, which is used in modified form in this inquiry. While Astin's (1993) model and contribution to the student and spiritual development literature is significant, his model is limited by its generality. Other models, this researcher contends, speak more specifically to spiritual or existential development as a distinct stage or epoch of student development. While the model may hold explanatory power, for these limitations, it was rejected as the guiding framework in this study.

\section{Conceptual Framework}

Chickering (1969) and Chickering and Reisser's (1993) Seven Vectors of Development convey how college students may develop psychosocially. Conceptualized as a way to describe how psychosocial development happens alongside cognitive development, the steps, or vectors, in the model serve a directional purpose. Chickering and Reisser's (1993) sixth vector, 
developing purpose, is particularly relevant to this study. It is important to note that the development of purpose, as conceptualized by Chickering and Reisser, described both internal and external activity. Reisser (1995) pointed to one's emerging, internal sense of purpose as evidenced by one's external decisions. One longitudinal study of 354 freshmen validated the sixth vector linking the development of purpose to college experiences (Martin, 2000). In their synthesis of student development literature, Pascarella and Terenzini (2005) contended that purpose development is heavily influenced by the student's view of self as established in the fifth vector. This means, according to this framework, that one's view of purpose is conditioned by one's view of self.

Chickering, Dalton, and Stamm (2006) advocated holistic education as a way to foster spiritual development in college students while noting a nuanced view of students who might distrust religion yet sense a "personal quest for meaning and purpose in their lives" (p. 91). The researchers contended that authenticity, related to vectors five through seven and defined broadly as living life by one's values, may be linked to spirituality, which they also defined broadly in terms of searching for and making meaning (Chickering, Dalton, \& Stamm, 2005).

Chickering and Reisser's (1993) model was selected for its ability to describe, as Creswell (2013) suggested, how independent and dependent variables may be related. As it relates to this study, Chickering and Reisser's (1993) model suggested the expectation that spiritual resources of first-generation and low-income students to influence their respective levels of psychological wellbeing and academic performance born out of experiences related to purpose making that occurs in the lives of college students as they develop a sense of identity. The internal and external processes associated with the sixth vector, such as developing an inner sense of values 
and articulating a set of goals, may be linked both with wellbeing and behaviors adaptive to academic achievement in first-generation and low-income college students at a public university.

This rationale is supported by at least three arguments. First, Chickering's (1969) model has been revisited, revised, and validated by other research (Martin, 2000; Reisser, 1995; Straub, 1987). Second, the framework acknowledges the interplay of both cognitive and psychosocial development in ways that are specific and predictive, such as the role of the fifth vector's semifoundational role in supporting development in the sixth vector. This relationship may be similar to the relationships, if any, between the variables under consideration in this study. Finally, the selection of this model allows for more inclusive understandings of spiritual experiences that may be non-religious in nature which aligns with the purpose of this study. Moreover, Chickering and Reisser's (1993) framework provides for the development of values and purpose that may or may not be related to religious beliefs, which can include non-religious students in an inquiry related to spiritual resources.

\section{Design of Study}

This study is framed from a post-positivist paradigm in that it seeks to test theories to better understand phenomena encountered in the world (Creswell, 2014). Consequently, this study utilizes a quantitative, cross-sectional survey design. The rationale for this choice is twofold. First, the study is structured so that researchers and practitioners can better understand what relationship, if any, exists between the variables of this study and first-generation, low-income students (Creswell, 2013). Secondly, the survey design itself is conducive for expedited online distribution and collection (Creswell, 2013). After data are collected, statistical tests will be administered to investigate hypothesized relationships between spirituality, wellbeing and academic performance among first-generation and low-income students. 


\section{Setting}

A public, regional, 4-year university in the Midwest will be the setting for this study given the majority of its enrollment is first-generation and/or low-income students (UCM, 2018). Due to the admissions selectivity of these institutions and their public nature, this type of institution provides a convenient yet appropriate setting for this study as these admissions criteria allow for higher shares of first-generation and Pell-eligible students (MDHE, 2019; Tebbs \& Turner, 2005).

\section{Participants}

Since $78 \%$ of traditionally college-aged Americans claim religious affiliation, male and female students aged 18-24 and enrolled as a degree-seeking student will be identified as the main participants in this study (Kosmin, Cragun, and Navarro-Rivea, 2009). Further, firstgeneration and low-income students, defined for this study as students whose biological parents lack a bachelor's degree and are eligible to receive any portion of the Pell grant, at a public, 4 year university in the Midwest comprise a subpopulation within the sample for this study. These students were selected given both established scholarly interest in first-generation and lowincome student experiences and outcomes and the prominent literature gap related to the variables of this study.

\section{Data Collection, Analysis, and Survey Protocol}

Participants completed a modified College Students' Beliefs and Values Survey and PERMA-Profiler online either using a personal electronic device or one provided by the researcher (Astin, et. al, 2007; Butler \& Kern, 2015). The researcher has obtained appropriate 
permissions from each survey owner (Appendix D; Appendix E). The CSBV survey was selected for its relevance to the research topic and its prior use on the national scale with over 14,000 students across over 100 institutions (HERI, 2004). The CBSV instrument was modified, with permission. Twenty-five (25) items related to spirituality and spiritual engagement will be retained from the CSBV, where scales like religious skepticism and ethic of caring will not be retained due to their irrelevance to this study.

The PERMA Profiler, assessing wellbeing, was integrated with the modified CSBV. The PERMA Profiler served as the second part of the survey. The combined and revised instrument included includes 42 scale items that collectively measure spirituality and PERMA dimension. This survey was selected given its relevance to the study's variables and the demonstrated validity of the instrument (Goodman, Disabato, Kashdan, \& Kauffman, 2017). The PERMA profiler will assess all five domains of wellbeing as defined by Seligman (2011). The survey will mostly consist of an 11-point sliding scale for each item. Data will be exclusively assessed through the survey. Construct validity and reliability of the CSBV and PERMA Profiler surveys have been previously assessed (Bravo, Pearson, \& Stevens, 2016; Butler \& Kern, 2016; Goodman, et. al., 2017). Reliability analysis of the 42 survey items rendered a Cronbach's alpha above $.8(\alpha=.86)$, which is well above the acceptable range (Cortina, 1993).

Principal components factor analysis was conducted on the 25 revised spirituality items revealing nine components accounting for $71 \%$ of the total variance. Keiser-Meyer-Olkin Measure of Sampling adequacy was sufficient at .814 and Barlett's Test of Sphericity was significant $\left(x^{2}(300)=1224.16, p<.001\right)$. Initial eigenvalues showed that the first four components explained $26 \%, 8 \%, 7 \%$, and $5 \%$, for a total of $46 \%$, of the variance. These four components were selected due to their relevance to the conceptual framework, the amount of 
variance accounted by the components, and the leveling of the associated scree plot. Composite scores for each of the four components were created as variables, based on factor loadings from the items. These four composite variables included Salient Spirituality, Spiritual Change, Humanism, and Spiritual Seeking. 
Table 1

Factor Analysis: Total Variance Explained

\begin{tabular}{|c|c|c|c|c|c|c|}
\hline \multirow[b]{2}{*}{ Component } & \multicolumn{3}{|c|}{ Initial Eigenvalues } & \multicolumn{3}{|c|}{ Extraction Sums of Squared Loadings } \\
\hline & Total & $\begin{array}{c}\% \text { of } \\
\text { Variance }\end{array}$ & $\begin{array}{c}\text { Cumulative } \\
\%\end{array}$ & Total & $\begin{array}{c}\% \text { of } \\
\text { Variance }\end{array}$ & $\begin{array}{c}\text { Cumulative } \\
\%\end{array}$ \\
\hline 1 & 6.563 & 26.252 & 26.252 & 6.563 & 26.252 & 26.252 \\
\hline 2 & 2.077 & 8.306 & 34.558 & 2.077 & 8.306 & 34.558 \\
\hline 3 & 1.947 & 7.788 & 42.346 & 1.947 & 7.788 & 42.346 \\
\hline 4 & 1.347 & 5.388 & 47.734 & 1.347 & 5.388 & 47.734 \\
\hline 5 & 1.299 & 5.198 & 52.932 & 1.299 & 5.198 & 52.932 \\
\hline 6 & 1.278 & 5.110 & 58.042 & 1.278 & 5.110 & 58.042 \\
\hline 7 & 1.160 & 4.641 & 62.683 & 1.160 & 4.641 & 62.683 \\
\hline 8 & 1.064 & 4.257 & 66.940 & 1.064 & 4.257 & 66.940 \\
\hline 9 & 1.007 & 4.028 & 70.968 & 1.007 & 4.028 & 70.968 \\
\hline
\end{tabular}

Figure 1

Scree plot

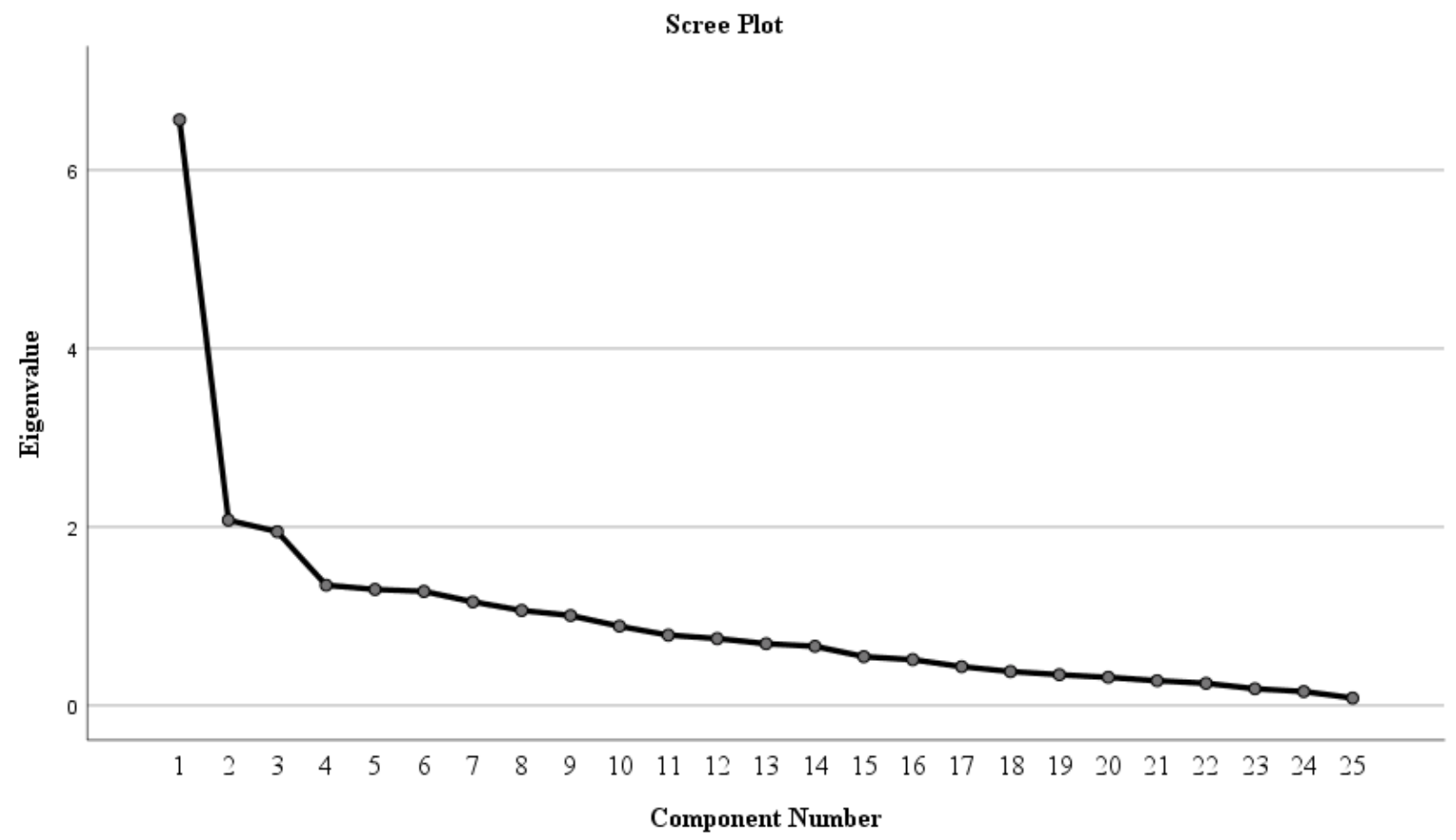


Table 2

Factor loadings

\begin{tabular}{|c|c|c|c|c|c|}
\hline \multicolumn{6}{|c|}{ Factor } \\
\hline Items & 1 & 2 & 3 & 4 & Dimension \\
\hline Setting a good example for my family & .247 & -.121 & .527 & .163 & \\
\hline Getting a high GPA & .151 & -.261 & .613 & & \\
\hline As much as possible we should try to get along & .199 & & .503 & .277 & 4.Humanis \\
\hline Most people are good & .357 & -.107 & .529 & -.204 & \\
\hline $\begin{array}{l}\text { Attended a class/workshop or retreat on matters } \\
\text { related to spirituality }\end{array}$ & .355 & .385 & .157 & .370 & $\begin{array}{l}\text { 3. Spiritual } \\
\text { Seeking }\end{array}$ \\
\hline $\begin{array}{l}\text { Anyone can be successful in college if they try } \\
\text { hard enough }\end{array}$ & .162 & -.267 & -.133 & .481 & \\
\hline Participated in volunteer work or service learning & .105 & .248 & .124 & .406 & \\
\hline Difficult times can make someone stronger & .383 & -.468 & .247 & .149 & \\
\hline Had disagreements with loved ones & -.172 & .464 & .146 & .158 & 2. Splritual \\
\hline Questioned religious/spiritual beliefs & -.169 & .683 & & & \\
\hline Changed your mind about a previously held belief & -.339 & .646 & .234 & & \\
\hline $\begin{array}{l}\text { I know someone I can turn to for spiritual } \\
\text { guidance }\end{array}$ & .630 & .137 & & .238 & $\begin{array}{l}\text { 1. Salient } \\
\text { Spirituality }\end{array}$ \\
\hline $\begin{array}{l}\text { My spiritual/religious belief have helped me } \\
\text { develop my identity }\end{array}$ & .724 & .231 & -.166 & & \\
\hline $\begin{array}{l}\text { My spiritual/religious beliefs are one of the most } \\
\text { important things in my life }\end{array}$ & .880 & & -.195 & & \\
\hline $\begin{array}{l}\text { My spiritual/religious beliefs give } \\
\text { meaning/purpose to my life }\end{array}$ & .868 & .182 & -.100 & & \\
\hline $\begin{array}{l}\text { My spiritual/religious beliefs help define the goals } \\
\text { I set for myself }\end{array}$ & .865 & & -.121 & & \\
\hline $\begin{array}{l}\text { My spiritual/religious beliefs provide me with } \\
\text { strength, support, and guidance }\end{array}$ & .886 & & -.209 & & \\
\hline $\begin{array}{l}\text { My spiritual/religious beliefs lie behind my whole } \\
\text { approach to life }\end{array}$ & .815 & & & -.156 & \\
\hline
\end{tabular}

Sampling design for this study used clustering, or sampling within several venues at the institution where groups of students congregate and have free time to complete surveys (Creswell, 2004). Sampling was non-random and non-stratified, soliciting involvement from participants throughout campus. Since both first-generation and low-income students will be compared with peers, to reduce bias and other sampling error, and to achieve the statistical 
power needed to perform the needed analyses, 135 students comprised the sample. The survey was administered in winter 2020. Survey response rates were monitored during the data collection phase to check for response bias (Creswell, 2004).

Descriptive analyses including means, standard deviations, and ranges were performed on spirituality, wellbeing, and academic performance, which comprise all measured variables in this study (Creswell, 2004). Using SPSS, this present study used Pearson product moment correlational analysis to examine statistical relationships between variables and independent samples t-tests to compare means of wellbeing and academic performance between firstgeneration and low-income students and their peers. This analysis is appropriate for this inquiry since the independent samples t-test is meant to compare "two means that come from conditions consisting of different entities" (Field, 2013, p. 331). This helped illustrate if any difference exists between the two populations, and whether or not this difference is statistically significant.

Mediation analysis was also used to assess if wellbeing mediates the relationship between spirituality and academic performance. Three regressions are needed to assess whether wellbeing mediates. The first regression has spirituality predicting academic performance. The second regression has spirituality predicting wellbeing. The final regression has spirituality and wellbeing predicting academic performance.

Baron and Kenny (1986) asserted that four steps are needed to support a mediation claim, in this case that wellbeing mediates spirituality in predicting academic performance. First, spirituality and wellbeing must be correlated. Second, wellbeing and academic performance must be correlated. Third, in the final regression, wellbeing should be a significant predictor of academic performance. Fourth, the final regression, should show wellbeing fully or partially predicting academic performance, and thus fully or partially mediating spirituality. 
Linearity, homoscedasticity, and multicollinearity, assumptions of multiple regression, was assessed (Field, 2013). The above analyses will show whether spirituality accounts for variance among wellbeing and academic performance among the sample. Data will be presented in appropriate and relevant tables and figures. Data then will be interpreted and the researcher will draw conclusions for the research questions and hypotheses. Statistical significance tests, with statistical significance reported at $\mathrm{p} \leq .05)$, confidence intervals, and effect sizes will be reported (Creswell, 2014).

\section{Limitations, Assumptions and Design Controls}

This study is limited by several factors. First, study participants were only sourced from a single public institution and the researcher's current employer, constituting a convenience sample. Second, and on a related note, the limited scope of this study, emphasizing a public 4year institution, increases the likelihood of bias and limits the potential generalizability of the results. Thirdly, sampling in this quantitative survey design is non-random and non-stratified which has a higher likelihood of introducing bias into the study (Creswell, 2014). Finally, the study uses self-reported data, which can be impacted by confounding variables (Creswell, 2014). These limitations are accounted for in design controls and also create opportunities for future researchers to address related to this topic.

\section{Assumptions}

This study has, at least, the following assumptions. First, spirituality, as defined by this study and the creators of the CSBV survey, is broad enough to include students who may or may not be religious, which aligns with the conceptual framework for this study (HERI, 2004). Secondly, the CSBV allows both for internal and external behaviors that demonstrate spirituality (HERI, 2004). Thirdly, the language used in the adapted survey would maintain the original 
authors' intent to use unambiguous or unnecessarily inaccessible language (HERI, 2004). Finally, and in summary of the previous assumptions, the goal is that any student from the identified population would find the survey to be clear, manageable to be completed in a reasonable amount of time, and relevant to the student's experiences.

\section{Design Controls}

Creswell (2014) recommended using random and stratified sampling to reduce bias in survey design quantitative analysis. Given the scope of this study and the specific population, non-random and non-stratified sampling were employed. This has the likelihood of introducing preventable selection bias, and is a noted limitation in this study. However, as described in the methods section, a proportional response rate and proper monitoring of responses over the suggested timeline helped reduce the likelihood of response bias (Creswell, 2014). Further, this study employs the use of existing instruments whose validity and reliability have been established in past studies (Bravo, Pearson, \& Stevens, 2016; Butler \& Kern, 2016; Goodman, et. al., 2017; HERI 2004).

Since this study is limited to one setting and, thus, not generalizable, Creswell (2014) recommends that the researcher conduct additional, future experiments in other settings. Relatedly, the researcher will also be cautious about which claims can be made about the realities of college students' lives, since only a specific subpopulation of college students, those being first-generation and low-income, are considered in this inquiry. Future research could investigate if any discovered relationships are germane and/or also occur in other student populations.

Fowler (2009) recommended controlling for limitations in surveys by selecting the appropriate sample size using three steps. First, he recommended the researcher select a margin of error, based on the researcher's tolerance, for the sake of showing how accurately the 
sample's responses correlate to the entire population. Next, he recommended selecting the confidence interval for the aforementioned margin of error. Third, he suggested estimating how respondents will respond in a given way, with given equal chance to all choices being the most conservative recommendation. Having an appropriate sample size can also help control for survey mortality or drop-out, which is an internal validity threat in survey design (Creswell, 2019).

\section{Definitions of Key Terms}

The following key terms will be used to guide understanding to the inquiry:

First-generation college student: First-generation college students are those students whose biological parents have not earned bachelor's degrees (U.S. Department of Education, 1996). Low-income college student: For this study, low-income students are defined as those who qualify to receive a partial or full Federal Pell Grant, which is need-based financial aid for individuals.

Spirituality: This study uses Hood, Hill, and Spilka's (2018) definition of spirituality which is the "cognitive, motivational, and social aspects of finding meaning in life" (Hood, Hill, \& Spilka, 2018. p.17).

Retention: Retention is the rate of students who return to continue studies the following fall semester, typically measured their freshman year.

Wellbeing: This study uses Seligman's (2002) definition of wellbeing using the PERMA framework: positive emotions, engagement, relationships, meaning, and achievement.

Academic performance: For this study, academic performance will be considered using three factors: whether or not a student is in good academic standing, a student's most recent semester GPA, and a student's cumulative grade point average (Walker \& Dixon, 2002). 
Salient spirituality: Spirituality that is conscious, deliberate, and foundational to how one finds meaning in life. This spirituality may or may not be religious in nature but is nevertheless unambiguous to the person.

Spiritual crisis and change: This experience reflects a spirituality in transition and is associated with questioning and changing one's understanding of how one defines meaning in life.

Humanism: A philosophy grounded in the belief in the worth of one's and others' existence that is not explicitly defined as spiritual, nor is seeking to be so.

Spiritual seeking: Beliefs and behaviors related to discovering meaning in life not born out of spiritual crisis. Describes an openness to spiritual matters and activity.

\section{Significance of Study}

Long before it became taboo or absent from conversations and curricula in higher education, taking lead in the spiritual formation of students was not only a part of the early colleges in America, it was a main focus (Brubacher, 2017; Rudolph, 1962). Since its origination at some of the earliest and most prestigious colleges that served as models for the land grant, regional, junior and technical colleges that would follow, spiritual formation curricula and services have declined or disappeared completely (Chickering, Dalton, \& Stamm, 2015).

The vast disparity between support and students looms large as, in the present era still reflects the majority (78\%) of students still claim religious affiliation (Kosmin, Cragun, \& Navarro-Rivea, 2009). Emerging adulthood, a developmental epoch that runs parallel to traditional college age, has characteristic elements of inward reflection and meaning-making (Fowler, 1981; Pascarella \& Terenzini, 2005). Few studies have investigated the spiritual resources and outcomes of first-generation, low-income students at public universities as most have focused on predominantly only on white students (Mattis, 2000). 
While first-generation and low-income students are growing in enrollment across public institutions in the United States, academic outcomes have struggled to improve (Perna, 2015). If a relationship between spiritual resources, wellbeing, and academic performance in firstgeneration and low-income students exists, the opportunity to support students could produce outcomes for which institutions will be increasingly accountable (Chickering, Dalton, \& Stamm, 2006). Methods for raising retention rates for first-generation and low-income student also tend to benefit the greater campus population (Thayer, 2000). Essentially, the goal of this study is to investigate ways to help both students and institutions accomplish shared goals in providing educational opportunity to all.

\section{Summary}

Practitioners concerned about the achievement gap have the opportunity to (re)consider supporting students in ways universities have abandoned or forgotten. When students struggle to make sense of adversity they encounter or stumble in their academic progress due to pre-college and college factors, perhaps a consideration for their inner understanding of ultimate concerns, meaning, and purpose is warranted. If student spirituality is linked to wellbeing and performance, then stakeholders have an obligation to investigate this relationship no matter how difficult, inconvenient, or problematic the topic. Challenging an assumption that public universities should avoid discussing the sacred might paradoxically reassert the university's essence as a public good. Therefore, to do so would abrogate the very responsibility the university was created to uphold: free inquiry. Perhaps, in this reclaiming of both a fundamental value and a historic practice, we might more holistically serve the most vulnerable students looking for opportunity in today's universities. 
SECTION TWO

\section{PRACTITIONER SETTING FOR THE STUDY}




\section{Introduction}

The University of Central Missouri’s history, organizational makeup, and leadership dynamics are outlined within this section. This section concludes with related research implications derived from the setting.

\section{History of the Organization}

Founded in 1871, The University of Central Missouri began as one of several normal, or teacher preparation, schools in Missouri (UCM, 2019). Originally known as Normal School Number 2, the university has experienced several iterations in mission, program offerings, even names. As the University of Central Missouri approaches its sesquicentennial, the university serves over ten thousand graduate and undergraduate students (UCM Fact Book, 2019).

Despite its modest locale in Warrensburg, MO, the university has several notable alumni and has been home to notable incidents during its tenure. Much of the campus was destroyed in a fire in the early twentieth century. New Deal public works programs assisted the building of the Morrow-Garrison Gymnasium, which now houses a student recreational center faculty in the College of Health Science and Technology.

Every public university with due process in its student disciplinary procedure is not doubt influenced by United States Circuit Court decision involving the university. In Esteban $v$. Central Missouri State College, two students alleged that their constitutional rights were infringed faced disciplinary action for participating in demonstrations and protests. Other unrest from the 1960s included three African American students were expelled for participating in demonstrations protesting racial injustice. All three, one posthumously, were awarded honorary degrees from the institution in 2018 (Murphy, 2018). 
UCM, similar to many postsecondary institutions, has undergone and a rapid shift in demographics over the last century (UCM Factbook, 2019). Class rosters dominated by white males of means have shifted to a female majority and growing numbers of minority students. Recently, students who intend to be the first in their immediate family to earn a bachelor's degree, known as first-generation students, or students who come from limited-income backgrounds or students whose race or ethnicity has been historically underrepresented in higher education now encompass the majority of students at UCM (UCM Office of University Analytics and Institutional Research, 2019). This enrollment shift has revealed discrepancies in student experience and gaps in student achievement (UCM Office of University Analytics and Institutional Research, 2019). As racial and community unrest has gripped the national and local landscape in Missouri, pressure to appropriately respond is a topical consideration for stakeholders (Hartocollis, 2017).

Alongside and perhaps in response to campus unrest in the state, the Missouri legislature has signaled divestment in public higher education with level and, at times, significantly reduced appropriations (Hardison \& Washburm, 2018). In 2017 and 2018, these events intersected to create a fiscal crisis at the university that led to widespread reorganization, incentivized retirement, and downsizing. In this reorganization, several student services were consolidated in a strategy to use limited resources to retain students and the revenue they generate. This choice was, and remains, controversial to university stakeholders who question either the motivation or the outcome or both. Others have expressed concern that the university's focus on underprepared and/or underrepresented students signals a shift in the university's identity. One faculty member, airing frustrations regarding the university's response to fiscal and demographic shifts, was revealing: "I didn't sign up to work at a community college." 
While para-institutional campus Christian and Islamic ministries dot the periphery of campus, the institution, like many public universities, does not provide spiritual support or curriculum to students. Further, there is no specific policy support elaborating or delineating institutional support for students spiritual development, despite a national example and precedent for this at Missouri's public, land grant institution, the University of Missouri - Columbia (Chickering, Dalton, \& Stamm, 2015).

Facing enrollment decline as peers continue to discount tuition and fees for students who are Pell-eligible, UCM struggles to iterate ahead of the 150th anniversary of its founding (University of Central Missouri, 2019). Central to its dilemma, is the need to support the students it has without sacrificing academic quality. Contemporary critics voice concern of an institution's realistic ability to do what might be mutually exclusive, while contemporary proponents see the next, natural iteration of public education in the state.

\section{Organizational Analysis}

UCM is a moderately selective institution in terms of admission requirements. For comparison, this means UCM is less selective than Missouri State University and more selective than Missouri Western University (MDHE, 2019). This selectivity defines the market for the institution and this market is in decline in an increasingly competitive environment. The scarcity of resources coupled with the value of public education in question or in crisis may be explained through the use of Bolman and Deal's (2013) political and symbolic frames which may explain how organizations function in complex situations.

First, the political frame, which may explain how power bases and coalitions form, how scarce resources are distributed, and power, as one of those finite resources, governs, is relevant to this organizational analysis (Bolman \& Deal, 2013). When declining state appropriations and 
undergraduate enrollment are juxtaposed, the political framework has strong explanatory power to make sense of organizational and individual behavior (Bolman \& Deal, 2013). For faculty, a stipend or release time that, in another era, might be more freely delegated, is given greater scrutiny and might encourage envy and/or conflict when one faculty member receives the resource and another does not.

Sensing a zero-sum game, a staff member might be more inclined to discredit his or her peers before their shared supervisor, hoping to gain favor, or preference, or actual funding, in order to accomplish an outcome. Political behavior may also look like a faculty member writing a grant proposal to gain funding for a service learning opportunity or a staff member becoming more affiliative with hopes to highlight a program the university cannot otherwise fund. These behaviors, either commendable or not, are essentially political because they have the same outcome: the acquisition of scarce resources (Bolman \& Deal, 2013).

The political frame may help to provide insight to several organizational phenomena within the University of Central Missouri. One such phenomenon, which provides a more explicit example of political process, is the university's transition from incremental budgeting to responsibility-centered management $(\mathrm{RCM})$. In the past, departmental budgets received annual incremental increases in times of increased revenue. In times of relative scarcity, budgets were held flat or incrementally decreased across the board. Using budget forecasting and revenue tracking, decisions were made centrally, usually by key personnel and budget-management offices, on whether to increase, hold flat, or decrease organizational budgets. While this lent some measure of predictability, it also inhibited strategic and difficult decisions. Some incremental increases were not meaningful enough to justify, for example, additional personnel, while incremental decreases were significant enough to make existing personnel cost-prohibitive. 
In RCM, revenue-generating units, such as the colleges who provide programs that generate revenue from tuition and fees, will now have more responsibility in determining how revenue-after-expenses is appropriated. In other models, college deans might lobby the provost to get funding for a tenure-track instructional line, competing with other deans and interests. In RCM, the dean will have more authority to decide where to appropriate his or her own funds, and is, thus, incentivized to become more entrepreneurial in creating sources of revenue. However, not every unit within the organization is able to generate revenue.

These units are known as cost centers (University of Central Missouri, 2019). Cost centers provide services to responsibility centers that, it is argued, help responsibility centers generate revenue. For example, student services like the Learning Commons, which is UCM's student learning center, or the advising office, are examples of cost centers. These cost centers, staffed with personnel to support students in programs across the various colleges and their programs, bear significant personnel cost. To support these operations, the responsibility centers, or colleges, are levied a tax to fund these operations.

Organizationally, using the political frame, cost centers might seek to decentralize focus from the president and provost's office to the colleges as it seeks to build a power base of support (Bolman \& Deal, 2013). Bolman and Deal (2013) stated bluntly: "as a manager, you need friends and allies to get things done. To sew up their support, you need to build coalitions" (p. 214). The deans and other college leaders must be convinced of the value the cost centers provide, or they will seek to reinvest their resources in investments that provide more value to the college, the reasoning suggests. Simply, student services that seek to serve the university now face a challenge for responsibility centers that are focused, fiscally, on their own college. While this may not make the organization more or less political in operation, it does shift the focus. 
This shift leaves those who fail or resist to see political processes bewildered when the organizational dynamics shift.

As a final element regarding the potential relevance of the political frame to this study, Bolman and Deal (2013) specifically mention that universities specifically find themselves within "alternating eras of feast and famine related to peaks and valleys in economic and demographic trends" (p. 190). Depending on how the current situation is viewed, one might say the current famine in resources is due to declining high school graduates and state appropriations, which are well-documented demographic challenges (Hancock, 2018). Another viewpoint is that there has been a seismic demographic shift that the organization has been either unable or unwilling to position itself to serve: adult and historically-underserved students.

The categories of undergraduate and graduate students seeking undergraduate or graduate degrees are unhelpful to an adult learner who might not fit these categories or the credentials they bear. He or she, on the contrary, might seek another credential, or at least some educational or continuing educational experience that is known, contemporarily, as workforce development. Another demographic shift is the growing numbers of first-generation, limited-income, and historically underserved racial and ethnic minorities (University of Central Missouri, 2019). To enrollment managers and budget offices who see 2019 as a famine are countered by the two year and four year schools whose enrollment of this particular demographic is growing steadily (University of Central Missouri, 2019). On this point, the political, and now symbolic, frames may be useful for understanding the organization (Bolman \& Deal, 2013).

The symbolic frame uses symbols, story, and narrative tension to "resolve confusion, find direction, [and] anchor hope and faith" (Bolman \& Deal, 2013,p. 248). In the symbolic frame, the organization is not a home, a machine, or a battleground, but a theater that might depict any 
of the aforementioned (Bolman \& Deal, 2013). In the symbolic frame there are angels and demons, dragons and dragon fighters, heroes and villains (Bolman \& Deal, 2013). These types are cast within a story and central tension derived from a mission; the narrative helps people within the organization find his or her place in the story (Bolman \& Deal, 2013). Using metaphor, the organization might cast itself as victim of the legislature, citing lack of funding support. Or another, who strives valiantly and increases enrollment when others struggle, might think of itself as the champion or the victor.

The central point is that transformation, whether positive or negative, and the language used to describe it, employ symbols, comparisons, and metaphor (Bolman \& Deal, 2013). At UCM, employees and leaders believe a story about themselves, the students, and the organization. Here, belief itself informs, and can even transform, the work. If, symbolically, one believes that a college student is and should be well-prepared for the academy, and that one's role is to impart knowledge only to the ready few that the available many, one might have extreme success and satisfaction in one context and extreme failure and dissatisfaction in another. Thus, in a sense, demographic changes have put competing stories within conflict for the main story of 2019.

To accept this assessment, one must be persuaded that the fundamental confusion inhibiting progress is a confusion over the university's identity or, simply, who UCM should $b e$. This draws comparison to how teams may encounter a period of storming, or conflict, until they develop norms of operating that then lead to performance (Levi, 2017). Both the political and symbolic frames make room for conflict and its utility, but the symbolic frame relishes' conflict as a necessary part of the story (Bolman \& Deal, 2013). Conflict, or narrative tension, related to who we are, who we serve, and how we serve them, is necessary in the institutional drama, 
contrary to critical opinion that an institution should lack such friction. One concern is, due to lack of tolerance for conflict or other situations that can be uncomfortable, is that leadership and subordinates find it intolerable, and thus seek to resolve it prematurely or in an authoritarian way.

To view this in a practical example, consider the plight of first-generation and lowincome students at the University of Central Missouri. The institution can choose, either implicitly or explicitly, to enfranchise or disenfranchise these students not only with its admission policies and degree requirements but with its extracurricular offerings, its building design, and its staffing. Symbolically, we can choose to view these students as either the protagonists or antagonists in the story of the institution. If we say that the students are the protagonists explicitly but yet we implicitly signal to them that they are antagonists, we should expect for the two way relationship to be antagonistic. Further we should anticipate and not be alarmed by students choosing competitors, ones who are also choosing those students and viewing them as protagonists, and seeing different outcomes for students at those institutions. This choice, who the university chooses it will serve and who it will not serve, remains at the very least a strategy that needs to be resolved and at the very most, it needs to define what role it will consistently perform for the students it chooses to serve.

\section{Leadership Analysis}

Similar to many universities, UCM is overseen by a board of governors appointed by the state. Its internal leadership consists of a president, provost, deans, and many corresponding leaders within in sub-structures that support the primary academic functions of the university. As it pertains to promoting retention and graduation, no one leader is responsible for this outcome at 
the University of Central Missouri. Unlike admissions, which can be identified as the office tasked with recruitment, retention and graduation are shared, decentralized objectives.

Nevertheless, there are specific student support services who consider retention and graduation to be their primary objectives: the Success Advising Center, the Learning Commons, and TRIO- Student Support Services, which is a federal, grant-funded retention initiative. Under a previous presidency, the university underwent a sweeping reorganization that centralized advising and placed the aforementioned student services within Enrollment Management. Since then, the Enrollment Management unit, by virtue of programs within it, was expected to increase retention and graduation, as well as enrollment.

The previous president and provost, both who have since left the university, were primarily responsible for the decision-making to reorganize these services for these shared purposes. A few other stakeholders were able to influence this outcome, but many were not included in the deliberations nor did they ratify the recommendation. This process is very similar to what is described in the Leader-Member Exchange (LMX) leadership theory, which may describe how leaders and followers exchange influence bi-directionally through an exchange between the leader(s) and an in-group of involved followers (Northouse, 2010). What makes the LMX unique is the delineation between the in-group and the out-group of followers. The ingroup are followers who, though they may be similar in rank, pay, or duties to those in the outgroup, are included in influencing the leader's decision-making (Northhouse, 2010). The ingroup is at the table, as it were. Their involvement and ability to consult is conditional upon their involvement in the in-group (Northouse, 2010). The out-group, by definition, is not enfranchised in this decision-making, despite having competence in their roles (Northouse, 2010). In the LMX, the onus for in-group or out-group membership lies both with the leader and the 
subordinate as the leader seeks to create opportunities for out-group members to join the ingroup, and the out-group members signal a desire to join by contributing beyond expectations and similar peers (Northouse, 2010).

The previous president and provost made the decision to centralize advising, once decentralized within each college. Since the centralized model was counter to many advisor recommendations, the advisors were not included in the decision to centralize, which categorizes them as out-group. Further, the decision, made as in response both to budget restrictions and to improve student services, required a specific and controversial change to be financially sustainable: faculty would need to provide advising to upperclassmen so that advising caseloads could be kept within manageable limits. Since faculty did not recommend nor ratify the change, faculty would also be considered in the out-group of this particular leadership dynamic. This created no small amount of friction among the constituencies affected by the decision. This reveals the unique and confounding nature of LMX in action. On the one-hand, within the leader in-group dyad, decision-making is shared, participative, and decentralized. On the other hand, since the out-group is necessarily larger and literally uninvolved in decision-making, this lends to a perspective that LMX fosters centralized, dogmatic, and unilateral decision making from the leader and in-group. This varied perception has impacted university efforts to promote retention and graduation.

\section{Summary and Implications for Research}

These organizational and leadership analyses are relevant for this study, as this study seeks to understand the relationships of factors that impact student experience and performance at public institutions like the setting described. The psychological wellbeing and academic performance of first-generation and low-income students is of concern to the leadership of all 
levels of a public institution charged with promoting the positive outcomes of these phenomena. Consequently, how a university is comprised, behaves, and makes decisions as it seeks to address these concerns also influences the factors this study is seeking to understand.

\section{Summary}

In its near 150-year existence, the University of Central Missouri has successfully evolved to meet the challenges and opportunities of the times it encountered. The first quarter of the 21st Century provides another juxtaposition of opportunities and challenge, requiring an organizational response in proportion to the magnitude of need. Once again, leadership at all levels of the institution both hold stake in and responsibility for that outcome. Central to that response are, at least, prerequisite answers to the following questions: What is the university's identity in the 21 st century? Who is it seeking to serve in the 21 st Century? The university and its employees will need to make choices if it aspires to become a change agent in this context (Ettling, 2012). 
SECTION THREE

\section{SCHOLARLY REVIEW FOR STUDY}




\section{Introduction}

In 1636, Harvard College became the first institution of higher learning in the American colonies. In the Harvard Charter, the governor noted how "through the good hand of God, many well devoted persons have been, and daily are, moved...for the advancement of all good literature, arts, and sciences...for the education of English and Indian youth...in knowledge and godliness" (Dudley, 1650, p.1). From its conception, Kuh and Gonyea (2006) assert that “religion has always had a place in American higher education (p. 40). In 2019, while architecture and other vestiges of the religious origins of universities line the quadrangles of America's universities, universities have largely abandoned the spiritual development of students (Brubacher, 2017; Chickering, Dalton, \& Stamm, 2005; Rudolph, 1962; Roberts, Turner, \& Turner, 2000). However, as institutional culture has become more secular, students have remained steadily religious or spiritual, with over $78 \%$ of students claiming religious affiliation (Kosmin, Cragun, \& Navarro-Rivea, 2009). This disconnect between public universities and the students they support creates a problem of practice for emerging adults, particularly for firstgeneration and low-income students whose academic outcomes lag behind their peers despite a growing representation on college campuses (Aruguete, 2017; McCarron \& Inkelas, 2006; Perna, 2015).

Researchers have been considering the problems of retention and achievement for decades (Duckworth, Peterson, Matthews, \& Kelly, 2007; Rendón, Jalomo, \& Nora, 2000; Strayhorn, 2012; Tinto, 1975). As institutional mission and demographics shift across the centuries, the acknowledgement of a pluralistic society with increasingly diverse beliefs challenge the viability of using any one religious curriculum or support in an effort to improve student outcomes. Emerging adulthood, a developmental epoch that runs parallel to traditional 
college age, has characteristic elements of inward reflection and meaning-making and might suggest an opportunity for spiritual development (Chickering \& Reisser, 1993; Fowler, 1981; Pascarella \& Terenzini, 2005). Further, both psychological and general medical literature have linked positive measures of personal wellbeing with spiritual salience or existential meaning, a link which may provide areas to support students in an attempt to address growing mental health challenges on college campuses (Bruffaerts, Mortier, Kiekens, Auerbach, Cuijpers, Demyttenaere, Green, Nock \& Kessler, 2018; Daaleman \& Frey, 2004; Davis, Kerr \& Kupius, 2003). Although Lindholm and Astin (2006) have noted that, among faculty, academic work can be disconnected from values and purpose; students' inner spiritual resources have been linked to a positive adjustment to college (Low \& Handal, 1995). If there is, as the literature suggests, disconnection between academic experience and student development, this may have implications for student wellbeing and performance in college.

Few studies have investigated whether spiritual resources are related to general student wellbeing and performance and a notable gap exists examining this phenomenon among firstgeneration and low-income students at public universities (Astin, Astin, \& Lindholm, 2011; Walker \& Dixon, 2002). While first-generation and low-income students are growing in enrollment across public institutions in the United States, academic outcomes have struggled to improve (Perna, 2015). Similarly, while some studies have examined the factors and characteristics of either first-generation or low-income students, few have considered students who are both first-generation and low-income as a population, though a relationship between both characteristics is established (Covarrubias \& Fryberg, 2015; (Engle \& Tinto, 2008; Terenzini, Springer, Yaeger, Pascarella, \& Nora, 1996). In the past decade, attention to grit and growth mindset as predictors for academic success in at-risk student populations may not seem 
related to spiritual resources, yet these behaviors might also be explained by inner, spiritual or value-based realities of college students (Duckworth, 2007; Dweck, 2008). Furthermore, if a relationship between spiritual resources, wellbeing, and academic performance in firstgeneration and low-income students exists, this presents an opportunity to investigate, create, and evaluate best practices in interventions and curricula to support students' spiritual development in ways institutions have abandoned or forgotten (Chickering, Dalton, \& Stamm, 2005)

Consequently, the purpose of this study is to see if the spirituality of first-generation and low-income students are different from their peers and whether or not there is a relationship between these students' spiritual resources, their wellbeing, and academic performance. Within this review is an overview of spiritual, cognitive, and psychosocial development of college student followed by a discussion of the college student development theories. Included, as well, is the critical literature gap related to the inner lives of first-generation and low-income students as a source of potential resources for improving wellbeing and academic performance.

\section{Theoretical Frameworks: Spirituality}

Much of the literature-to-date has focused on cognitive and non-cognitive resources affecting first-generation and low-income students experiences in college (Muraskin \& Lee, 2004; Duckworth, Peterson, Matthews, \& Kelly, 2007). Religion and spirituality have been popular but difficult topics to define in the literature. Capturing both mystical experiences and perennial concerns about the nature of life, the variability in definitions between scholars and laity has drawn the interest of researchers (Clark, 1958; Zinnbauer, Pargament, Cole, Rye, Butter, Belavich, Hipp, Scott \& Kadar, 1997). Others treat the terms spirituality and religion as synonyms (Miller \& Martin, 1988). Some have considered college student's subjective use of 
religiousness to include conventional behaviors like church attendance or even more conceptual attitudes related to altruistic beliefs (Pargament, Sullivan, Balzer, Van Haitsma, \& Raymark; 1995) One survey of over 100,000 college students at over 200 colleges and universities found that $76 \%$ of students were searching for meaning and purpose in life (Astin, Astin, Lindholm, \& Bryant, 2005). Zinnbauer's (1998) work on Christian religious conversion sought to make distinctions between religious conversion and incremental changes in religiousness among Christian college students. Mattis (2000) described spirituality as being multidimensional including: an understanding of transcendence, connections with the divine, living according to values, and internalizing values/beliefs. Pargament (2001) describes spirituality as "a search for the sacred" that may or may not be religious in nature (p.32).

However, Hood, Hill, and Spillka's (2018) framework takes effort to transcend and include previous work both meant to define and differentiate spirituality and religion while also measuring it/them. Consequently, their framework articulates these tensions as the "cognitive, motivational, and social aspects of finding meaning in life” (Hood, Hill, \& Spilka, 2018, p. 17). Moving beyond attribution theory supported in previous editions, Hood, Hill \& Spilka (2018) contend that this framework is most inclusive of decades of empirical data and variation among humans and is the guiding theoretical framework for understanding spirituality in first-generation and low-income students in this study.

\section{Spirituality and College Students}

While little is known, from a research perspective, about the collective spirituality of first-generation and low-income students, many have investigated spirituality among college students. The largest and most comprehensive study, the Spirituality Project at UCLA conducted by the Higher Education Research Institute, found that $75 \%$ of college freshmen were searching 
for meaning and $80 \%$ mentioned personal interest in spirituality (HERI, 2004). This project described many spiritual experiences or practices that college students engage in including: prayer, meditation, and discussions about spirituality with friends and/or family, reading sacred texts or books with sacred themes, and engaging in retreats/meetings with spiritual emphases (HERI, 2004).

One study found that students who are engaged in spiritual activities such as prayer or meditation tended to exercise more, attend cultural events more often are also more likely to perform community service, spend less time partying. Further, the researchers found and that there no evidence that spiritual practices negatively impact collegiate experiences. (Kuh \& Gonyea, 2006). Walker and Dixon (2002) discovered a positive correlation between spirituality and academic performance among African American students. African American students, who are more likely to be first-generation and low-income, did scored more highly on one spirituality assessment than non-African American students (Engle \& Tinto, 2008; Jagers \& Smith, 1996).

Astin (2004) suggested that popular college offerings, such as freshman seminar and service learning, as examples of promoting spiritual issues via holistic learning. Citing the former example, Astin (2004) asserted that seminar encourages "students to look at their education in a more holistic way, and to make deeper connections between their academic work and their sense of meaning and purpose in life." (p. 40). Yeh (2010) found that service learning helped develop coping skills, find personal meaning, clarify personal values and find motivation for first-generation and low-income students. Spirituality as it relates to purpose and meaning in life, forms the foundation for the conceptual framework addressed later in this section.

Greenway (2006) found her path model hypothesizing purpose in life positively predicting academic engagement and academic success accounted for $42 \%$ of the variance in 
academic success. Though defining first-generation students differently, as students whose parents have not had any college experiences, she found those students whose parents had some college scored more highly on having purpose in life than those that did not. Greenway (2006) also found female students scored more highly on spirituality and purpose in life than male students. Greenway (2006) contended her findings "point to the need for higher education to cultivate the search for meaning, to assist students in finding purpose in life, and to promote intrinsic motivation through personal meaning-making that leads to academic engagement (p. 3).

Dalton, Eberhardt, Bracken and Echols (2006) suggested a delineation between religious and secular spirituality among college students that lead to four types of spiritual seekers. The first two types, faith centered seekers and multi-religious seekers, are alike in that they seek spirituality within a particular religion but differ in the latter's ability to "deepen their religious spirituality through interfaith and multi-religious exploration, dialogue, and practice" (Dalton, et. al, 2006, p. 7). The remaining two types are categorically secular in that they seek spirituality outside of religion. The difference between the mindfulness seeker and the wellness seeker is the former is "focused in their inner search... to heighten self-awareness" and the latter is "engage in spirituality activities to achieve a more holistic, healthy, and integrated way of life" (Dalton, et. al, 2006, p.7). These avenues may mark the religious and non-religious spiritual classifications of today's college students. To cultivate spirituality, Dalton, et. al., (2006) stressed the importance of physical space(s) dedicated for these purposes, citing public institution examples like Salisbury State, Central Oklahoma University, and University of California- San Diego.

One study $(\mathrm{N}=43)$ of successful minority students in a teacher education program revealed that they cited spirituality---more than their father, other mentors, or employment--- as one of the six most important factors to their success in college (Clark, et. al, 2006). While the 
respondents mentioned other internal factors, many "associated their feelings of motivation, strength and hope, with God and belief in a higher being (Clark, et. al, 2006, p. 131).

It is worth noting, again, that there is little available research investigating spirituality as a phenomenon in the lives of first-generation and low-income college students, let alone whether spirituality has any effect on those students' wellbeing or success in college. Later in this section, college student development theorists offer models that may explain how or why spirituality remains a persistent interest or pursuit during the college years.

\section{Theoretical Frameworks: Wellness and Wellbeing}

Student psychological and emotional wellbeing in college has garnered much attention in recent years. Looking for predictors of wellbeing for college students, researchers have identified behaviors, but not always inner resources, that contribute to positive wellbeing. Dunn (1961) was the first to formally recognize wellness as a concept though it would take several decades until others offered model to explain how wellness or wellbeing might be composed.

For example, Wrosch, Scheier, Miller, Schulz, and Carver, (2003) found goal regulation, a student's ability to abandon unattainable goals in pursuit of alternative goals, was predictive of general positive levels of wellbeing among college students as opposed to a more static understanding of goals. For sake of this study, the beliefs that precede behavior are of central concern. Furthermore, the personal circumstances that accompany personal beliefs are germane to this study. The impact of first-generation status on wellbeing is documented under at least three themes: disproportionate stress related to being underprepared for the college environment, being under- resourced for college expenses, and the related sense of feeling as if one does not belong (Padgett, Johnson, \& Pascarella, 2012; Pascarella \& Terenzini, 2005; Stephens, Brannon, Markus, \& Nelson, 2015; Strayhorn, 2006). 


\section{Spirituality and Wellbeing}

The link between spirituality and wellbeing is also well-documented in the literature.

Fehring, Brennan, and Keller (1987) determined there were strong inverse relationships between spiritual outlook and negative moods among a small group of nursing students. One study ( $\mathrm{n}=$ 509) found a high correlation between spirituality and subjective, general wellbeing (.62) and an inverse correlation with the Zung Depression Scale (-.42) (Daaleman \& Frey, 2004). Another researched investigating preventative factors for non-suicidal self-injury in college students found that factors of spirituality "may be potentially positive influences that may insulate people from self-injuring" and encouraged counselors in college contexts to "explore what aspects of spirituality and religiosity can be strengthened to reduce or eliminate self-injury" (Kress, Newgent, Whitlock, \& Mease, 2015, p.171).

Others have attempted to understand the link between inner spiritual resources of college students and their personal health. Klassen and Greken (2017) found positive indicators of spirituality were negatively correlated with likelihood of heavy drinking. Nelms, et. al., (2006) found students who considered themselves physically healthy also seemed to have spiritual components to their concepts of physical and emotional wellness.

\section{Hedonic and Eudaimonic Wellbeing}

Ryff's (1989) Six Factor Model of Psychological Wellbeing (PWB) depicts the concept of psychological wellbeing and its interplay with the following components: autonomy, environmental mastery, personal growth, positive relations with others, purpose in life, and selfacceptance Wang and Castenada-Sound (2008) noted the alignment between Ryff's (1989) model and the stated outcomes or aspirational values of many or most higher education institutions.. Ryff's (1989) heavy with its emphasis on the pursuit of a meaningful life as 
opposed, as noted by Seligman (2011), to an emphasis to positive emotions such as happiness or pleasure, makes the PWB a eudaimonic model for wellbeing. El Ansari and Stock (2010) noted how student wellbeing has been linked to performance, examining several instances in the United Kingdom.

Hettler (1984) highlighted six dimensions in his individual wellness model: social, occupational, spiritual, physical, intellectual, and emotional. Hettler (1984) also suggested the applicability of his concept to university student populations. Though spiritual components of wellness were suggested and were, perhaps, intuitive, few rigorous studies investigated to what degree, if any, spirituality plays in wellbeing, particularly among college students. Years later, Adams, Bezner, Drabbs, Zambarano, and Steinhardt (2000) were the first to provide a model incorporating spiritual wellness alongside psychological or physical wellness among college students. Improving upon Hettler's (1984) work, Mayol (2012) emphasized the multidimensionality of wellness, retaining spirituality alongside environmental, physical, social, spiritual, intellectual, occupational, financial, and mental wellness. Further, Mayol, Scott, and Schreiber (2017) did not find significant wellness differences between first-generation and nonfirst-generation students.

A contemporary of Hettler, Diener (1984) asserted that subjective wellbeing (SWB) as a framework to understand life satisfaction, positive affect, and negative affect. In a later update, he defined his framework as "a person's cognitive and affective evaluations of his or her life" (Diener, Lucas, \& Oishi’s, 2002, p.187). Central to his framework is its subjective nature which both ties and limits the assessment to an individual's experience, such as life satisfaction. In this sense, Diener's (1984) SWB, with its emphasis on felt or intuited appreciation of one's life, 
makes SWB a hedonic assessment of wellbeing. Dolan, Layard, and Metcalfe (2011) found life satisfaction, as measured with SWB, is correlated with income, marital status, and health.

\section{Wellbeing for First-Generation and Low-Income College Students}

Wang and Castañeda-Sound (2008) found that first-generation students lag behind their peers in measures of self-efficacy, which is demonstrated to be a predictor for positive wellbeing. Low-income students have greater difficulty adjusting to college (Terenzini, Rendon, Upcraft, Millar, Allison, \& Gregg, 1994). While one study found the difference in wellbeing between first-generation and non-first generation students was minimal, first-generation students were more likely to have lower self-acceptance than non-first-generation students (Bowman, 2010). First-generation and low-income students are more likely to delay beginning college, attend parttime, and work while in school (Engle \& Tinto, 2008). Being first-generation and low-income makes students four times more likely than peers to leave after the first year of college (Engle \& Tinto, 2008). Lippincott and German (2007) argued first-generation students face unique challenges that result in wellbeing needs other students may not have. In a student of 10 firstgeneration and low-income students, Hebert (2018) found all had encountered psychological stress relating to the difficulties of their socioeconomic status and that this stress was experienced over several years. Stebelton, Soria, and Huesman (2014) argued that whether or not first-generation students sense they belong or matter to the campus can impact both their wellbeing and likelihood of persisting in college. Eitel and Martin (2009) found first-generation and low-income students may struggle to find the availability to attempt to belong, as a lack of finances made it likely to for $50 \%$ of first-generation students to leave college prematurely. 


\section{Seligman's PERMA Framework for Wellbeing}

Seligman's (2011) framework for wellbeing included positive emotion, engagement, relationships, meaning, and achievement (PERMA). PERMA is unique among other wellbeing theories in that each element in Seligman's (2011) framework must be contribute to wellbeing, be worth seeking on its own, and that each element is exclusive and measurable .PERMA is also distinct from other wellbeing theories because it includes "meaning", which was underemphasized in other wellbeing theories (Coffey, Wray-Lake, Mashek, \& Branand, 2016). Meaning, which is a eudaimonic or self-actualizing factor of wellbeing, is here contrasting with positive emotions which could be described as hedonic (Khaw \& Kern, 2014). For example, people may report feeling both a sense of meaning and feelings of happiness, while others may sense profound meaning but not have a happy life in the hedonic sense (Baumeister, Vohs, Aaker, \& Garbinsky, 2013) This component, meaning, helps people feel their life is fulfilling and satisfying (Seligman, 2011). Meaning, alongside achievement and happiness and other factors in Seligman's (2011) model are required for human flourishing, which is the end function of wellbeing.

Seligman's (2011) PERMA framework is selected as the wellbeing framework for this study due to its attempt to reconcile hedonic and eudaimonic components of earlier frameworks and its alignment with the conceptual framework for this study. Further, PERMA was found to demonstrate "adequate psychometric properties" (Butler \& Kern, 2016. p.16) Finally, there is evidence for the model's validity within a college setting (Coffey, et. al., 2016).

\section{Theoretical Frameworks: College Student Development Theories}

As this study concerns spiritual development as well as the binary outcome variables of wellbeing and academic performance, several college student development theories are relevant 
in informing an approach to this inquiry and were considered and determined not suitable for this studyfor a myriad of reasons. Ultimately, Chickering and Reisser's (1993) theory of development is the conceptual framework that guides this study.

\section{Perry's Epistemological Development}

Perry (1970) outlined a nine-stage process (later grouped into four clusters) that attempt to explain how college students might make meaning in the world in which they find themselves. These clusters are duality, multiplicity, relativism, and commitment-within-relativism. In these stages, understanding about the ultimate concerns in life moves from being primarily inherited, dualistic view of 'right vs. wrong,' to a reactionary pluralistic worldview, then on to a relativistic stage where truth is acknowledged to be local or subjective for each person. Finally, commitment-within-relativism acknowledges the subjective experiences of individuals while making reasoned analysis commitments to accepted truths within a complex society (Perry, 1970). Perry's work, while foundational, is limited by a sample comprised solely of Harvard College students (Pascarella \& Terenzini, 2005) and therefore was discarded for this inquiry.

\section{Faith Development Theory}

Fowler $(1981,1991,2006)$ was one of the first to attempt to describe how and why spiritual understanding develops across the lifespan with Faith Development Theory (FDT). Although his work was developed from an early ministerial role, Fowler's model was concerned less with particular beliefs and more with how students come to believe what they believe (Chickering, Dalton, \& Stamm, 2005; Pascarella \& Terenzini, 2005). Faith development, in this framework, has four uses: lending life both coherence and direction, connecting people in shared loyalty, connecting people to a larger, communal reference point, and helping people "face and deal with the challenges of human life and death, relying on that which has the quality of 
ultimacy in their lives" (Fowler \& Dell, 2006, p. 36). The stage, which overlaps most notably with the traditional pre-college and college years in FDT, is Synthetic-Conventional Faith (Fowler, 1981). In this stage, conflict from apparent contradictions among worldviews promotes reflective evaluation of one's beliefs that can cause college students to struggle to integrate new information with conventional belief just short of a critical view of one's beliefs. It is both the internal conflict coupled with the external social interaction with other students, who may come from different religious traditions but is experiencing the same internal dilemmas, that can usher students to the next, more reflective, stage: Individuative-Reflective Faith (Fowler, 1981).

This stage has two primary tasks: the opportunity for an individual to become critical of one's values and to develop an internalized sense of faith not necessarily connected to one's family, community, or culture (Fowler \& Dell, 2006). Key to making the transition from Synthetic-Conventional to Individuative-Reflective Faith is the willingness to part, as the sole method of validation, external authorities of belief, posing a risk to the social structures that often accompany strong communities of belief (Fowler, 1981). While others have addressed the phenomenon of evolving faith in college, FDT explained how this might happen in an interpersonal, collegiate context (Pascarella \& Terenzini, 2005).

Many have expanded upon or noted the limitations of FDT. Streib (2001) contended that FDT, as a framework, over-relies on cognitive development at the neglect of other situational or environmental factors that affect how one interacts with the ultimate concerns of life. While not analyzing FDT directly, others note critiques similar to Gilligan's (1977) that there may be moral developmental differences between men and women, which might not have been captured in Fowler's early analyses due to the bias inherent in predominantly male sampling. Parks (2000) critiqued the "cognitive and stage-structure bias" similar to other theorists heavily influenced by 
the work of Jean Piaget (p.60). For these reasons, FDT was not chosen as the guiding framework for spiritual development or spirituality in this study.

\section{Parks's Faith Development Model}

Parks (1986:2000) contends that faith development is driven by a college student's response to appropriately respond to the world as a college student finds it. Five questions, she suggests, need to be appropriately answered students: Who am I? Where am I going? What can I believe in? How can I be happy? Will my life make a difference? (Parks, 2000). Parks (1986; 2000) both critiqued and expanded upon Fowler in her four-stage framework: Adolescent or Conventional, Young Adult, Tested Adult, and Mature Adult. While still using the term faith, her frame included an understanding of spirituality that may be non-religious or lack dogma (Parks, 2000). Further, Parks' model included a stage of development, Young Adult, which aligns with the traditional college age, due to the influence of previous, prominent student and moral development theorists (Parks, 2000). Park's model is also notable for describing how faith development might also be related to how one interacts both with oneself and with one's community. For example, students moving into the Young Adult stage might experience an emerging sense of inner dependence while the surrounding community evolves from conventional authority to more a mentoring presence (Parks, 2000). This mentoring community offers a sense "belonging" for students "as they are and as who they are becoming" (Parks, 2000, p.95). This mentoring experience can be found both in curricular and co-curricular contexts through interactions with students, professors, and other university personnel (Chickering, Dalton, \& Stamm, 2005). Parks contended students are "not being asked big-enough questions. They are not being invited to entertain the greatest questions of their own lives or their times" (Parks, 2000, p.138). 
In a review of her work, Love (2002) noted that Park's made room for spiritual development to happen in campus spaces such as residence halls, but contended the type of interaction she describes is more likely to occur in academic environments like learning communities. The destination, in Parks' model, is neither dependence on a traditional authority nor a rigid individuality, but interdependence or integration, similar to her contemporary theorists. Parks also asserted the college experience could affect faith in positive and negative ways (Pascarella \& Terenzini, 2005). Like FDT, Parks' (2000) model has been critiqued, as a stage model, in its arguable limitation for explaining human experience. Furthermore, Chickering and Reisser (1993) noted that the college student experience, due to the nature of rapidly changing student populations and diversity within those populations, leads to increasingly complex phenomena in which stage models might strain to explain, thus the rejection of this model for use in this inquiry.

\section{Fry's Spiritual Leadership Theory}

Fry $(2003 ; 2005 ; 2009)$ posited that spiritual leadership might link both the development of spirituality and leadership in college students that may result in positive outcomes. Two fundamental processes comprise spiritual leadership: creating service as a value so that students sense a calling in life and operationalizing that value by joining others in a mission to live for the benefit of self and others. Fry (2009) contended that satisfaction in one's outer life is linked to spirituality cultivated in one's inner life, linking spirituality with psychological wellbeing. Similarly, Fry (2003) also contended that personal spiritual leadership can be cultivated independently of religious affiliation or dogma. Fry (2009) suggested that volunteerism or creative work can be experienced to develop students' spirituality. In his framework, spiritual 
development is evidenced by students being "more grounded, more self-aware, less self-centered and confident of their vision and values" (p.81)

Astin (2004) also suggested the "connectedness" and "reflection" of service learning where students "collectively reflect on the meaning of their service experience" is what you find in the "most powerful service learning experiences" (p. 41). Ultimately, since the research questions in this inquiry are not concerned with leadership as a construct, this model was rejected.

\section{Astin's Input-Environment-Outcome Model}

Astin’s (1993) Input-Environment-Outcome (I-E-O) model described how internal student characteristics, including religious values/belief, might interact with the educational environment and the supports it does or does not provide. The model shows how pre-college factors, like students' spiritual outlook or religious upbringing, affect both their college experiences and ultimate outcomes. One study investigating the spiritual dimensions of first-year students used Astin's model to describe the religious behaviors and practices of students and found that while students' religious attendance and activity declined, their spiritual understanding continued to develop (Bryant. Choi, \& Yasuno, 2003). While his model is not explicitly spiritual, Astin (2004) has called for growing emphasis for spiritual development within the liberal arts curriculum and participated in the creation of the College Student Beliefs and Values Survey, which is used in modified form in this inquiry. Although Astin's (1993) model and contribution to the student and spiritual development literature is significant, his model is limited by its generality where other models speak more specifically to spiritual development as a distinct stage or epoch of student development. Though the model may hold explanatory power, for these limitations, it was rejected as the guiding framework in this study. 


\section{Love and Talbot's Five Processes of Spiritual Development}

Whereas short of a framework, Love and Talbot (1999) outlined five interrelated processes of spiritual development to assist student affairs professionals. Love and Talbot (1999) stress that these processes are neither stages nor linear and "are often in evidence concurrently" (p. 364). The first process involves seeking a unified, authentic sense of self where behaviors and beliefs are aligned. The second process involves transcending self-centeredness in a way that demotes narcissism and promotes enlightenment. As others have suggested, the third process involves developing a greater interconnection oneself, each other, and the community at large. The authors cited "united efforts" akin to service learning as opportunities to foster such development (Love \& Talbot, 1999, p. 365). The fourth process outlines the seeking and development of purpose. The fifth and final process involves openness to and seeking a relationship with "an intangible and pervasive power...that exists beyond human existence and rational human knowing" (Love \& Talbot, 1999, p. 367). This, according to their outline, allows for the inclusion of both eastern and western religious views.

Love and Talbot (1999) have several assumptions that underlie their five processes. They assume that the quest for spirituality is innate for all, that spirituality and spiritual development are interchangeable concepts, and that trait openness is required for spiritual development. Love and Talbot's (1999) processes also suggest that organized religion is not required for spiritual development and that development "has no endpoint" (p. 364). As the processes tend to be more descriptive of spiritual development phenomena and lack organization or flow similar to other frameworks, these processes were not selected as the framework in this study given Creswell's (2013) admonition to select a framework that supports logic for relationship between variables under consideration. 


\section{Conceptual Framework}

Theorists have been interested in the inner lives of college students for decades. Many of their contributions, and their limitations, have been noted. Where limitations in methodology such as non-representative samples have limited some foundational theories, others have been critiqued on their dependence on cognitive development theory. Still, others have lacked rigorous validity and reliability testing or fall short of comprising a framework. These limitations and the specific foci of this study drive the selection of Chickering and Reisser's (1993 Seven Vectors of Development as the guiding conceptual framework for this study.

\section{Chickering and Reisser's Seven Vectors of Development}

Chickering (1969) and Chickering and Reisser's (1993) Seven Vectors of Development convey how college students may develop psychosocially: developing competence, managing emotions, becoming interdependent, developing mature interpersonal relationships, establishing identity, developing purpose, and the development of integrity. As college students gain skills and receive feedback, they develop a sense of their abilities, which support a stronger view of self. In the next vector, students learn adaptive ways of managing and coping with emotions, particularly negative emotions and environmental frustrations typical to college. In a critique of cognitive, stage models, Chickering and Reisser (1993) asserted the seven vectors assume that “emotional, interpersonal, and ethical development deserve equal billing with intellectual development" (p.39).

In the third vector, students learn ways to negotiate autonomy with interdependence. Developing a capacity for inclusivity and pluralism marks development in the fourth vector. The fifth vector is concerned with the establishment and acceptance of one's identity. The sixth vector links psychosocial development with the development of one's purpose in life. Finally, 
the seventh vector manifests and aligns personal values with lived behavior as students develop integrity.

Conceptualized as a way to describe how psychosocial development happens alongside cognitive development, the steps, or vectors, in the model serve a directional purpose. Movement from lower to higher positions within the vectors signals growth and movement can very between each vector. Undergoing a revision in 1993 that reordered and modified some vectors in response to continued research, the model accounts for developmental differences between students, including males and females (1993). For example, research has suggested men and women vary both in how they view relationships and groups outside of themselves (Taub, 1995).

Chickering and Reisser's (1993) sixth vector, developing purpose, is particularly relevant to this study. The authors suggested developing purpose necessitates the alignment of career plans, personal interests, and interpersonal commitments (Chickering \& Reisser, 1993). This also includes goal-oriented thinking, goal-oriented behavior, and the articulation of priorities (Chickering \& Braskamp, 2009). Where passive involvement may have served utility in other vectors, intentionality is required in the sixth vector (Pascarella \& Terenzini, 2005). It is important to note the development of purpose, as conceptualized by Chickering and Reisser, describes both internal and external activity. Reisser (1995) pointed to ones emerging, internal sense of purpose is evidenced by one's external decisions. One longitudinal study of 354 freshmen validated the sixth vector linking the development of purpose to college experiences (Martin, 2000). In their synthesis of student development literature, Pascarella and Terenzini (2005) contended purpose development is heavily influenced by the student's view of self as established in the fifth vector. This means, according to this framework, that one's view of purpose is conditioned by one's view of self. 
Chickering and Reisser (1993) suggested seven components needed to help college students develop along the seven vectors: institutional objectives, institutional size, studentfaculty relationships, curriculum, teaching, communities, and student development programs. Chickering, Dalton, and Stamm (2006) advocated for holistic education as a way to foster spiritual development in college students while noting a nuanced view of students who might distrust religion yet sense a "personal quest for meaning and purpose in their lives" (p. 91). The authors contend that authenticity, related to vectors five through seven and defined broadly as living life by one's values, may be linked to spirituality, which they also define broadly in terms of searching for and making meaning (Chickering, Dalton, \& Stamm, 2005).

While not an explicitly spiritual framework, others have noted the "distinctly spiritual tone" implicit within the vectors (Love \& Talbot, 1999, p. 369). Chickering and Reisser's (1993) model was selected for its ability to describe how, as Creswell (2013) suggested, its utility in describing how independent and dependent variables may be related. As it relates to this study, Chickering and Reisser's (1993) model suggested the expectation that spiritual resources of first-generation and low-income students to influence their respective levels of psychological wellbeing and academic performance born out of experiences related to purpose making that occurs in the lives of college students as they develop a sense of identity. The internal and external processes associated with the sixth vector, such as developing an inner sense of values and articulating a set of goals, may be linked both with wellbeing and behaviors adaptive to academic achievement in first-generation and low-income college students at a public university.

This rationale is supported by at least three arguments. First, Chickering's (1969) model has been revisited, revised, and validated by other research (Martin, 2000; Reisser, 1995; Straub, 1987). Second, the framework acknowledged the interplay of both cognitive and psychosocial 
development in ways that are specific and predictive, such as the role of the fifth vector's semifoundational role in supporting development in the sixth vector. This relationship may be similar to relationships, if any, between the variables in this study. Finally, the selection of this model allows for more inclusive understandings of spiritual experiences that may be non-religious is nature which aligns with the purpose of this study. In other words, Chickering and Reisser's (1993) framework allows for the development of values and purpose that may or may not be related to religious beliefs, which can include non-religious students in an inquiry related to spiritual resources.

\section{Extant Literature}

The gap in achievement between persons of high and low socioeconomic status is a persistent and perennial focus of research and policy. In the United States, the emphasis on achievement rates, signifying whether or not students have earned the degree or certificate they originally sought, has increased in recent years (Martinez \& Turner, 2015; Mullin, 2013) A student of over 1800 first-generation college students found that they lagged behind their peers in both on-campus engagement and retention (Soria \& Stebleton, 2012). A comparative analysis investigating the relationship between religiosity and academic performance between white and black American students found that religious behaviors were positively correlated with academic performance in both groups, though there were differences in religious behavior between both groups (Walker and Dixon, 2002). A study investigating a wide range of predictors for academic success among 200 randomly sampled students found that while work hours and late waking times were negatively correlated with GPA, strength training and the study of spiritual material were positively linked (Trockel, Barnes, \& Egget, 2010). 
First-generation and low-income students who have experienced service learning have noted how the experience helped build a sense of meaning that they connect to their academic persistence (Yeh, 2010). College students, particularly first-generation and low-income students, are as spiritual and/or religious as they have ever been despite the phenomenon that their educational experiences are virtually devoid of spiritual support or development in public institutions (Astin, et al., 2011; Chickering, Dalton, \& Stamm, 2005). The links between spirituality and wellbeing as well as wellbeing and academic performance are well established in the literature (Brennan \& Keller, 1987; Ramos-Sanchez \& Nichols, 2007; Trockel, Barnes, and Egget, 2010; Walker and Dixon, 2002; Yeh, 2010). However, while educators have observed these phenomena across the aggregate college student population, they do not yet know if this relationship exists among first-generation and low-income students or what degree. If it does exist, then this has potentially disruptive implications for public colleges and universities who have the mandate to increase outcomes for the most vulnerable students while simultaneously sensing an obligation to remain secular or agnostic when it comes to matters of ultimate concern.

\section{Summary}

In summary, the purpose of this inquiry is to determine if a relationship exists between spiritual resources and psychological wellbeing as well as academic performance in firstgeneration and low-income college students at a public university. As stated previously, researchers and policy-makers have taken an interest in increasing achievement outcomes of this population, and little is known whether supporting the spiritual development of all students, but especially those that are first-generation and low-income, is efficacious for improving wellbeing and academic performance. Perry (1970) and Fowler (1981) have laid foundations in studying the development of students' capacity to develop spiritually. Parks (2000) and Love and Talbot 
(1999) has built on that foundation, revisiting both the assumptions and limitations of previous work and suggesting new components more representative of contemporary college students. Others, like Astin (1993) or Chickering and Reisser (1993) have address spirituality by way of inner resources or processes that accompany environmental, cognitive, and psychosocial occurring with students in college. This inquiry is meant to address a notable and critical gap in that literature, the spiritual resources of first-generation and low-income students at public universities. Perhaps in an attempt to build on previous work by respectfully encountering new challenges and opportunities with the students public universities are seeking to support, this inquiry can bring some manner of insight to realities we have not yet begun, are reluctant to consider, or given this history of higher education, might offer us a chance to reconsider. 
PLAN FOR SECTION FOUR

\section{CONTRIBUTION TO PRACTICE}




\section{Introduction}

Despite extensive literature linking spirituality with psychological wellbeing, little is known as to what relationship, if any, spirituality has with psychological wellbeing and academic performance, particularly among first-generation and low-income students. This study uses a cross-sectional survey design. The study was conducted at a public, regional Midwestern institution within an hour driving radius of the Kansas City metropolitan area. Conducted at a public, regional, Midwestern institution within an hour's driving radius of the Kansas City metropolitan area was this study. Using a cross-sectional survey design, data were collected from 135 participants.

\section{Research Questions}

This present study has four research questions:

RQ 1: Are there differences in spirituality between first-generation and low-income students and their peers at a public Midwestern university?

RQ 2: Is there a relationship between spirituality and psychological wellbeing among first-generation or low-income students at a public Midwestern university?

RQ 3: Is there a relationship between spirituality and academic performance among first-generation or low-income students at a public Midwestern university?

RQ 4: Does spirituality affect academic performance when mediated by psychological wellbeing among students at a public Midwestern university?

\section{Connection to Conceptual Framework}

Purpose in life, Chickering and Reisser (1993) asserted, is born out of a sense one's self. Martin (2000) found college freshmen further develop their sense of purpose alongside their 
college experiences. If spirituality is a factor in developing and sustaining ones self for the sake of cultivating purpose, then perhaps spirituality could be a factor influencing student psychological wellbeing and academic performance. Chickering and Reisser's (1993) sixth vector, developing purpose, may provide the scaffolding needed to improve mental health and academic outcomes among college students, especially those most vulnerable to attrition. While this spirituality may or may not be fundamentally religious in nature, it may be fundamental to flourishing both in college and beyond.

\section{Participants and Data Collection}

A survey with scales measuring spirituality and psychological wellbeing were distributed to undergraduate and graduate students at the University of Central Missouri in the fall of 2019. The survey had 134 respondents with only 1 non-student participating. Provided in Tables 1 and 2 is a breakdown of basic student demographics including class rank and sex/gender of respondents.

Table 3

Participant Classification by Class Ranking

\begin{tabular}{|c|c|c|c|c|c|}
\hline & & Frequency & $\underline{\text { Percent }}$ & $\underline{\text { Valid Percent }}$ & Cumulative \% \\
\hline \multirow[t]{6}{*}{ Valid } & Freshman & 15 & 11.2 & 11.3 & 11.3 \\
\hline & Sophomore & 21 & 15.7 & 15.8 & 27.1 \\
\hline & Junior & 45 & 33.6 & 33.8 & 60.9 \\
\hline & Senior & 45 & 33.6 & 33.8 & 94.7 \\
\hline & Graduate & 7 & 5.2 & 5.3 & 100.0 \\
\hline & Total & 133 & 99.3 & 100.0 & \\
\hline Missing & System & 1 & .7 & & \\
\hline Total & & 134 & 100.0 & & \\
\hline
\end{tabular}


Two thirds of participants were clustered among upperclassmen. Since the methodology for this student did not make distinctions between undergraduates and graduates, all enrolled students are included in the analysis.

Table 4

Participant Classification by Sex and/or Gender

\begin{tabular}{|c|c|c|c|c|c|}
\hline \multirow{4}{*}{ Valid } & \multirow[b]{2}{*}{ Male } & \multirow{2}{*}{$\frac{\text { Frequency }}{26}$} & \multirow{2}{*}{$\frac{\text { Percent }}{19.4}$} & \multirow{2}{*}{$\frac{\text { Valid Percent }}{19.5}$} & \multirow{2}{*}{$\frac{\text { Cumulative } \%}{19.5}$} \\
\hline & & & & & \\
\hline & Female & 104 & 77.6 & 78.2 & 97.7 \\
\hline & Other identified & 3 & 2.2 & 2.3 & 100.0 \\
\hline & Total & 133 & 99.3 & 100.0 & \\
\hline Missing & System & 1 & .7 & & \\
\hline Total & & 134 & 100.0 & & \\
\hline
\end{tabular}

As shown in Table 4, respondents are predominately female. This may be representative of current enrollment trends while also potentially skewing results.

First generation and low-income college students are the population of interest in this inquiry. The participant breakdown is shown in Tables 5 and 6, respectively. Also, participants who were either first-generation or low-income are shown in Table 7 and participants who are both first-generation and low-income are shown in Table 8. 
Table 5

Participant Classification by First Generation Status

\begin{tabular}{|c|c|c|c|c|c|}
\hline & & Frequency & Percent & Valid Percent & Cumulative Percent \\
\hline \multirow{3}{*}{ Valid } & No & 72 & 53.7 & 53.7 & 53.7 \\
\hline & Yes & 62 & 46.3 & 46.3 & 100.0 \\
\hline & Total & 134 & 100.0 & 100.0 & \\
\hline
\end{tabular}

Table 6

Participant Classification Low Income Status

\begin{tabular}{|c|c|c|c|c|c|}
\hline & & Frequency & Percent & Valid Percent & Cumulative Percent \\
\hline \multirow[t]{3}{*}{ Valid } & No & 73 & 54.5 & 54.5 & 54.5 \\
\hline & Yes & 61 & 45.5 & 45.5 & 100.0 \\
\hline & Total & 134 & 100.0 & 100.0 & \\
\hline
\end{tabular}

Table 7

Participant Classification First Generation and/or Low Income Status

\begin{tabular}{|c|c|c|c|c|c|}
\hline & & Frequency & $\underline{\text { Percent }}$ & $\underline{\text { Valid Percent }}$ & Cumulative \% \\
\hline \multirow[t]{3}{*}{ Valid } & Neither FG nor LI & 23 & 17.2 & 17.3 & 17.3 \\
\hline & Either FG or LI & 110 & 82.1 & 82.7 & 100.0 \\
\hline & Total & 133 & 99.3 & 100.0 & \\
\hline Missing & System & 1 & .7 & & \\
\hline Total & & 134 & 100.0 & & \\
\hline
\end{tabular}

Table 8

Participant Classification First Generation and Low Income Status

\begin{tabular}{|c|c|c|c|c|c|}
\hline & & Frequency & $\underline{\text { Percent }}$ & $\underline{\text { Valid Percent }}$ & Cumulative $\%$ \\
\hline \multirow[t]{3}{*}{ Valid } & $\begin{array}{l}\text { Not FG } \\
\text { and LI }\end{array}$ & 120 & 89.6 & 90.2 & 90.2 \\
\hline & FG and LI & 13 & 9.7 & 9.8 & 100.0 \\
\hline & Total & 133 & 99.3 & 100.0 & \\
\hline \multirow[t]{2}{*}{ Missing } & System & 1 & .7 & & \\
\hline & Total & 134 & 100.0 & & \\
\hline
\end{tabular}




\section{Presentation of the Data}

Quantitative data derived from statistical analyses addressing the four research questions are presented in this section.

\section{Descriptive Statistics}

Listed in Table 9 are the descriptive statistics for all relevant variables in this inquiry, including standardized values for compositive variables created as a result of principal components analysis. Of note are the GPA means closer to maximum end of the range.

Table 9

Descriptive Statistics

\begin{tabular}{|c|c|c|c|c|c|c|}
\hline & $\underline{\mathrm{N}}$ & $\underline{\text { Range }}$ & $\underline{\text { Minimum }}$ & Maximum & Mean & $\underline{\mathrm{SD}}$ \\
\hline Previous semester GPA: & 120 & 2.30 & 1.70 & 4.00 & 3.38 & .59 \\
\hline Cumulative GPA: & 121 & 2.00 & 2.00 & 4.00 & 3.42 & .49 \\
\hline Positive Emotions & 125 & 7.67 & 2.00 & 9.67 & 6.60 & 1.52 \\
\hline Engagement & 125 & 5.67 & 4.33 & 10.00 & 7.58 & 1.39 \\
\hline Relationships & 125 & 7.00 & 3.00 & 10.00 & 7.56 & 1.63 \\
\hline Meaning & 125 & 7.67 & 2.33 & 10.00 & 7.36 & 1.59 \\
\hline Achievement & 125 & 7.67 & 2.33 & 10.00 & 7.39 & 1.48 \\
\hline $\begin{array}{l}\text { Psychological Wellbeing } \\
\text { (PERMA) }\end{array}$ & 125 & 5.75 & 3.94 & 9.69 & 7.29 & 1.19 \\
\hline Salient Spirituality & 120 & 4.28 & -2.73 & 1.55141 & -.02 & .99 \\
\hline Spiritual Change and Crisis & 120 & 4.30 & -1.93 & 2.37229 & 0 & 1.01 \\
\hline $\begin{array}{l}\text { Humanism, Non-spiritually } \\
\text { Identified }\end{array}$ & 120 & 4.66 & -2.53 & 2.13314 & -.01 & 1.01 \\
\hline Spiritual Seeking Behavior & 120 & 5.43 & -3.76 & 1.66584 & .03 & .97 \\
\hline Valid N (listwise) & 113 & & & & & \\
\hline
\end{tabular}

Provided in Table 10 are descriptive statistics for the six items that comprised the composite variable, Salient Spirituality. 
Table 10

Descriptive Statistics: Salient Spirituality

$\underline{\mathrm{N}} \underline{\text { Range }}$ Minimum $\underline{\text { Maximum }}$ Mean $\underline{\text { SD }}$

My spiritual/religious beliefs have

126

helped me develop my identity

My spiritual/religious beliefs are one of

the most important things in my life

My spiritual/religious beliefs give

12

meaning/purpose to my life

My spiritual/religious beliefs help

125

define the goals I set for myself

My spiritual/religious beliefs provide

$\begin{array}{llllll}126 & 3 & 2 & 5 & 3.80 & .996 \\ 126 & 3 & 2 & 5 & 4.02 & .959 \\ 125 & 3 & 2 & 5 & 3.95 & .932 \\ 125 & 3 & 2 & 5 & 4.07 & .952 \\ 126 & 3 & 2 & 5 & 3.69 & .959 \\ 124 & & & & & \end{array}$

me with strength, support, and guidance

My spiritual/religious beliefs lie behind

my whole approach to life

Valid N (listwise)

Provided in Table 11 are descriptive statistics for prayer as a spiritual practice and proxy for spirituality, reflecting Kuh and Gonyea's (2006) earlier work. Prayer is used as a predictor variable in a later mediation analysis.

Table 11

Spiritual Behavior: Prayer

\begin{tabular}{|c|c|c|c|c|c|}
\hline & & Frequency & Percent & Valid Percent & Cumulative $\%$ \\
\hline \multirow[t]{3}{*}{ Valid } & Yes & 76 & 56.7 & 60.3 & 60.3 \\
\hline & No & 50 & 37.3 & 39.7 & 100.0 \\
\hline & Total & 126 & 94.0 & 100.0 & \\
\hline Missing & System & 8 & 6.0 & & \\
\hline Total & & 134 & 100.0 & & \\
\hline
\end{tabular}




\section{Research Question One}

Are there differences in spirituality and wellbeing between first-generation and lowincome students and their peers at a public Midwestern university?

Walker and Dixon (2002) found differences in spirituality among different groups of students. To examine whether there was any difference in spirituality and wellbeing between first-generation or low-income students and their peers, independent sample $\mathrm{t}$ tests were conducted to compare spirituality and wellbeing. For this study, students whose biological parents lacked a bachelor's degree were considered first-generation and student who will eligible to receive a Pell grant were considered low-income.. Included in Table 12 are the independent tTests for Spirituality Factors First Generation Students vs. Non-First Generation Students.

Table 12

Independent Samples T Test: Spirituality Factors First Generation Students vs. Non-First Generation Students

\begin{tabular}{|c|c|c|c|c|c|}
\hline Salient Spirituality & \multicolumn{3}{|l|}{ First } & \multirow{2}{*}{$\begin{array}{c}\frac{\text { Std. }}{\text { Deviation }} \\
\underline{\underline{n}}\end{array}$} & \multirow{2}{*}{$\frac{\text { Std. Error }}{\underline{\text { Mean }}}$} \\
\hline \multirow{3}{*}{ Salient Spirituality } & Generation & $\underline{N}$ & $\underline{\text { Mean }}$ & & \\
\hline & Yes & 54 & .083 & .93 & .13 \\
\hline & No & 66 & -.11 & 1.04 & .13 \\
\hline Spiritual Change and & Yes & 54 & .02 & .91 & .12 \\
\hline Crisis & No & 66 & -.01 & 1.08 & .13 \\
\hline Humanism, Non- & Yes & 54 & -.05 & 1.06 & .14 \\
\hline Spiritually Identified & No & 66 & .03 & .97 & .12 \\
\hline Spiritual Seeking & Yes & 54 & -.06 & 1.14 & .16 \\
\hline Behavior & No & 66 & .10 & .81 & .10 \\
\hline
\end{tabular}


Independent Samples T-Test

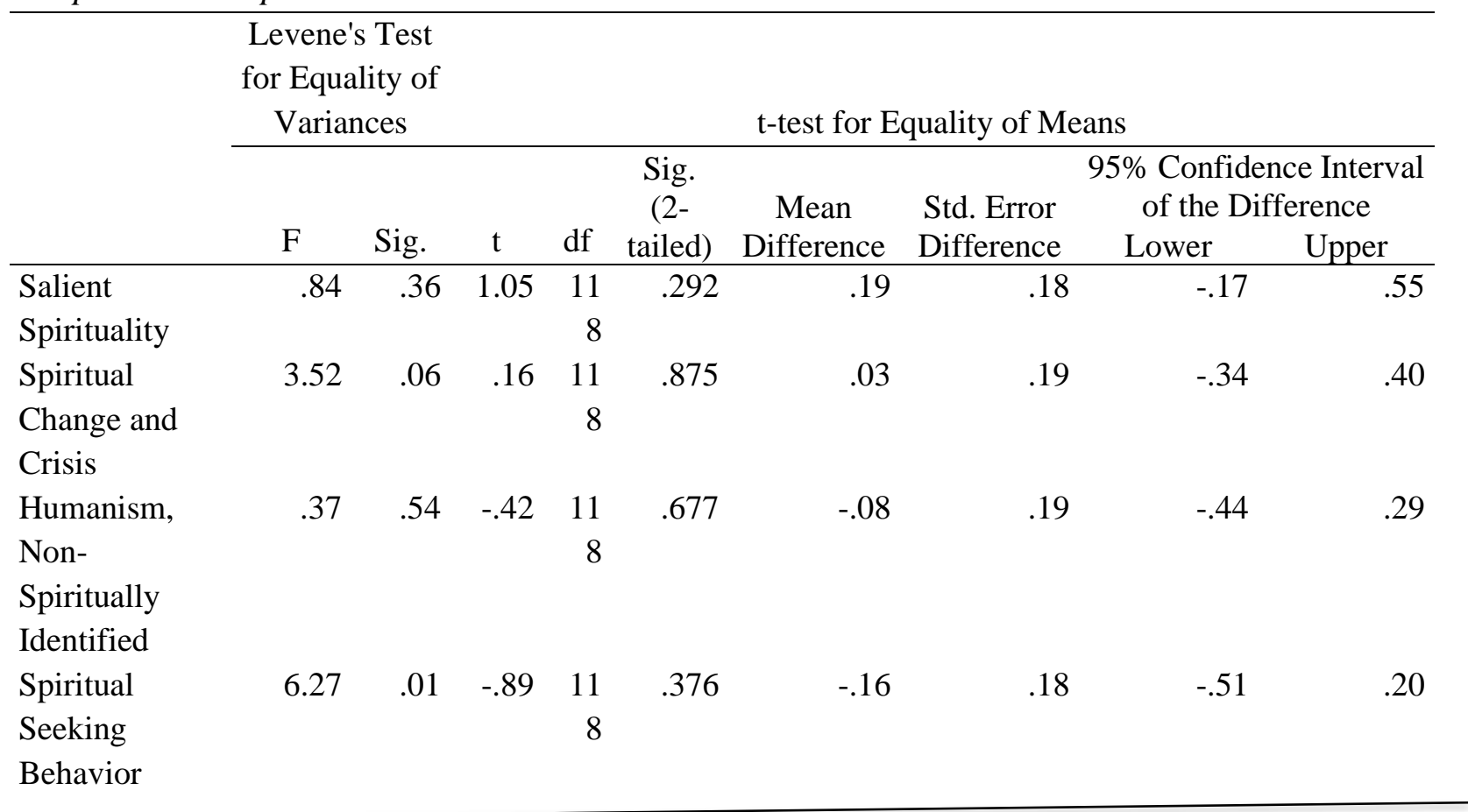

For the four indices of spirituality derived from survey data, there was not a significant difference in the scores for spirituality for first generation students These results, as depicted in Table 12, suggest that there is no significant difference in spirituality between first generation and non-first generation students at public midwestern university. 
Table 13

Independent Samples T Test: Spirituality Factors Low Income Students vs. Non-Low Income Students

\begin{tabular}{|c|c|c|c|c|c|}
\hline & Low Income & $\underline{\mathrm{N}}$ & Mean & $\underline{\text { Std. Deviation }}$ & $\underline{\text { Std. Error Mean }}$ \\
\hline \multirow[t]{2}{*}{ Salient Spirituality } & Yes & 57 & -.0771957 & 1.08069538 & .14314160 \\
\hline & No & 63 & .0266849 & .91152144 & .11484091 \\
\hline \multirow[t]{2}{*}{ Spiritual Change and Crisis } & Yes & 57 & .1060334 & 1.03099518 & .13655865 \\
\hline & No & 63 & -.0871524 & .98432133 & .12401283 \\
\hline Humanism, Non-Spiritually & Yes & 57 & .0607012 & 1.05276947 & .13944272 \\
\hline Identified & No & 63 & -.0680824 & .96792037 & .12194650 \\
\hline \multirow[t]{2}{*}{ Spiritual Seeking Behavior } & Yes & 57 & .0247388 & .82715262 & .10955904 \\
\hline & No & 63 & .0373696 & 1.09421357 & .13785795 \\
\hline
\end{tabular}

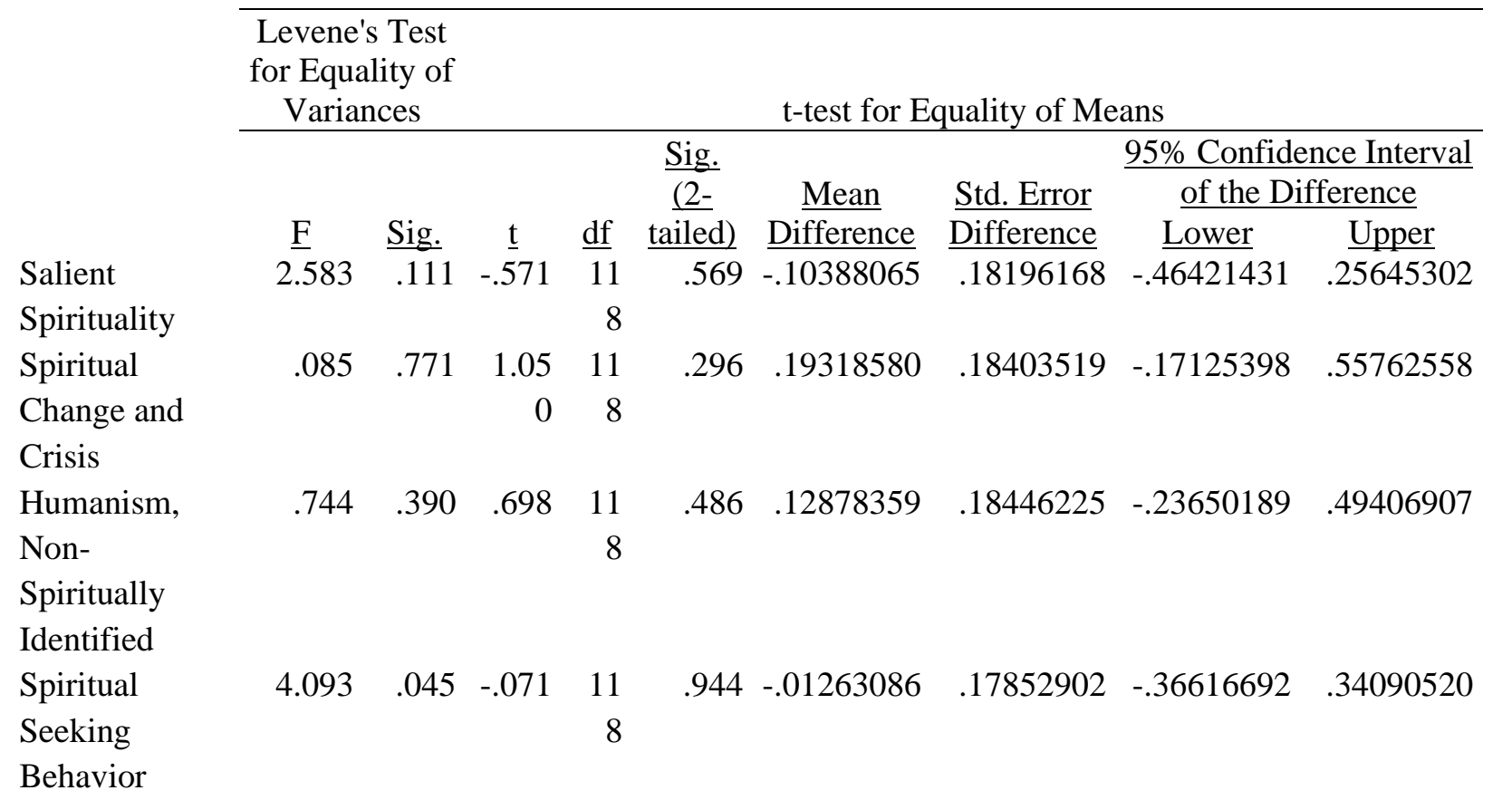

For the four indices of spirituality derived from survey data, there was not a significant difference in the scores for spirituality for low income students $(\mathrm{M}=-.077 \mathrm{SD}=1.08 ; \mathrm{M}=-.1046$ $\mathrm{SD}=1.03: \mathrm{M}=.061 \mathrm{SD}=1.05: \mathrm{M}=-.025 \mathrm{SD}=.827)$, and non-low income $(\mathrm{M}=.027 \mathrm{SD}=.911: \mathrm{M}=-$ $.087 \mathrm{SD}=.984: \mathrm{M}=-.068 \mathrm{SD}=.968: \mathrm{M}=.037 \mathrm{SD}=1.09)$ students. With T-tests revealing, $\mathrm{t}(118)=-$ $.571, \mathrm{p}=.569 ; \mathrm{t}(118)=1.05, \mathrm{p}=.296 ; \mathrm{t}(118)=-.698, \mathrm{p}=.486 ; \mathrm{t}(118)=-.071, \mathrm{p}=.944$. These results, as 
depicted in Table 13, suggest that there is no significant difference in spirituality indices between low income and non-low income students at the university.

Table 14

Independent Samples T Test: Overall and Dimensional Psychological Wellbeing First Generation Students vs. Non-First Generation Students

\begin{tabular}{|c|c|c|c|c|c|}
\hline & $\underline{\text { First Generation }}$ & $\underline{N}$ & $\underline{\text { Mean }}$ & $\underline{\text { Std. Deviation }}$ & $\frac{\text { Std. Error }}{\text { Mean }}$ \\
\hline \multirow[t]{2}{*}{ Happiness } & Yes & 57 & 7.1579 & 1.52115 & .20148 \\
\hline & No & 68 & 7.0147 & 1.49119 & .18083 \\
\hline \multirow[t]{2}{*}{ Positive Emotions } & Yes & 57 & 6.7135 & 1.61397 & .21378 \\
\hline & No & 68 & 6.4975 & 1.44021 & .17465 \\
\hline \multirow[t]{2}{*}{ Engagement } & Yes & 57 & 7.6316 & 1.36812 & .18121 \\
\hline & No & 68 & 7.5417 & 1.41286 & .17133 \\
\hline \multirow[t]{2}{*}{ Relationships } & Yes & 57 & 7.3450 & 1.67731 & .22216 \\
\hline & No & 68 & 7.7451 & 1.58257 & .19192 \\
\hline \multirow[t]{2}{*}{ Meaning } & Yes & 57 & 7.2719 & 1.54002 & .20398 \\
\hline & No & 68 & 7.4265 & 1.63284 & .19801 \\
\hline \multirow[t]{2}{*}{ Achievement } & Yes & 57 & 7.3977 & 1.43847 & .19053 \\
\hline & No & 68 & 7.3922 & 1.53017 & .18556 \\
\hline Psychological & Yes & 57 & 7.2662 & 1.18810 & .15737 \\
\hline Wellbeing (PERMA) & No & 68 & 7.3041 & 1.20467 & .14609 \\
\hline
\end{tabular}




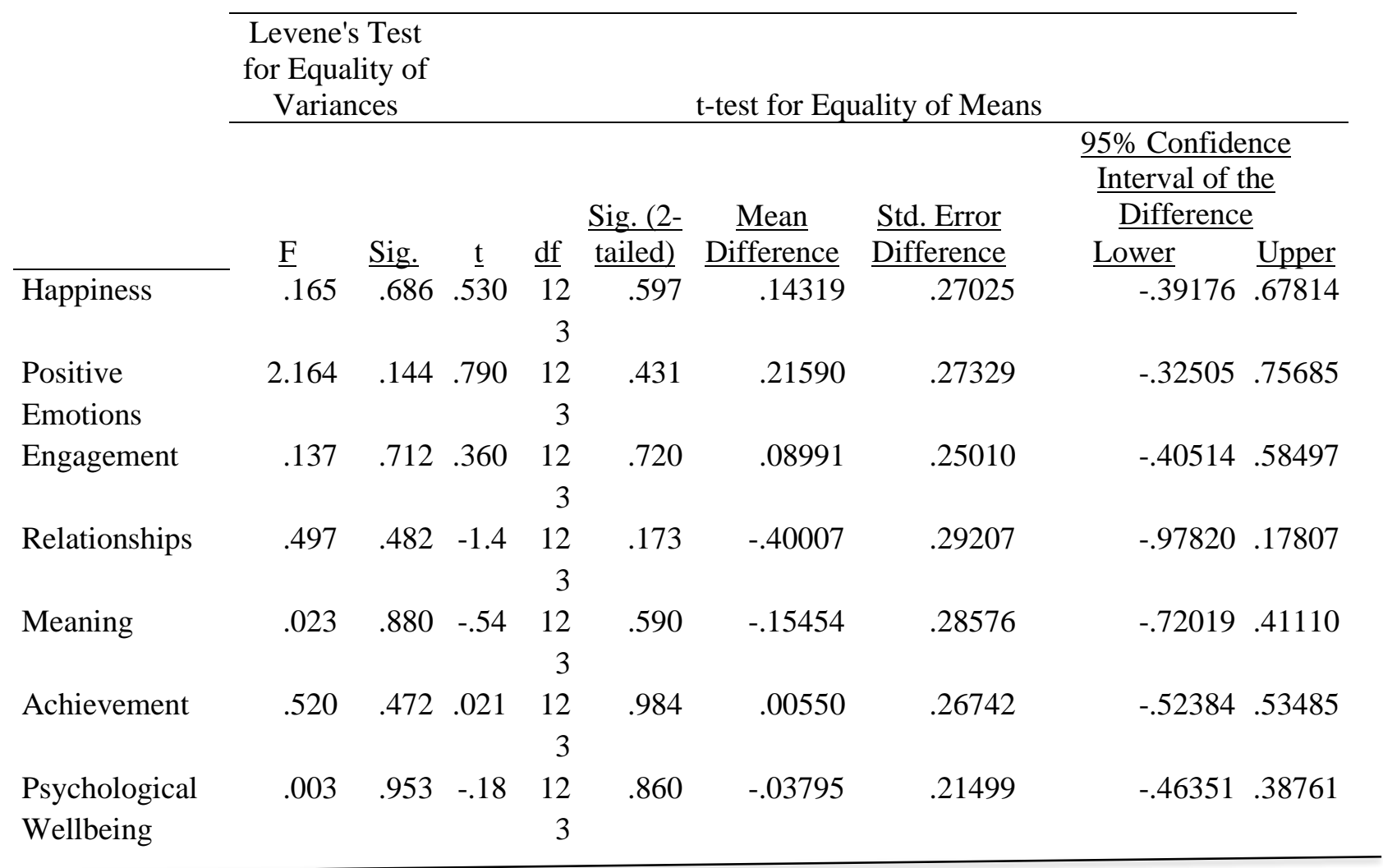

For the single measure of happiness, the five dimensions of psychological wellbeing, and its overall score (PERMA), there was not a significant difference in scores for first-generation $(\mathrm{M}=7.16 \mathrm{SD}=1.52 ; \mathrm{M}=6.71 \mathrm{SD}=1.61: \mathrm{M}=7.63 \mathrm{SD}=1.37: \mathrm{M}=7.35 \mathrm{SD}=1.68 ; \mathrm{M}=7.27 \mathrm{SD}=1.54$ $\mathrm{M}=7.40 \mathrm{SD}=1.44 ; \mathrm{M}=7.27 \mathrm{SD}=1.19)$ and non-first generation $(\mathrm{M}=7.01 \mathrm{SD}=1.49 ; \mathrm{M}=6.50$ $\mathrm{SD}=1.44: \mathrm{M}=7.54 \mathrm{SD}=1.41: \mathrm{M}=7.75 \mathrm{SD}=1.58 ; \mathrm{M}=7.43 \mathrm{SD}=1.65 ; \mathrm{M}=7.39 \mathrm{SD}=1.53 ; \mathrm{M}=7.30$ $\mathrm{SD}=1.10)$ students: $\mathrm{t}(123)=-.530, \mathrm{p}=.597 ; \mathrm{t}(123)=.790, \mathrm{p}=.431 ; \mathrm{t}(123)=.360, \mathrm{p}=.720 ; \mathrm{t}(123)=-$ $1.370, p=.173 ; \mathrm{t}(123)=-.541, \mathrm{p}=.590 ; \mathrm{t}(123)=.021, \mathrm{p}=.984 ; \mathrm{t}(123)=-.177, \mathrm{p}=.860$. These results, as depicted in Table 14, suggest that there is no significant difference in psychological wellbeing measures between first generation and non-first generation students at the university. 
Table 15

Independent Samples T Test: Overall and Dimensional Psychological Wellbeing Low Income Students vs. Non-Low Income Students

\begin{tabular}{|c|c|c|c|c|c|}
\hline & $\underline{\text { Low Income }}$ & $\mathrm{N}$ & $\underline{\text { Mean }}$ & $\underline{\text { Std. Deviation }}$ & $\frac{\text { Std. Error }}{\text { Mean }}$ \\
\hline \multirow[t]{2}{*}{ Happiness } & Yes & 59 & 6.9492 & 1.56936 & .20431 \\
\hline & No & 66 & 7.1970 & 1.43816 & .17703 \\
\hline \multirow[t]{2}{*}{ Positive Emotions } & Yes & 59 & 6.5311 & 1.59275 & .20736 \\
\hline & No & 66 & 6.6540 & 1.46068 & .17980 \\
\hline \multirow[t]{2}{*}{ Engagement } & Yes & 59 & 7.5989 & 1.39344 & .18141 \\
\hline & No & 66 & 7.5682 & 1.39320 & .17149 \\
\hline \multirow[t]{2}{*}{ Relationships } & Yes & 59 & 7.5819 & 1.60888 & .20946 \\
\hline & No & 66 & 7.5455 & 1.66475 & .20492 \\
\hline \multirow[t]{2}{*}{ Meaning } & Yes & 59 & 7.3418 & 1.62901 & .21208 \\
\hline & No & 66 & 7.3687 & 1.56033 & .19206 \\
\hline \multirow[t]{2}{*}{ Achievement } & Yes & 59 & 7.3333 & 1.44105 & .18761 \\
\hline & No & 66 & 7.4495 & 1.52864 & .18816 \\
\hline \multirow[t]{2}{*}{ Psychological Wellbeing } & Yes & 59 & 7.2602 & 1.20186 & .15647 \\
\hline & No & 66 & 7.3106 & 1.19272 & .14681 \\
\hline
\end{tabular}




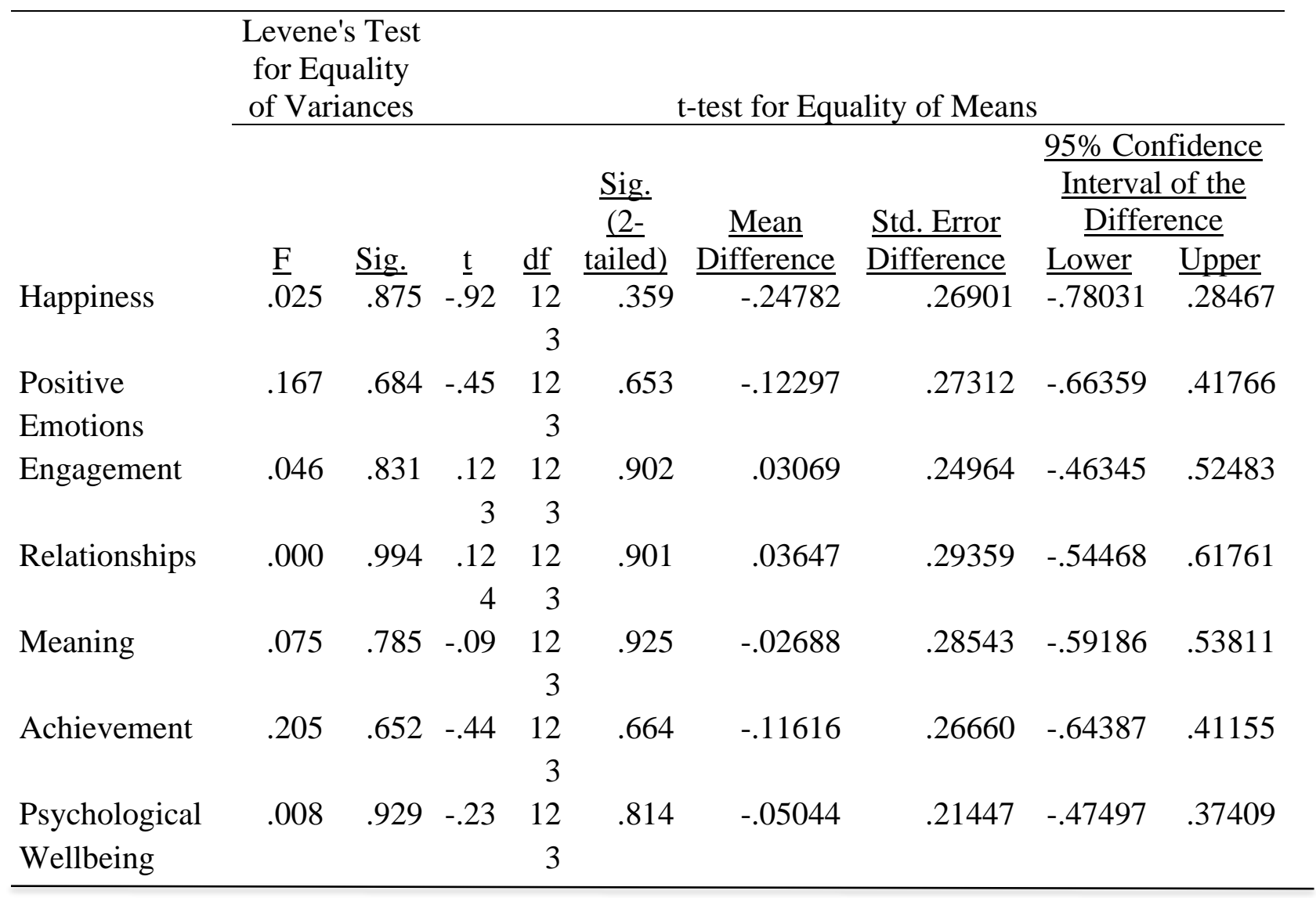

For the single measure of happiness, the five dimensions of psychological wellbeing, and its overall score (PERMA), there was not a significant difference in scores for low income $(\mathrm{M}=6.95 \mathrm{SD}=1.57 ; \mathrm{M}=6.53 \mathrm{SD}=159: \mathrm{M}=7.60 \mathrm{SD}=1.39: \mathrm{M}=7.58 \mathrm{SD}=1.61 ; \mathrm{M}=7.34 \mathrm{SD}=1.63 ;$ $\mathrm{M}=7.33 \mathrm{SD}=1.44 ; \mathrm{M}=7.26 \mathrm{SD}=1.20)$ and non-low income $(\mathrm{M}=7.20 \mathrm{SD}=1.44 ; \mathrm{M}=6.65$ $\mathrm{SD}=1.46: \mathrm{M}=7.57 \mathrm{SD}=1.39: \mathrm{M}=7.75 \mathrm{SD}=1.58 ; \mathrm{M}=7.43 \mathrm{SD}=1.65 ; \mathrm{M}=7.39 \mathrm{SD}=1.53 ; \mathrm{M}=7.31$ $\mathrm{SD}=1.19)$ students: $\mathrm{t}(123)=-.921, \mathrm{p}=.359 ; \mathrm{t}(123)=-.450, \mathrm{p}=.653 ; \mathrm{t}(123)=.123, \mathrm{p}=.902$; $\mathrm{t}(123)=.123, \mathrm{p}=.902 ; \mathrm{t}(123)=-.124, \mathrm{p}=.901 ; \mathrm{t}(123)=-.094, \mathrm{p}=.925 ; \mathrm{t}(123)=-4.36, \mathrm{p}=.664 ; \mathrm{t}(123)=-$ $.235, \mathrm{p}=.814$. These results, as depicted in Table 15 , suggest that there is no significant difference in psychological wellbeing measures between low income and non-low income students at the university. 


\section{Research Question Two}

Is there a relationship between spirituality and psychological wellbeing among firstgeneration or low-income students at a public Midwestern university?

Table 16

Correlations Matrix - Spiritual Factors and Psychological Wellbeing

\begin{tabular}{|c|c|c|c|c|c|c|c|c|c|c|}
\hline First Generation / Low Income & 1 & 2 & 3 & 4 & 5 & 6 & 7 & 8 & 9 & 10 \\
\hline 1. $\quad$ Salient Spirituality & & & & & & & & & & \\
\hline 2. Spiritual Change and Crisis & .014 & & & & & & & & & \\
\hline 3. Humanism & -.050 & .008 & & & & & & & & \\
\hline 4. Spiritual Seeking Behavior & .028 & -.036 & -.026 & & & & & & & \\
\hline 5. Happiness & $.379^{* *}$ & $-.362^{* *}$ & -.020 & .111 & & & & & & \\
\hline 6. Positive Emotions & $.415^{* *}$ & $-.248^{* *}$ & .100 & .102 & $.797^{* *}$ & & & & & \\
\hline 7. Engagement & $.278^{* *}$ & .060 & $.247^{* *}$ & .054 & $.399^{* *}$ & $.422^{* *}$ & & & & \\
\hline 8. Relationships & $.311^{* *}$ & $-.222^{*}$ & .105 & $.261^{* *}$ & $.716^{* *}$ & $.688^{* *}$ & $.486^{* *}$ & & & \\
\hline 9. Meaning & .160 & $-.327^{* *}$ & .105 & .068 & $.608^{* *}$ & $.654^{* *}$ & $.316^{* *}$ & $.567^{* *}$ & & \\
\hline 10. Achievement & 094 & $-.292^{* *}$ & .104 & -.122 & $.543^{* *}$ & $.503^{* *}$ & $.342^{* *}$ & $.451^{* *}$ & $.648^{* *}$ & \\
\hline 11. Psychological Wellbeing & $.330^{* *}$ & $-.277^{* *}$ & .154 & .100 & $.820^{* *}$ & $.854^{* *}$ & $.633^{* *}$ & $.832^{* *}$ & $.820^{* *}$ & $.747^{* *}$ \\
\hline
\end{tabular}

**. Correlation is significant at the 0.01 level (1-tailed).

*. Correlation is significant at the 0.05 level (1-tailed).

To examine whether a relationship exists between the relevant variables of the study among first generation or low-income students, Pearson correlations were conducted. Results of the Pearson correlations show a significant, modest, positive relationship between Salient Spirituality and Psychological Wellbeing $(r(97)=.330 \mathrm{p}=<.001)$, a significant, modest, negative relationship between Spiritual Change and Crisis and Psychological Wellbeing $(r(97)=-.277$ $\mathrm{p}=.003$ ), a slight, positive, near-significant relationship between Humanism, Non-spiritually Identified and Psychological Wellbeing $(\mathrm{r}(97)=.154 \mathrm{p}=.066)$, and a slight, positive, nonsignificant relationship between Spiritual Seeking Behavior and Psychological Wellbeing $(\mathrm{r}(97)=.100 \mathrm{p}=.165)$. These results reject the null hypothesis that there is no relationship between spirituality and psychological wellbeing. 


\section{Research Question Three}

Is there a relationship between spirituality and academic performance among firstgeneration or low-income students at a public Midwestern university?

Table 17

Correlations Matrix: Spirituality and Academic Performance

\begin{tabular}{llrrrrr}
\hline First Generation or Low Income & 1 & 2 & 3 & 4 & 5 & 6 \\
\hline 1. Salient Spirituality & & & & & & \\
2. Spiritual Change and Crisis & .014 & & & & & \\
3. Humanism, Non-Spiritually Identified & -.050 & .008 & & & & \\
4. Spiritual Seeking Behavior & .028 & -.036 & -.026 & & & \\
5. Previous Semester GPA & -.100 & -.009 & -.050 & $.179^{*}$ & & \\
6. Cumulative GPA & .041 & -.072 & -.001 & .116 & $.758^{* *}$ & \\
7. Good Academic Standing & .003 & $-.233^{*}$ & -.040 & .033 & $.172^{*}$ & $.418^{* *}$ \\
$*$ * Correlation is significant at the 0.05 level (1-tailed). & & & & & \\
$* *$ Correlation is significant at the 0.01 level (1-tailed). & & & & & & \\
\hline
\end{tabular}

To examine whether a relationship exists between spirituality and academic performance among first generation or low-income students, a Pearson Correlation was conducted. Results of the Pearson correlation show a non-significant, weak, negative relationship between Salient Spirituality and Previous Semester GPA (r(93)=-.1000 p= .171), a non-significant, weak, positive relationship between Salient Spirituality and Crisis and Cumulative GPA (r(94)=.041 $\mathrm{p}=.349)$, and no relationships between Salient Spirituality and Good Academic Standing, $(\mathrm{r}(99)=$ $\cdot \mathrm{p}=.488)$.

Results of the Pearson correlation also showed no relationship between Spiritual Change and Crisis and Previous Semester GPA $(r(93)=-.009 \mathrm{p}=.466)$, no relationship between Spiritual Change and and Crisis and Cumulative GPA (r(94)=-.072 p=.246), and a significant, modest, 
negative relationship between Spiritual Change and Crisis and Good Academic Standing, $(\mathrm{r}(99)=-.233 \cdot \mathrm{p}=.01)$.

Further, results of the Pearson correlation also showed no relationship between Humanism, Non-spiritually Identified and Previous Semester GPA (r(93)=-.050 p= .315), no relationship between Humanism, Non-spiritually Identified and Cumulative GPA (r(94)=-.001 $\mathrm{p}=.495$ ), and no relationship between Humanism, Non-spiritually Identified and Good Academic Standing, $(\mathrm{r}(99)=-.040 \cdot \mathrm{p}=.346)$.

Finally, results of the Pearson correlation also showed a significant, slight positive relationship between Spiritual Seeking Behavior and Previous Semester GPA $(r(93)=.179$ p= .043), a near significant, slight positive relationship between Spiritual Seeking Behavior and Cumulative GPA (r(94)=.133 p=.133), and no relationship between Spiritual Seeking Behavior and Good Academic Standing, $(\mathrm{r}(99)=.033$. $\mathrm{p}=.375)$. While some relationships appear to exist between wellbeing and academic performance, the researcher cannot reach a clear conclusion about the hypothesis due to inconsistency in results.

\section{Research Question Four}

Does spirituality predict academic performance when mediated by psychological wellbeing among students at a public Midwestern university?

To see if spiritually predicts academic performance when mediated by psychological wellbeing, two mediation analyses were performed based upon established statistical relationships from previous analyses. 
Figure 1

Mediation Model - Spirituality Crisis and Change, Wellbeing, and Academic Standing

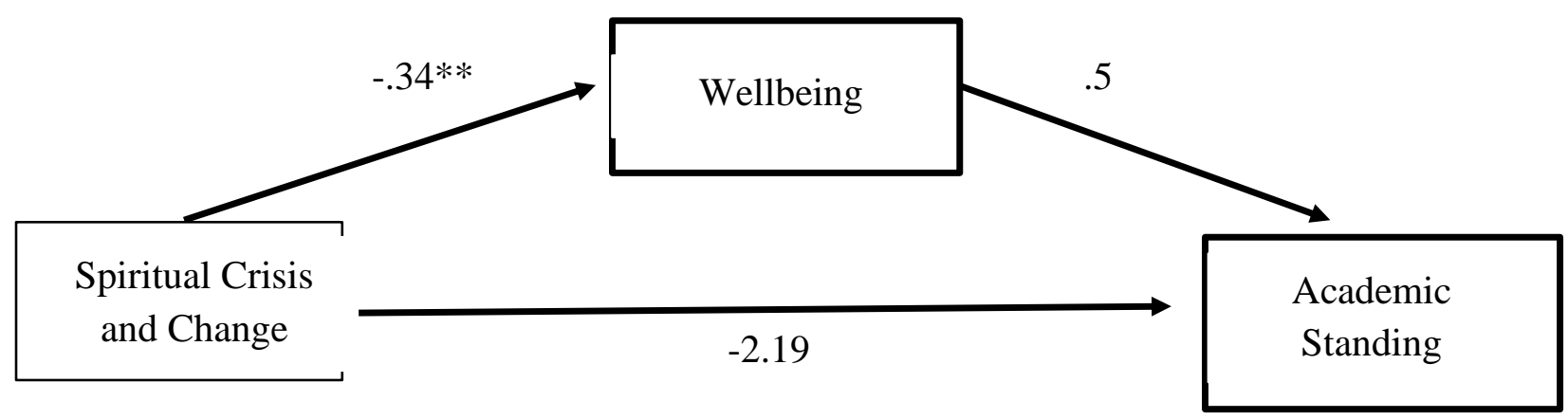

Regression analysis was used to investigate the hypothesis that psychological wellbeing mediates the effect of spirituality on academic performance. Results indicated that spiritual crisis and change were a near-significant predictor of psychological wellbeing, $B=-2.19, \mathrm{SE}=.129, \mathrm{p}$ $=.09$, and that psychological wellbeing was a non-significant predictor of academic standing, $\mathrm{B}=$ $.5, \mathrm{SE}=1.29 \mathrm{p}=.80$. These results do not support the mediational hypothesis, though spirituality is shown by way of mediation model, to be a significant predictor of psychological wellbeing. 
Figure 2

Mediation Model - Prayer, Wellbeing, and Academic Standing

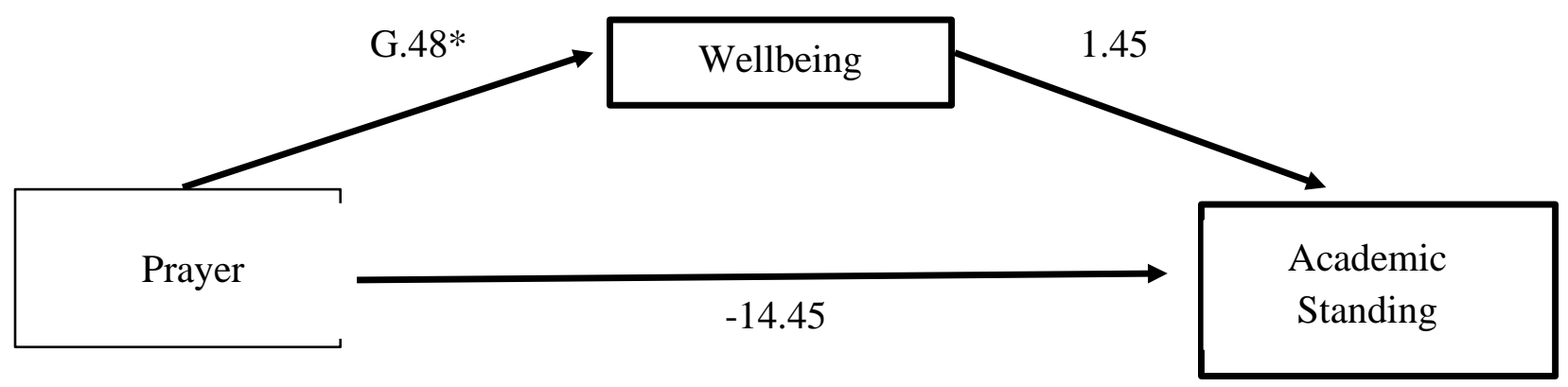

Recalling that prayer, a common spiritual exercise, was practiced by $60 \%$ of study participants, consideration was given as to what relationship, if any, it had with psychological wellbeing and academic performance. Considering Kuh and Gonyea's (2006) finding that practices like prayer correlate positively with exemplary student behaviors like decreased partying and increased involved in volunteering, perhaps prayer could serve as a proxy for spirituality.

Again, regression analysis was used to investigate the hypothesis that psychological wellbeing mediates the effect of spirituality on academic performance. Results indicated that prayer was a significant predictor of wellbeing, $\mathrm{B}=.48, \mathrm{SE}=.2151, \mathrm{p}<.05$, and that wellbeing was a near-significant predictor of academic performance, $\mathrm{B}=1.45, \mathrm{SE}=.829 \mathrm{p}=.08$. These results support the mediational hypothesis. Prayer was no longer a significant predictor of academic performance after controlling for the mediator, psychological wellbeing, $\mathrm{B}=14.45, \mathrm{SE}$ $=401.48, \mathrm{~ns}$, consistent with full mediation. 
Approximately $31 \%$ of the variance in academic standing was accounted for by the predictors $\left(R_{\mathrm{McFadden}}^{2}=.3066\right)$. The indirect effect was tested using a percentile bootstrap estimation approach with 5000 samples, implemented with the PROCESS macro Version 3.4 (Hayes, 2013). These results indicated the indirect coefficient was significant, $(\mathrm{B}=.6904, \mathrm{SE}=$ $18.34,95 \% \mathrm{CI}=.0469,60.8110)$. The indirect effect of prayer as associated with academic standing had an effect size of .69 when potentially mediated by psychological wellbeing.

While Baron and Kenny's (1986) assumptions require for the direct path between $\mathrm{x}$ and $\mathrm{y}$ (path C) variables to be significant, McFatter (1979) suggested that there may be situations where variable suppression causes $\mathrm{x}$ not to predict $\mathrm{y}$ in the mediation model, erroneously leading to the conclusion that mediation is not supported. Judd and Kenny (1981) also suggested that this may be possible. While indirect effect is supported in this model, whether mediation exists between the variables is inconclusive.

\section{Discussion of Findings}

According to Creswell (2014), quantitative research is concerned with testing theories by examining relationships between variables. Spirituality, wellbeing, and academic performance, viewed through the Chickering and Reisser's (1993) framework, are the relevant variables of this study.

\section{Four Components of Spirituality and Differences Between Groups}

Four components of spirituality, defined as the "cognitive, motivational, and social aspects of finding meaning in life", accounted for nearly $50 \%$ of the variance among survey respondents: Salient spirituality, Spiritual Change and Crisis, Humanism, Non-spiritually identified, and Spiritual Seeking (Hood, Hill, \& Spilka, 2018. p.17). Salient Spirituality described individuals who articulate either strong belief or agreement with spiritual propositions 
or belief. In principal component analysis, this component of spirituality was the most strongly and positively correlated to survey items regarding spirituality being one of the most important aspects of one's life and lend meaning/purpose to one's life (Hood, Hill, \& Spilka, 2018). As it relates to the conceptual framework, this component of spirituality was also strongly correlated to identity development. Salient Spirituality was moderately, negatively correlated with changing one's spiritual belief, suggesting stability, robustness, or rigidity.

The second component, Spiritual Crisis and Change, was most strongly correlated with questioning and changing one's beliefs. Incidentally, this component was also moderately connected with experiencing disagreements with loved ones and feeling overwhelmed. Further, Spiritual Crisis and Change was negatively, moderately correlated with the belief that difficult times can make someone stronger and slightly-negatively correlated with the belief that it is important to get a high GPA. Of the four components, this type had the strongest positive correlation to attending a retreat on spiritual matters. Whether or not the retreat prompted spiritual crisis or change or was meant to aid in the transition is unknown in this study and represents a future area of inquiry. A spirituality in transition, showing negatively correlations to wellbeing and aspiration of academic performance, may represent an overlooked but needed area of support for college students.

The third component, Humanism, represents beliefs about life and existence that are not derived from a religious or explicitly spiritual source, as suggested by Pargament (2001). This component was strongly positively correlated to altruistic beliefs of magnanimity and the inherent goodness of people, more so than even the Spiritually Salient. Humanism, though moderately so, most correlated to feelings of being overwhelmed among the four modes of spirituality in college students. Interestingly, and lending to its designation as its own type, this 
component most consistently showed a weak, negative correlation to almost all explicit spiritual beliefs about existence.

The fourth and final component, Spiritual Seeking, described three types of behaviors moderately-to-strongly and positively correlated with this component: participating in spiritual retreats, volunteering, and service learning. While spirituality is less salient in the component, it is more demonstrable. For example, this type correlated significantly with volunteer work and service learning, consistent with Yeh (2010). Of the components, Spiritual Seeking was the most moderately, negatively correlated with feeling overwhelmed but also slightly, negatively correlated with the belief that life is a gift.

\section{Spirituality and Psychological Wellbeing}

For this study, psychological wellbeing is defined using Seligman's (2011) PERMA framework which has dimensions of positive emotions $(\mathrm{P})$, engagement $(\mathrm{E})$, relationships $(\mathrm{M})$, and achievement (A). In a Pearson product moment correlation, Salient Spirituality was modestly and significantly correlated with psychological wellbeing and three of its five dimensions among first generation and low-income students. Conversely, Spiritual Crisis and Change was significantly and slightly, correlated with psychological wellbeing including four of its five dimensions. Further, in mediation analysis, spirituality was found to be a significant predictor of psychological wellbeing. As it pertains to the second research question, there is a statistically significant relationship between spirituality and psychological wellbeing among first-generation and low-income students, which is consistent with known literature (Daaleman \& Frey, 2004; Fehring, Brennan, \& Keller, 1987; Klasses \& Greken, 2017; Kress, Newgent, Whitlock, \& Mease, 2015; Nelms et.al, 2006). 
However, the relationship between spirituality and the dimensions of psychological wellbeing organized differently than described by this study's conceptual framework.

Chickening and Reisser's (1993) sixth vector, developing purpose, if one could draw a logical connection with Seligman's (2011) understanding of meaning, showed no significant relationship with spirituality, excepting for the case where spirituality is a negative predictor for meaning among students experiencing spiritual crisis or change. Incidentally, salient spirituality was only significantly correlated with positive emotions, engagement, and relationships, this study is concerned with, to what extent if any, spirituality serves as a predictor of wellbeing. Results from regression analysis support prayer as a predictor for psychological wellbeing.

These findings suggest that supporting students who identify as spiritual, particularly those who have either a salient sense of spirituality or are in crisis, has promise to support improving wellbeing measures, consistent with Hettler (1984). Further, this finding, is found to be consistent in other contexts, suggests that hesitance or reluctance to discuss spirituality on college campuses may come at the cost of student wellbeing. Stated directly, if higher education practitioners aspire to deal with the college mental health crisis seriously, they must be willing to address student spirituality authentically and robustly with students who are are/are becoming/no longer are spiritual. The initiatives, while likely inconvenient and uncomfortable for institutions unsure how to navigate within the tensions of spirituality and pluralism, may be more preferable than the present alternative.

\section{Academic Performance}

Academic Performance, defined in this study as cumulative GPA, semester GPA, and Academic Standing, comprised the third variable of analysis. If spirituality and wellbeing were linked, did this relationship extend to student behaviors that impact academic performance? Did 
students who were more spiritual than others or who reported higher levels of wellbeing than others also do better in a university setting? In this study, salient spirituality had no significant relationship with academic performance, inconsistent with the scant literature (Trockel, Barnes, \& Egget, 2010; Walker \& Dixon, 2002). However, spiritual crisis and change was significantly negatively correlated with academic standing, one component of academic performance as measured in this study. Also, spiritual seeking was slightly yet significantly correlated with previous semester GPA.

Due to the significant, though modest, negative correlations between spiritual crisis and the two outcome variables, psychological wellbeing and academic standing, a mediation analysis was conducted to see if spiritual crisis affected academic standing by way of psychological wellbeing, as hypothesized. When spiritual crisis was regressed on psychological wellbeing and academic standing, it was found to be a significant predictor of each though mediation, ultimately, was not supported in the model. However, in a separate mediation analysis, prayer was found to be an indirect predictor of good academic standing when mediated by psychological wellbeing. More analysis is needed to determine how these variables interact, with other proxies for academic performance considered. GPA, while the standard measure for academic performance, has limitations as variable in describing a student's performance and likelihood of retention and graduation. Future research is needed to determine what relationships, if any, spirituality has with various and sundry measures of academic performance beyond grade point averages. Overall, potentially due to the constraints of the definition used in this study, spirituality and psychological wellbeing showed inconsistent or insignificant relationships with academic performance among students at a Midwestern university. 


\section{Conclusions}

In conclusion, this study was concerned with three phenomena: spirituality, psychological wellbeing, and academic performance among college students at public Midwestern university. The factors that affect these phenomena are numerous and there is a no study rigorous enough to account for all of the relevant variables. However, the results from this study have implications for scholars and practitioners alike, which are addressed at the end of this section.

Firstly, an initial finding is that students continue to have inner experiences and concerns that encroach upon spiritual or ultimate matters. Most pray and many have strong, salient understandings of their reality buttressed by beliefs and practices that prop up how they live. Many, still, struggle with changes or unexpected evolutions regarding their ontological understandings of reality. Whatever the experience, students' experience of spirituality can and does change and cannot be separated with their experience of the world.

This connection leads to another finding: spirituality and psychological wellbeing are linked. Students who had higher levels of spirituality also tended to have higher levels of selfreported wellbeing, including its subdimensions.

Finally, while more research is needed to understand how, if at all, spirituality helps students perform well academically, more focused attention is needed to replicate, confirm, pilot, modify, and scale interventions to help students in times of spiritual growth or change. To simplify, the link between wellbeing and spirituality has implications for research and practice.

\section{Recommendations}

Four recommendations for future research are included in this section. First, while having a sample large enough to obtain the statistical power needed to meet the assumption of the 
analyses in this inquiry, the sample is still limited by the use of one site. Moreover, the sample is predominantly female and not evenly distributed among class rank, likely contributing to bias.

Next, suppression by confounding variables may be a factor inhibiting a direct effect between spirituality and academic performance as predictor and outcome variables, respectively. While the apparent observation, that another variable mediates the affect or that there is no casual path, may be more accurate, the evidence of an indirect path at least suggests the possibility of inconsistent mediation (Mackinnon, Krull, \& Lockwood, 2000).

Third, more research is needed to understand whether spiritual experiences can impact new or worsening mental health problems for college students. While salient spirituality seems to correlate positively with psychological wellbeing, the opposite is true for students who have less salience with spirituality, but are in crisis or transition preceding an event or events that preceded change in beliefs. Stakeholders will insist on a return on investment. More experimental methods utilizing randomization and a control group could assess spiritual development intervention or curriculum effectiveness.

Finally, while Fowler (1981) and Parks (2000) suggested models to describe how spirituality may develop before, during, and after the student lifecycle, more research is needed to understand how students experience this phenomena. For example, one survey item what significantly correlated with students who were spiritually salient, in spiritual crisis, or spiritually seeking: attending a seminar or retreat on spiritual matters. Did these events create formative spiritual experiences for students? Did they support the development of spiritual salience for one student and precipitate crisis for another? The impact of spiritual retreats or events create an avenue of inquiry for future research. 
The following executive summary contains the findings of this inquiry, along with the recommendations that will be presented to this University. 
SPIRTTUALTTY,

WELLBENG, \&ACADEMTC PERFORMANGE IN COLLEGE

Examining the relationships between spirituality, wellbeing and academic performance among first-generation and low-income at a public Midwestern university

\section{RESEARCH QUESTIONS}

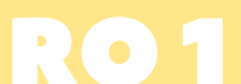

Are there differences in spirituality and wellbeing between first-generation and lowincome students and their peers?
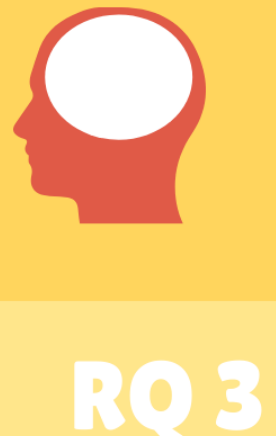

Is there a relationship between spirituality and academic performance among firstgeneration and low-income students at a public Midwestern university?

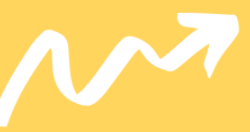

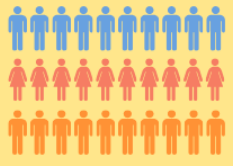

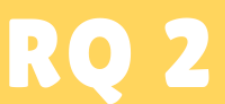

Is there a relationship between spirituality and psychological wellbeing among first-generation and low-income students?
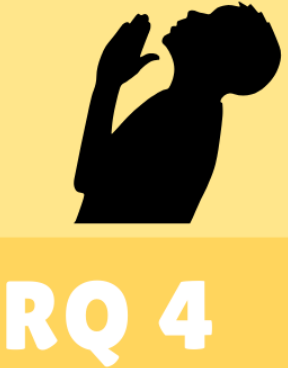

Does spirituality affect academic performance when mediated by psychological wellbeing among students?

WHAT IS THE RELATIONSHIP BETWEEN SPIRITUALITY, WELLBING, AND ACADEMIC PERFORMANCE? 


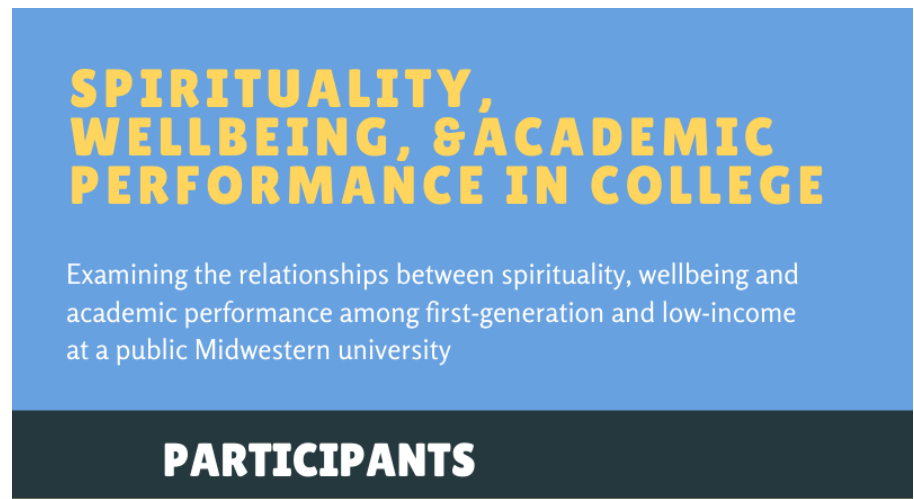

\section{AVG WELLBEING SCORE \\ As defined by Seligman (2011), wellbeing is comprised of positive emotions, engagement, relationships, meaning, and achievement or PERMA}

\section{TYPES OF}

Making meaning in life (Hood, Hill,

Spilka, 2018)

1.Spiritual salience

2. Spiritual crisis and change 3.Humanism 4.Spiritual seeking

\section{SPIRITUALITY}

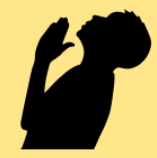

\section{AVG GPA}

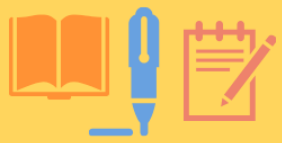

Minimum GPA 2.0

Maximium GPA 4.0

\section{WHAT IS THE RELATIONSHTP BETWEEN}

SPIRITUALITY, WELLBING, AND ACADEMIC PERFORMANCE? 


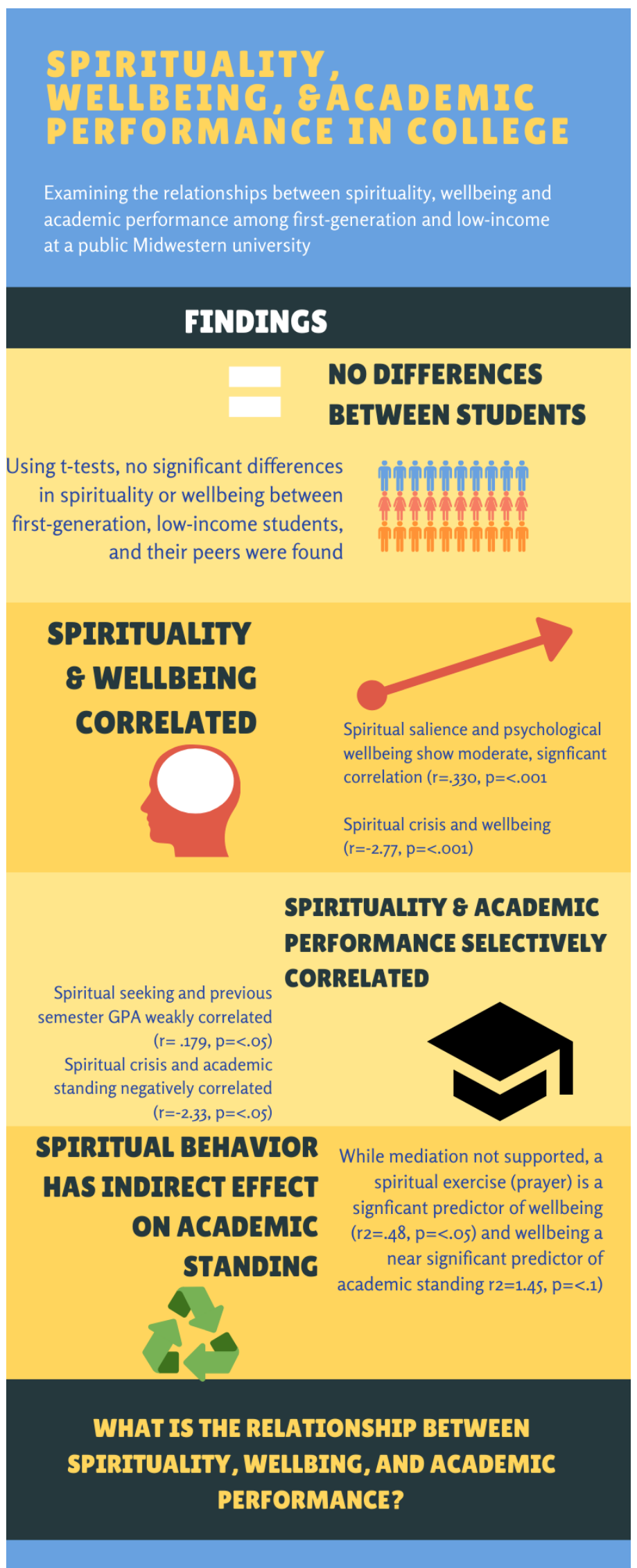




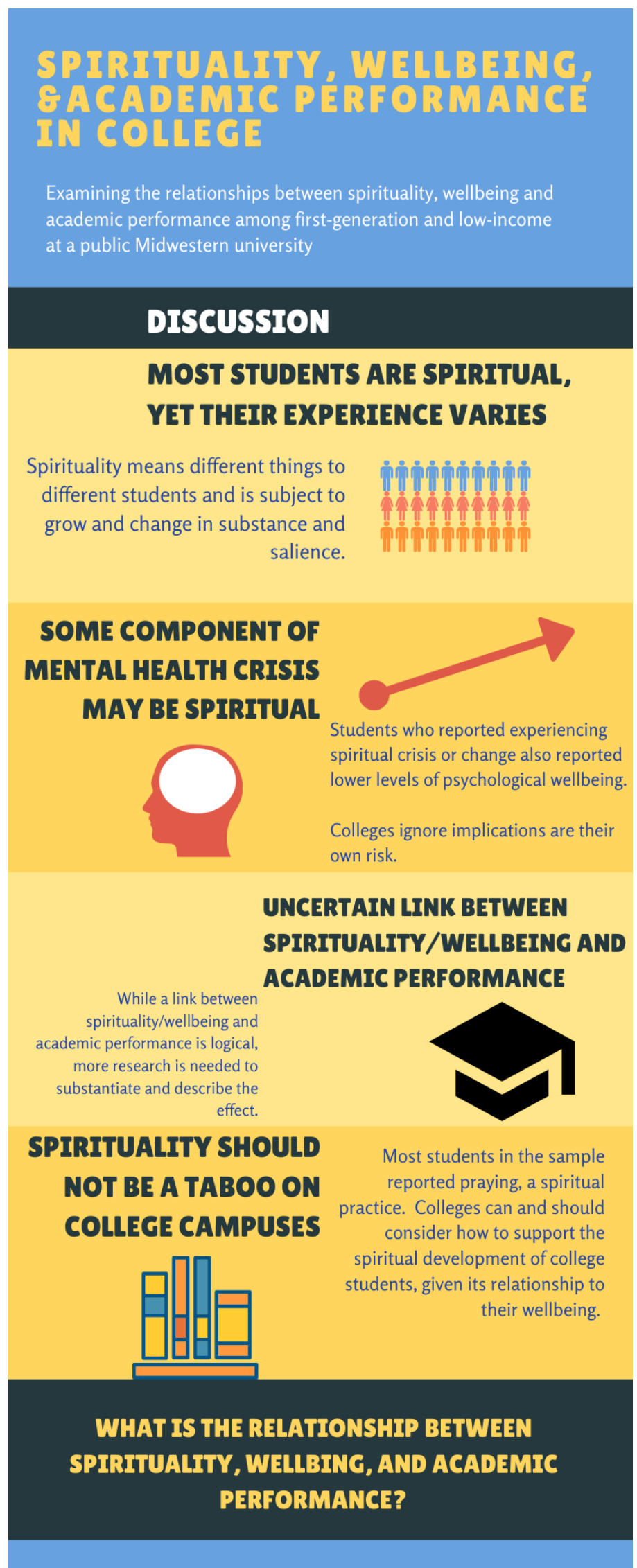


SECTION FIVE

CONTRIBUTION TO SCHOLARSHIP 


\section{Editorial Board, Journal of College Student Development}

Please accept this article submission for review in the upcoming issue of Journal of College Student Development. The nexus of the mental health and college attainment crises on America's college and university campuses create opportunities and no shortage of challenges for campus partners, practitioners, and scholars. JCSD provides a medium for the aforementioned to (re)consider familiar but increasingly taboo topic in today's university: spirituality.

This submission contains quantitative analysis of spirituality, psychological wellbeing, and academic performance among 135 college students, especially those who are first-generation and low-income, at a public university in the Midwest. This cross-sectional survey designed study used established scales from the College Students Beliefs and Values survey to assess spirituality and the PERMA-Profiler to address psychological wellbeing. The purpose of the

study is to consider what degree, if any, spirituality can help alleviate problems created by the aforementioned mental health and college attainment crises.

This submission adheres to all relevant JCSD guidelines included margins, page length (not to exceed a total of 30 pages) and reviews college student development literature. All files will be saved and uploaded separately in the requested doc format. Also, this article is not currently under consideration at any other journal.

Thank you

Chris R.T. Beggs, Ed.D.

6501 Noland Road, Kansas City, MO 64133

ctbeggs@gmail.com 
(Re)Considering the Sacred in Higher Education: The Role of Spirituality in Psychological Wellbeing and Academic Performance

Christopher R.T. Beggs, Ed.D

6501 Noland Road

Kansas City, MO 64133

$816-977-8762$

ctbeggs@gmail.com 


\section{Introduction}

From the beginning of Harvard College in 1636 until 1819 when Thomas Jefferson founded the University of Virginia, every college in America was religiously affiliated and spiritual development was foundational in the curriculum (Brubacher, 2017; Rudolph, 1962). Over time, institutions became more secular and fostering spiritual development of students became all but absent from public colleges and universities (Chickering, Dalton, \& Stamm, 2015; Rudolph, 1962; Roberts, Turner, \& Turner, 2000). However, college students remain perennially interested in spiritual matters, with the majority claiming religious affiliation (Kosmin, Cragun, \& Navarro-Rivea, 2009).

This schism between student interest and institutional offerings happens alongside two concurrent crises in higher education: the mental health crisis and the achievement gap between historically underserved students and their peers (Markowitz, 2017;Wolverton, 2019).This difference between public universities and the students they support creates a problem of practice for emerging adults, particularly for first-generation and low-income students whose academic outcomes lag behind their peers despite their growing representation on college campuses (Katrevich \& Aruguete, 2017; McCarron \& Inkelas, 2006; Perna, 2015).

\section{Statement of the Problem}

\section{Problem of Practice}

While first-generation and low-income students are growing in enrollment across public institutions in the United States, academic outcomes have not improved alongside enrollment gains (Perna, 2015). A notable and persistent degree achievement gap exists between firstgeneration and low-income college students and their peers (Pascarella, Pierson, Wolniak, \& Terenzini, 2004; Tinto, 2012). Theorists have contended with the student attrition phenomenon, 
suggesting models that may describe critical areas of needed support or intervention (Pascarella \& Terenzini, 2005, Tinto, 2006). Further, there is growing national concern for college students' mental health (Auerbach, et. al., 2018). First-generation and low-income students face common and unique wellbeing challenges. For example, first-generation and low-income students often encounter greater problems related to financial stress, academic adjustment, and family-related conflict when compared to their peers (Lippincott \& German, 2007).

Psychiatric problems have impeded students' abilities to complete college on a national scale (Breslau, Lane, Sampson, \& Kessler, 2008). Evidence supports a positive relationship between mental health and retention (Kitzrow, 2009). One central question in this inquiry is whether spirituality has any relationship to wellbeing and mental health for first-generation and low-income students. Public colleges and universities are virtually secular, despite $78 \%$ of college-aged students claim religious affiliation (Kosmin, Cragun, \& Navarro-Rivea, 2009). The researcher seeks to discover if this phenomenon is also observed within student subpopulations that are more likely to be first-generation and/or low-income. Stewart (2009) noted, "Spirituality is a key factor in the lives of Black college students as part of a cultural heritage passed down through generations" (p.255). When surveying the problem nationally, the wellbeing and academic performance of first-generation and low-income students presents a problem of practice for institutions of higher education in the United States.

\section{Existing Literature Gap}

Though multiple studies have examined the factors and characteristics of either firstgeneration or low-income students, few have considered students who are both first-generation and low-income as a population, though a relationship between both characteristics is welldocumented (Engle \& Tinto, 2008; Thayer, 2000). There is a notable literature gap regarding the 
inner experiences of first-generation and low-income students, despite first-generation students representing nearly $50 \%$ of all college students since the beginning of the 21 st Century (Choy, 2002). While psychological and other medical literature have linked positive measures of personal wellbeing with spirituality, few studies have investigated whether a student's spirituality is related to general student wellbeing and performance (Adams, Bezner, Drabbs, Zambarano \& Steinhardt, 2000). If a relationship exists, this link may illuminate areas to support students in an attempt to address growing mental health challenges on college campuses (Astin, Astin, \& Lindhold, 2011; Bruffaerts, Mortier, Kiekens, Auerbach, Cuijpers, Demyttenaere, Green, Nock \& Kessler, 2018; Daaleman \& Frey, 2004; Davis, Kerr \& Kupius, 2003; Walker \& Dixon, 2002).

Prior attention to non-cognitive factors like grit and growth mindset as predictors for academic success in at-risk student populations may seem unrelated to spiritual resources (Duckworth, 2007; Dweck, 2008). However these behaviors might also be explained or mediated by inner, spiritual, or value-based realities of college students. While Low and Handal (1995) suggested a link between students' inner spiritual resources and their positive adjustment to college, there is a lack of recent studies investigating this phenomenon, especially among firstgeneration and low-income students.

\section{Purpose of the Study}

The purpose of this study is to determine if the spirituality of first-generation and lowincome students is different from their peers and whether or not there is a relationship between these students' spirituality and their psychological wellbeing and academic performance. If psychological wellbeing is a critical component necessary to promote academic achievement, and if spirituality is a critical component of psychological wellbeing, then an investigation into 
whether a relationship exists between these phenomena is warranted. If fostering the spiritual development of students has become forgotten or taboo, perhaps practitioners should reconsider the usefulness of a foundational educational practice in American higher education.

Much of the research concerning the experiences of first-generation and low-income students has focused on the cognitive and non-cognitive resources of these students (Adebayo, 2008; Muraskin \& Lee, 2004). While Adams, et.al (2000) discovered relationships between spirituality and wellness through rigorous quantitative methods, few have used such methods in considering these phenomena among first-generation and low-income students, explicitly. Religion and spirituality have been popular but difficult topics to define in the literature (Hood, Hill, \& Spillka, 2018). Scholars have considered the diversity of experiences related to spirituality and religion, even considering the terms both synonymously and distinctly, to describe the human search for meaning and significance (Clark, 1958; Miller \& Martin, 1988; Zinnbauer, Pargament, Cole, Rye, Butter, Belavich, Hipp, Scott \& Kadar, 1997). Some have considered college student's subjective use of religiousness to include conventional behaviors like church attendance or while others have included more conceptual attitudes related to altruistic beliefs (Pargament, Sullivan, Balzer, Van Haitsma, \& Raymark; 1995)

\section{Research Questions}

This present study has three research questions:

RQ 1: Is there a relationship between spirituality and psychological wellbeing among first-generation and low-income students at a public Midwestern university? RQ 2: Is there a relationship between spirituality and academic performance among first-generation and low-income students at a public Midwestern university? 
RQ 3: Does spirituality affect academic performance when mediated by psychological wellbeing among students at a public Midwestern university?

\section{Theoretical Frameworks}

\section{Spirituality}

While spirituality is of abundant interest to scholars across various disciplines, there is no consensus on its definition. Miller and Martin (1988) use spiritualty and religion interchangeably, while Pargament (2001) argued that spirituality may not even have a religious component. Clark (1958) focused spirituality as experienced through conversion experiences. Mattis (2000) suggested that spirituality, similar to wellbeing, may be multidimensional. Despite a lack of scholarly consensus, the Higher Education Research Institute (2004) did discover one majority finding: $80 \%$ of college students are personally interested in spirituality.

While little is known regarding what relationship, if any, exists between spirituality and first-generation and low-income student experiences, the relationship between wellbeing and spirituality in the general college student population is documented (Daaleman \& Frey, 2004; Fehring, Brennan, and Keller, 1987; Klasses \& Greken, 2017; Kress, Newgent, Whitlock, and Mease, 2015; Nelms et.al, 2006). Walker and Dixon (2002) were some of the first to consider how spirituality might impact academic behavior in minority students, many whom are firstgeneration and low-income (Engle \& Tinto, 2008).

Responding to the lack of scholarly consensus of what spirituality may be, Hood, Hill, and Spillka (2018) synthesized scholarly spirituality literature to produce a definition that is inclusive and contains measurable language, promoting further inquiry. They suggest, at its core, spirituality is born out of aspects of the interplay of internal and external factors that come with 
how one makes or finds meaning for his or her life (Hood, Hill, and Spillka, 2018). As a definition, it is inclusive of both a religious and non-religious understanding of spirituality, which aligns with what we know about how college students' spirituality is as a concept (HERI, 2004). This framework, born out of rich synthesis, is what guides and defines spirituality for this study.

\section{Wellbeing}

Wellbeing, similar to spirituality, has also garnered much interest and discussion among scholars. The challenges impacting college student wellbeing, particularly for students who are first-generation or low-income, are well-documented in college student counseling, student development, and retention literature ( Padgett, Johnson, \& Pascarella, 2012; Pascarella \& Terenzini, 2005; Stephens, Brannon, Markus, \& Nelson, 2015; Strayhorn, 2006; Wang \& Castaneda-Sound, 2008). Punctuating perennial challenges is the growing mental health crisis across college campuses in the United States (Auerbach, et. al, 2018; Bruffaerts, et. al, 2018; Markowitz, 2017; Wolverton, 2019).

Hettler (1984) was the first to explicitly highlight how spirituality may impact wellbeing, particularly in college students. Hettler and Diener (1984) contributed the concept of subjective wellbeing (SWB) which particularly focused on one's emotional or hedonic experience. Ryff's (1989) Six Factor Model for Psychological Wellbeing (PWB) was also predominant in the literature, and included more existential, or eudaimonic, experiences. Later, Seligman (2011) would attempt to reconcile the apparent differences between SWB and PWB with his PERMA framework which includes both hedonic and eudaimonic components. Seligman's (2011) framework, distinct for its inclusivity and intuitiveness, is the selected framework for wellbeing for this study. 


\section{Conceptual Framework}

Chickering (1969) and Chickering and Reisser's (1993) Seven Vectors of Development convey how college students may develop psychosocially. Conceptualized as a way to describe how psychosocial development happens alongside cognitive development, the steps, or vectors, in the model serve a directional purpose. Chickering and Reisser's (1993) sixth vector, developing purpose, is particularly relevant to this study. It is important to note that the development of purpose, as conceptualized by Chickering and Reisser, described both internal and external activity. Reisser (1995) pointed to one's emerging, internal sense of purpose as evidenced by one's external decisions. One longitudinal study of 354 freshmen validated the sixth vector linking the development of purpose to college experiences (Martin, 2000). In their synthesis of student development literature, Pascarella and Terenzini (2005) contended that purpose development is heavily influenced by the student's view of self as established in the fifth vector. This means, according to this framework, that one's view of purpose is conditioned by one's view of self.

This rationale is supported by at least three arguments. First, Chickering's (1969) model has been revisited, revised, and validated by other research (Martin, 2000; Reisser, 1995; Straub, 1987). Second, the framework acknowledges the interplay of both cognitive and psychosocial development in ways that are specific and predictive, such as the role of the fifth vector's semifoundational role in supporting development in the sixth vector. This relationship may be similar to the relationships, if any, between the variables under consideration in this study. Finally, the selection of this model allows for more inclusive understandings of spiritual experiences that may be non-religious in nature which aligns with the purpose of this study. In other words, Chickering and Reisser's (1993) framework allows for the development of values and purpose 
that may or may not be related to religious beliefs, which can include non-religious students in an inquiry related to spiritual resources.

\section{Design of Study}

This study is framed from a postpositivist paradigm in that it seeks to test theories to better understand phenomena encountered in the world (Creswell, 2014). Consequently, this study utilizes a quantitative, cross-sectional survey design. The rationale for this choice is twofold. First, the study is structured so that researchers and practitioners can better understand what relationship, if any, exists between the variables of this study and first-generation, low-income students (Creswell, 2013). Secondly, the survey design itself is conducive for expedited online distribution and collection (Creswell, 2013). After data are collected, statistical tests will be administered to investigate hypothesized relationships between spirituality, wellbeing and academic performance among first-generation and low-income students.

\section{Setting}

A public, regional, 4-year university in the Midwest will be the setting for this study given the majority of its enrollment is first-generation and/or low-income students (UCM, 2018). Due to the admissions selectivity of these institutions and their public nature, this type of institution provides a convenient yet appropriate setting for this study as these admissions criteria allow for higher shares of first-generation and Pell-eligible students (MDHE, 2019; Tebbs \& Turner, 2005).

\section{Participants}

Since $78 \%$ of traditionally college-aged Americans claim religious affiliation, male and female students aged 18-24 and enrolled as a degree-seeking student will be identified as the main participants in this study (Kosmin, Cragun, and Navarro-Rivea, 2009). Further, first- 
generation and low-income students, defined for this study as students whose biological parents lack a bachelor's degree and are eligible to receive any portion of the Pell grant, at a public, 4 year university in the Midwest comprise a subpopulation within the sample for this study. These students were selected given both established scholarly interest in first-generation and lowincome student experiences and outcomes and the prominent literature gap related to the variables of this study.

\section{Data Collection, Analysis, and Survey Protocol}

Participants took a modified College Students'Beliefs and Values Survey and PERMAProfiler online either using a personal electronic device or one provided by the researcher (Astin, et. al, 2007; Butler \& Kern, 2015). The researcher has obtained appropriate permissions from each survey owner (Appendix D; Appendix E). The CSBV survey was selected for its relevance to the research topic and its prior use on the national scale with over 14,000 students across over 100 institutions (HERI, 2004). The CBSV instrument will be modified, with permission.

Twenty-five (25) items related to spirituality and spiritual engagement will be retained from the CSBV, where scales like religious skepticism and ethic of caring will not be retained due to their irrelevance to this study.

The PERMA Profiler, assessing wellbeing, was integrated with the modified CSBV. The PERMA Profiler served as the second part of the survey. The combined and revised instrument included includes 42 scale items that collectively measure spirituality and PERMA dimension. This survey was selected given its relevance to the study's variables and the demonstrated validity of the instrument (Goodman, Disabato, Kashdan, \& Kauffman, 2017). The PERMA profiler will assess all five domains of wellbeing as defined by Seligman (2011). The survey will mostly consist of an 11-point sliding scale for each item. Data will be exclusively assessed 
through the survey. Construct validity and reliability of the CSBV and PERMA Profiler surveys have been previously assessed (Bravo, Pearson, \& Stevens, 2016; Butler \& Kern, 2016;

Goodman, et. al., 2017). Reliability analysis of the 42 survey items rendered a Cronbach's alpha above $.8(\alpha=.86)$, which is well above the acceptable range (Cortina, 1993).

Principal components factor analysis was conducted on the 25 revised spirituality items revealing nine components accounting for $71 \%$ of the total variance. Keiser-Meyer-Olkin Measure of Sampling adequacy was sufficient at .814 and Barlett's Test of Sphericity was significant $\left(x^{2}(300)=1224.16, p<.001\right)$. Initial eigenvalues showed that the first four components explained $26 \%, 8 \%, 7 \%$, and $5 \%$, for a total of $46 \%$, of the variance. These four components were selected due to their relevance to the conceptual framework, the amount of variance accounted by the components, and the leveling of the associated scree plot. Composite scores for each of the four components were created as variables to describe their factor loadings. These four composite variables included Salient Spirituality, Spiritual Change, Humanism, and Spiritual Seeking.

Sampling design for this study used clustering, or sampling within several venues at the institution where groups of students congregate and have free time to complete surveys (Creswell, 2004). Sampling was non-random and non-stratified, soliciting involvement from participants throughout campus. Since both first-generation and low-income students will be compared with peers, to reduce bias and other sampling error, and to achieve the statistical power needed to perform the needed analyses, 135 students comprised the population. The survey was administered in winter 2020. Survey response rates were monitored during the data collection phase to check for response bias (Creswell, 2004). 
Descriptive analyses including means, standard deviations, and ranges were performed on spirituality, wellbeing, and academic performance, which comprise all measured variables in this study (Creswell, 2004). Using SPSS, this present study used Pearson product moment correlational analysis to examine statistical relationships between variables and independent samples t-tests to compare means of wellbeing and academic performance between firstgeneration and low-income students and their peers. This analysis is appropriate for this inquiry since the independent samples t-test is meant to compare "two means that come from conditions consisting of different entities" (Field, 2013, p. 331). This helped illustrate if any difference exists between the two populations and whether or not this difference is statistically significant.

Mediation analysis was also used to assess if wellbeing mediates the relationship between spirituality and academic performance. Three regressions are needed to assess whether wellbeing mediates. The first regression has spirituality predicting academic performance. The second regression has spirituality predicting wellbeing. The final regression has spirituality and wellbeing predicting academic performance.

\section{Limitations, Assumptions and Design Controls}

This study is limited by several factors. First, study participants were only sourced from a single public institution and the researcher's current employer, constituting a convenience sample. Second, and on a related note, the limited scope of this study, emphasizing a public 4year institution, increases the likelihood of bias and limits the potential generalizability of the results. Thirdly, sampling in this quantitative survey design is non-random and non-stratified which has a higher likelihood of introducing bias into the study (Creswell, 2014). Finally, the study uses self-reported data, which can be impacted by confounding variables (Creswell, 2014). 
These limitations are accounted for in design controls and also create opportunities for future researchers to address related to this topic.

\section{Assumptions}

This study has, at least, the following assumptions. First, spirituality, as defined by this study and the creators of the CSBV survey, is broad enough to include students who may or may not be religious, which aligns with the conceptual framework for this study (HERI, 2004). Secondly, the CSBV allows both for internal and external behaviors that demonstrate spirituality (HERI, 2004). Thirdly, the language used in the adapted survey would maintain the original authors' intent to use unambiguous or unnecessarily inaccessible language (HERI, 2004). Finally, and in summary of the previous assumptions, the goal is that any student from the identified population would find the survey to be clear, manageable to be completed in a reasonable amount of time, and relevant to the student's experiences.

\section{Findings and Discussion}

Participant Classification by Class Ranking

\begin{tabular}{|c|c|c|c|c|c|}
\hline & & Frequency & $\underline{\text { Percent }}$ & $\underline{\text { Valid Percent }}$ & Cumulative \% \\
\hline \multirow[t]{6}{*}{ Valid } & Freshman & 15 & 11.2 & 11.3 & 11.3 \\
\hline & Sophomore & 21 & 15.7 & 15.8 & 27.1 \\
\hline & Junior & 45 & 33.6 & 33.8 & 60.9 \\
\hline & Senior & 45 & 33.6 & 33.8 & 94.7 \\
\hline & Graduate & 7 & 5.2 & 5.3 & 100.0 \\
\hline & Total & 133 & 99.3 & 100.0 & \\
\hline Missing & System & 1 & .7 & & \\
\hline Total & & 134 & 100.0 & & \\
\hline
\end{tabular}


First generation and low-income college students are the population of interest in this inquiry. Their participant breakdown is shown in Tables 3 and 4, respectively. Also, participants who were either first-generation or low-income are shown in Table 5 and participants who are both first-generation and low-income are shown in Table 6.

Participant Classification First Generation and/or Low Income Status

\begin{tabular}{llrrrr}
\hline \multirow{2}{*}{ Valid } & Neither FG nor LI & 23 & 17.2 & 17.3 & 17.3 \\
& Either FG or LI & 110 & 82.1 & 82.7 & 100.0 \\
& Total & 133 & 99.3 & 100.0 & \\
Missing & System & 1 & .7 & & \\
Total & & 134 & 100.0 & & \\
\hline
\end{tabular}

Participant Classification First Generation and Low Income Status

\begin{tabular}{|c|c|c|c|c|c|}
\hline \multirow{3}{*}{ Valid } & & Frequency & Percent & Valid Percent & Cumulative \% \\
\hline & $\begin{array}{c}\text { Not FG } \\
\text { and LI }\end{array}$ & 120 & 89.6 & 90.2 & 90.2 \\
\hline & FG and LI & 13 & 9.7 & 9.8 & 100.0 \\
\hline \multirow{3}{*}{ Missing } & Total & 133 & 99.3 & 100.0 & \\
\hline & System & 1 & .7 & & \\
\hline & Total & 134 & 100.0 & & \\
\hline
\end{tabular}

\section{Presentation of the Data}

Quantitative data derived from statistical analyses addressing the four research questions are presented in this section.

\section{Descriptive Statistics}

Listed in Table 7 are the descriptive statistics for all relevant variables in this inquiry, including standardized values for compositive variables created as a result of principal components analysis. Of note are the GPA means closer to maximum end of the range. Also, of 
note is apparent "averaging" of psychological wellbeing scores with means within the $70^{\text {th }}$ percentile, including all subdimentions with the exception of positive emotions $(M=6.596)$.

Table 7

Descriptive Statistics

\begin{tabular}{|c|c|c|c|c|c|c|}
\hline & $\underline{\mathrm{N}}$ & $\underline{\text { Range }}$ & Minimum & Maximum & Mean & $\underline{\mathrm{SD}}$ \\
\hline Previous semester GPA: & 120 & 2.30 & 1.70 & 4.00 & 3.3798 & .58688 \\
\hline Cumulative GPA: & 121 & 2.00 & 2.00 & 4.00 & 3.4168 & .48968 \\
\hline Positive Emotions & 125 & 7.67 & 2.00 & 9.67 & 6.5960 & 1.51948 \\
\hline Engagement & 125 & 5.67 & 4.33 & 10.00 & 7.5827 & 1.38777 \\
\hline Relationships & 125 & 7.00 & 3.00 & 10.00 & 7.5627 & 1.63212 \\
\hline Meaning & 125 & 7.67 & 2.33 & 10.00 & 7.3560 & 1.58670 \\
\hline Achievement & 125 & 7.67 & 2.33 & 10.00 & 7.3947 & 1.48311 \\
\hline $\begin{array}{l}\text { Psychological Wellbeing } \\
\text { (PERMA) }\end{array}$ & 125 & 5.75 & 3.94 & 9.69 & 7.2868 & 1.19247 \\
\hline Salient Spirituality & 120 & 4.28110 & -2.72969 & 1.55141 & -.022658 & .99257534 \\
\hline Spiritual Change and Crisis & 120 & 4.29763 & -1.92533 & 2.37229 & .004610 & 1.00717247 \\
\hline $\begin{array}{l}\text { Humanism, Non-spiritually } \\
\text { Identified }\end{array}$ & 120 & 4.66282 & -2.52968 & 2.13314 & -.006910 & 1.00690207 \\
\hline Spiritual Seeking Behavior & 120 & 5.42697 & -3.76113 & 1.66584 & .031370 & .97252915 \\
\hline Valid N (listwise) & 113 & & & & & \\
\hline
\end{tabular}

Provided in Table 8 are the descriptive statistics for the six items that helped comprise the composite variable, Salient Spirituality. 
Illustrated in Table 9 are the descriptive for prayer as a spiritual practice and proxy for spirituality, reflecting Kuh and Gonyea's (2006) earlier work. Prayer is used as a predictor variable in a later mediation analysis.

Table 9

Spiritual Behavior: Prayer

\begin{tabular}{|c|c|c|c|c|c|}
\hline \multirow{4}{*}{ Valid } & & Frequency & Percent & Valid Percent & Cumulative $\%$ \\
\hline & Yes & 76 & 56.7 & 60.3 & 60.3 \\
\hline & No & 50 & 37.3 & 39.7 & 100.0 \\
\hline & Total & 126 & 94.0 & 100.0 & \\
\hline Missing & System & 8 & 6.0 & & \\
\hline Total & & 134 & 100.0 & & \\
\hline
\end{tabular}

\section{Research Question One}

Is there a relationship between spirituality and psychological wellbeing among firstgeneration or low-income students at a public Midwestern university?

Included in Table 14 are the correlations Matrix of spiritual factors and psychological wellbeing. 


\section{Table 14}

Correlations Matrix - Spiritual Factors and Psychological Wellbeing

\begin{tabular}{|c|c|c|c|c|c|c|c|c|c|c|}
\hline First Generation / Low Income & 1 & 2 & 3 & 4 & 5 & 6 & 7 & 8 & 9 & 10 \\
\hline 12. Salient Spirituality & & & & & & & & & & \\
\hline 13. Spiritual Change and Crisis & .014 & & & & & & & & & \\
\hline $\begin{array}{l}\text { 14. Humanism, Non-Spiritually } \\
\text { Identified }\end{array}$ & -.050 & .008 & & & & & & & & \\
\hline 15. Spiritual Seeking Behavior & .028 & -.036 & -.026 & & & & & & & \\
\hline 16. Happiness & $\begin{array}{c}.379^{*} \\
*\end{array}$ & $\begin{array}{c}- \\
.362^{* *}\end{array}$ & -.020 & .111 & & & & & & \\
\hline 17. Positive Emotions & $\begin{array}{c}415^{*} \\
*\end{array}$ & $\begin{array}{c}- \\
.248^{* *}\end{array}$ & .100 & .102 & $.797^{* *}$ & & & & & \\
\hline 18. Engagement & $\begin{array}{c}.278^{*} \\
*\end{array}$ & .060 & $.247^{* *}$ & .054 & $.399^{* *}$ & $.422^{* *}$ & & & & \\
\hline 19. Relationships & $\begin{array}{c}.311^{*} \\
*\end{array}$ & $-.222^{*}$ & .105 & $.261^{* *}$ & $.716^{* *}$ & $.688^{* *}$ & $.486^{* *}$ & & & \\
\hline 20. Meaning & .160 & $\begin{array}{c}- \\
.327^{* *}\end{array}$ & .105 & .068 & $.608^{* *}$ & $.654^{* *}$ & $.316^{* *}$ & $.567^{* *}$ & & \\
\hline 21. Achievement & .094 & $.292^{* *}$ & .104 & -.122 & $.543^{* *}$ & $.503^{* *}$ & $.342^{* *}$ & $.451^{* *}$ & $.648^{* *}$ & \\
\hline 22. Psychological Wellbeing & $\begin{array}{c}.330^{*} \\
*\end{array}$ & $\begin{array}{c}- \\
.277^{* *}\end{array}$ & .154 & .100 & $.820^{* *}$ & $.854^{* * *}$ & $.633^{* *}$ & $.832^{* *}$ & $.820^{* * *}$ & $.747^{* *}$ \\
\hline
\end{tabular}

To examine whether a relationship exists between the relevant variables of the study among first generation or low-income students, a Pearson Correlation was conducted. Results of the Pearson correlation show a significant, modest, positive relationship between Salient Spirituality and Psychological Wellbeing $(\mathrm{r}(97)=.330 \mathrm{p}=<.001)$, a significant, modest, negative relationship between Spiritual Change and Crisis and Psychological Wellbeing $(\mathrm{r}(97)=-.277$ $\mathrm{p}=.003$ ), a slight, positive, near-significant relationship between Humanism, Non-spiritually Identified and Psychological Wellbeing $(\mathrm{r}(97)=.154 \mathrm{p}=.066)$, and a slight, positive, nonsignificant relationship between Spiritual Seeking Behavior and Psychological Wellbeing 
$(\mathrm{r}(97)=.100 \mathrm{p}=.165)$. These results reject the null hypothesis that there is no relationship between spirituality and psychological wellbeing.

\section{Research Question Two}

Is there a relationship between spirituality and academic performance among firstgeneration or low-income students at a public Midwestern university?

Provided in Table 15 are the correlations between spirituality and academic performance.

Table 15

Correlations Matrix: Spirituality and Academic Performance

\begin{tabular}{lrrrrrr}
\hline First Generation or Low Income & 1 & 2 & 3 & 4 & 5 & 6 \\
\hline 8. Salient Spirituality & & & & & & \\
9. Spiritual Change and Crisis & .014 & & & & & \\
10. Humanism, Non-Spiritually Identified & -.050 & .008 & & & & \\
11. Spiritual Seeking Behavior & .028 & -.036 & -.026 & & & \\
12. Previous Semester GPA & -.100 & -.009 & -.050 & $.179^{*}$ & & \\
13. Cumulative GPA & .041 & -.072 & -.001 & .116 & $.758^{* *}$ & \\
14. Good Academic Standing & .003 & $-.233^{*}$ & -.040 & .033 & $.172^{*}$ & $.418^{* *}$ \\
$*$ * Correlation is significant at the 0.05 level (1-tailed). & & & & & \\
$* *$ Correlation is significant at the 0.01 level (1-tailed). & & & & & \\
\hline
\end{tabular}

To examine whether a relationship exists between spirituality and academic performance among first generation or low-income students, a Pearson Correlation was conducted. Results of the Pearson correlation show a non-significant, weak, negative relationship between Salient Spirituality and Previous Semester GPA (r(93)=-.1000 p= .171), a non-significant, weak, positive relationship between Salient Spirituality and Crisis and Cumulative GPA (r(94)=.041 $\mathrm{p}=.349)$, and no relationships between Salient Spirituality and Good Academic Standing, $(\mathrm{r}(99)=$ $\cdot \mathrm{p}=.488)$ 
Results of the Pearson correlation also showed no relationship between Spiritual Change and Crisis and Previous Semester GPA $(\mathrm{r}(93)=-.009 \mathrm{p}=.466)$, no relationship between Spiritual Change and and Crisis and Cumulative GPA ( $(94)=-.072 \mathrm{p}=.246)$, and a significant, modest, negative relationship between Spiritual Change and Crisis and Good Academic Standing, $(\mathrm{r}(99)=-.233 \cdot \mathrm{p}=.01)$.

Further, results of the Pearson correlation also showed no relationship between Humanism, Non-spiritually Identified and Previous Semester GPA (r(93)=-.050 p= .315), no relationship between Humanism, Non-spiritually Identified and Cumulative GPA (r(94)=-.001 p=.495), and no relationship between Humanism, Non-spiritually Identified and Good Academic Standing, $(\mathrm{r}(99)=-.040 \cdot \mathrm{p}=.346)$.

Finally, results of the Pearson correlation also showed a significant, slight positive relationship between Spiritual Seeking Behavior and Previous Semester GPA $(r(93)=.179$ p= .043), a near significant, slight positive relationship between Spiritual Seeking Behavior and Cumulative GPA (r(94)=.133 p=.133), and no relationship between Spiritual Seeking Behavior and Good Academic Standing, $(\mathrm{r}(99)=.033$. $\mathrm{p}=.375)$. While some relationships appear to exist between wellbeing and academic performance, the researcher can neither accept nor reject the null hypothesis due to inconsistency in results.

\section{Research Question Three}

Does spirituality affect academic performance when mediated by psychological wellbeing among students at a public Midwestern university?

To see if spiritually predicts academic performance when mediated by psychological wellbeing, two mediation analyses were performed based upon established statistical relationships from previous analyses 
Figure 1

Mediation Model - Spirituality Crisis and Change, Wellbeing, and Academic Standing

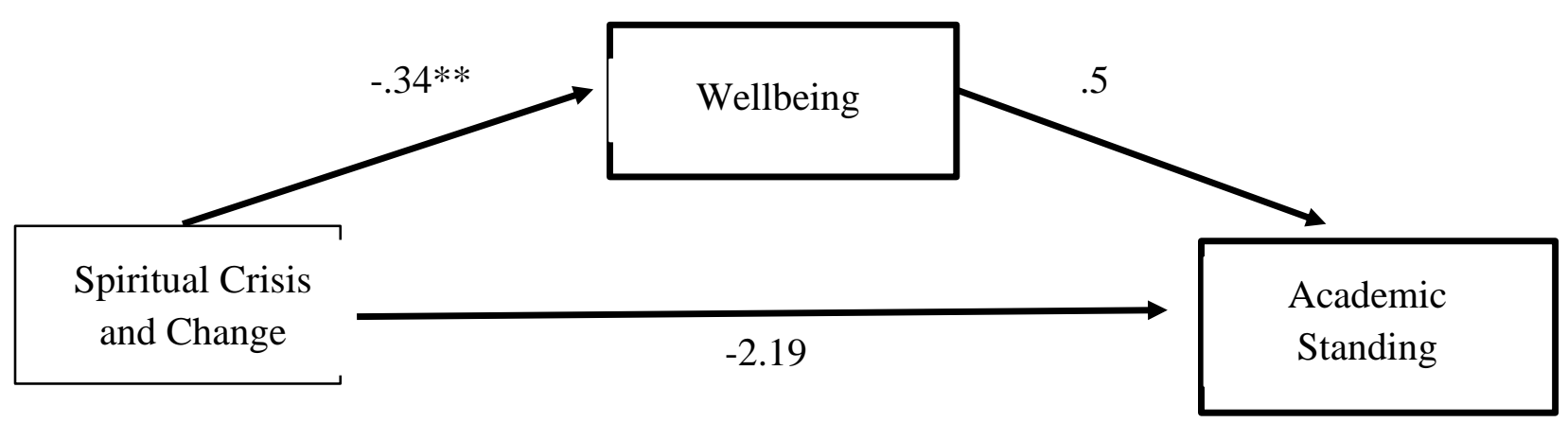

Regression analysis was used to investigate the hypothesis that psychological wellbeing mediates the effect of spirituality on academic performance. Results indicated that spiritual crisis and change was a near-significant predictor of psychological wellbeing, $B=-2.19, \mathrm{SE}=.129, \mathrm{p}$ $<.1$, and that psychological wellbeing was a non-significant predictor of academic standing, $\mathrm{B}=$ $.5, \mathrm{SE}=1.29 \mathrm{p}=.80$. These results do not support the mediational hypothesis, though spirituality is shown by way of mediation model, to be a significant predictor of psychological wellbeing. 
Figure 2

Mediation Model - Prayer, Wellbeing, and Academic Standing

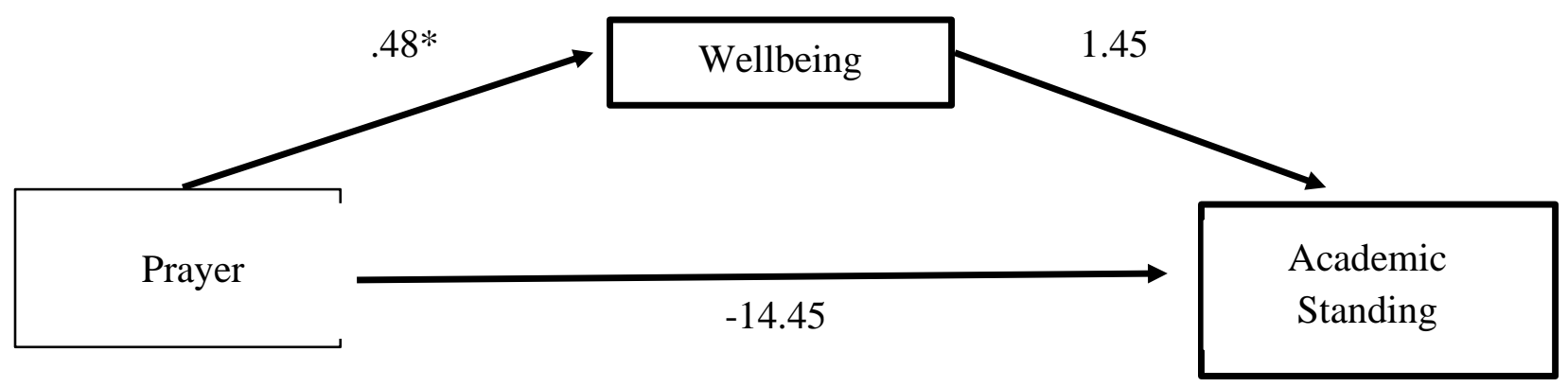

Recalling that prayer, a common spiritual exercise, is practiced by $60 \%$ of study participants, consideration was given as to what relationship, if any, it had with psychological wellbeing and academic performance. Considering Kuh \& Gonyea’s (2006) finding that practices like prayer correlate positively with exemplary student behaviors like decreased partying and increased involved in volunteering, perhaps prayer could serve as a proxy for spirituality.

Again, regression analysis was used to investigate the hypothesis that psychological wellbeing mediates the effect of spirituality on academic performance. Results indicated that prayer was a significant predictor of wellbeing, $\mathrm{B}=.48, \mathrm{SE}=.2151, \mathrm{p}<.05$, and that wellbeing was a near-significant predictor of academic performance, $\mathrm{B}=1.45, \mathrm{SE}=.829 \mathrm{p}=.08$. These results support the mediational hypothesis. Prayer was no longer a significant predictor of academic performance after controlling for the mediator, psychological wellbeing, $\mathrm{B}=14.45, \mathrm{SE}$ $=401.48, \mathrm{~ns}$, consistent with full mediation. 
Approximately $31 \%$ of the variance in academic standing was accounted for by the predictors $\left(R_{\mathrm{McFadden}}^{2}=.3066\right)$. The indirect effect was tested using a percentile bootstrap estimation approach with 5000 samples, implemented with the PROCESS macro Version 3.4 (Hayes, 2013). These results indicated the indirect coefficient was significant, $(\mathrm{B}=.6904, \mathrm{SE}=$ $18.34,95 \% \mathrm{CI}=.0469,60.8110)$. The indirect effect of prayer as associated with academic standing had an effect size of .69 when potentially mediated by psychological wellbeing.

While Baron and Kenny's (1986) assumptions require for the direct path between $\mathrm{x}$ and $\mathrm{y}$ (path C) variables to be significant, McFatter (1979) suggests that there may be situations where variable suppression causes $\mathrm{x}$ not to predict $\mathrm{y}$ in the mediation model, erroneously leading to the conclusion that mediation is not supported. Judd and Kenny (1981) also suggested that this may be possible. While indirect effect is supported in this model, whether mediation exists between the variables is inconclusive.

\section{Discussion of Findings}

\section{Four Components of Spirituality and Differences Between Groups}

Four components of spirituality accounted for nearly $50 \%$ of the variance among survey respondents: Salient spirituality, Spiritual Change and Crisis, Humanism, Non-spiritually identified, and Spiritual Seeking. Salient Spirituality describes individuals who articulate either strong belief or agreement with spiritual propositions or belief. In principal component analysis, this component of spirituality was the most strongly and positively correlated to survey items regarding spirituality being one of the most important aspects of one's life and lend meaning/purpose to one's life. As it relates to the conceptual framework, this component of spirituality was also strongly correlated to identity development. Salient Spirituality was 
moderately, negatively correlated with changing one's spiritual belief, suggesting stability, robustness, or rigidity.

The second component, Spiritual Crisis and Change, was most strongly correlated with questioning and changing one's beliefs. Incidentally, this component was also moderately connected with experiencing disagreements with loved ones and feeling overwhelmed. Further, Spiritual Crisis and Change was negatively, moderately correlated with the belief that difficult times can make someone stronger and slightly-negatively correlated with the belief that it is important to get a high GPA. Of the four components, this type had the strongest positive correlation to attending a retreat on spiritual matters. Whether or not the retreat prompted spiritual crisis or change or was meant to aid in the transition is unknown in this study and represents a future area of inquiry. A spirituality in transition, showing negatively correlations to wellbeing and aspiration of academic performance, may represent an overlooked but needed area of support for college students.

The third component, Humanism, Non-spiritually Identified represents beliefs about life and existence that are not derived from a religious or explicitly spiritual source. This component was strongly positively correlated to altruistic beliefs of magnanimity and the inherent goodness of people, more so than even the Spiritually Salient. Humanism, though moderately so, most correlated to feelings of overwhelm among the four modes of spirituality in college students. Interestingly, and lending to its designation as its own type, this component most consistently showed a weak, negative correlation to almost all explicit spiritual beliefs about existence.

The fourth and final component, Spiritual Seeking, describes three types of behaviors moderately-to-strongly and positively correlated with this component: participating in spiritual retreats, volunteering, and service learning. While spirituality is less salient in the component, it 
is more demonstrable. Of the components, Spiritual Seeking was the most moderately, negatively correlated with feeling overwhelmed but also slightly, negatively correlated with the belief that life is a gift.

As it relates to relates to RQ 1, results from independent samples t-tests comparing spirituality means between first-generation and low-income students and their peers suggest that there is no significant difference in spirituality between college students in the sample. These data support the null hypothesis.

\section{Spirituality and Psychological Wellbeing}

For this study, psychological wellbeing is defined using Seligman's (2011) PERMA framework which has dimensions of positive emotions $(\mathrm{P})$, engagement $(\mathrm{E})$, relationships $(\mathrm{M})$, and achievement (A). In a Pearson product moment correlation, Salient Spirituality was modestly and significantly correlated with psychological wellbeing and three of its five dimensions among first generation and low-income students. Conversely, Spiritual Crisis and Change was significantly and slightly, correlated with psychological wellbeing including four of its five dimensions. Further, in mediation analysis, spirituality was found to be a significant predictor of psychological wellbeing. As it pertains to the second research question, there is a statistically significant relationship between spirituality and psychological wellbeing among first-generation and low-income students.

However, the relationship between spirituality and the dimensions of psychological wellbeing organized differently than described by this study's conceptual framework. Chickening and Reisser's (1993) sixth vector, developing purpose, if one could draw a logical connection with Seligman's (2011) understanding of meaning, showed no significant relationship with spirituality, excepting for the case where spirituality is a negative predictor for 
meaning among students experiencing spiritual crisis or change. Incidentally, salient spirituality was only significantly correlated with positive emotions, engagement, and relationships.

Further, this study is concerned with, to what extent if any, spirituality serves as a predictor of wellbeing. Results from regression analysis support prayer as a predictor for psychological wellbeing. 6.997 is the expected PERMA, or psychological wellbeing score, when when prayer, as a predictor, is at zero. .48 is the expected change in psychological wellbeing among students who pray. This means that prayer is expected to improve aggregate wellbeing scores above the mean, which is 7.2868. Prayer, as one spiritual practice, is shown to be a predictor for psychological wellbeing among students at a public midwestern university.

These findings suggest that supporting students who identify as spiritual, particularly those who have either a salient sense of spirituality or are in crisis, has promise to support improving wellbeing measures. Further, this finding, if found to be consistent in other contexts, suggests that hesitance or reluctance to discuss spirituality on college campuses may come at the cost of student wellbeing. Stated directly, if higher education practitioners aspire to deal with the college mental health crisis seriously, they must be willing to address student spirituality authentically and robustly with students who are are/are becoming/no longer are spiritual. The initiatives, while likely inconvenient and uncomfortable for institutions unsure how to navigate within the tensions of spirituality and pluralism, are much more preferable than the present alternative.

\section{Academic Performance}

Academic Performance, defined in this study as cumulative GPA, semester GPA, and Academic Standing, comprised the third variable of analysis. If spirituality and wellbeing were linked, did this relationship extend to student behaviors that impact academic performance? Did 
students who were more spiritual than others or who reported higher levels of wellbeing than others also do better in a university setting? In this study, salient spirituality had no significant relationship with academic performance. However, spiritual crisis and change was significantly negatively correlated with academic standing, one component of academic performance as measured in this study. Also, spiritual seeking was slightly yet significantly correlated with previous semester GPA.

Due to the significant, though modest, negative correlations between spiritual crisis and the two outcome variables, psychological wellbeing and academic standing, a mediation analysis was conducted to see if spiritual crisis affected academic standing by way of psychological wellbeing, as hypothesized. When spiritual crisis was regressed on psychological wellbeing and academic standing, it was found to be a significant predictor of each though mediation, ultimately, was not supported in the model. However, in a separate mediation analysis, prayer was found to be an indirect predictor of good academic standing when mediated by psychological wellbeing. More analysis is needed to determine how these variables interact, with other proxies for academic performance considered. GPA, while the standard measure for academic performance, has limitations as variable in describing a student's performance and likelihood of retention and graduation. Future research is needed to determine what relationships, if any, spirituality has with various and sundry measures of academic performance beyond grade point averages.

Overall, potentially due to the constraints of the definition used in this study, spirituality and psychological wellbeing showed inconsistent or insignificant relationships with academic performance among students at a Midwestern university. 


\section{Implications for Practice}

The results of the study may serve as, at best, an illumination and, at worst, a warning, about an aspect of the mental health crisis on college and university campuses. If college and universities continue to, actively or passively, ignore the ultimate concerns of college students, colleges and universities will experience ultimate consequences.

At the very least, faculty and staff can begin by talking more openly about spiritual matters, lessening the taboo surrounding the subject. Fears that this will breach constitutionally protected rights are unlikely to be realized and dissipate under almost universal commitment to academic freedom. An inclusive understanding of spirituality, like one proposed by Hood, Hill, and Spillka (2018), promote a dialogue that transcends yet includes religion. Continued silence about this topic may not only be disingenuous given our understandings of each other, it may be dishonest given our understandings of ourselves.

Also, practitioners can create spaces to support the growth and development of spirituality across the student lifecycle. Expecting and anticipating for development, curricula, service learning, organizations, parainstutional campus ministries, ecumenical campus ministers, and pro-spiritual policies can create environments that support students as they are and as they are becoming. Advisors can, similar to other known student crises that the advisor has no direct experience with, receive training on how to support and guide students encountering existential crises. Other university staff can learn to probe beyond the common transitional concerns of students, moving beyond the superficial, to the spiritual. Institutions can do this without preferring one expression of spirituality or religion over another. To ensure that programs, curricula, and policies are effective, scholars can, emboldened with academic freedom, look 
deeper into the relationships between these phenomena and share the voices of students who have these experiences.

\section{Implications for Research}

Due to its taboo nature, much remains to be known about how spirituality may function within the lives of college students. Qualitative research is needed to understand the how spirituality is experienced by students, including their voices to articulate variables needing further analysis. Students, as evidenced by this study, also hold beliefs that inform their understanding of reality that are not explicitly religious or spiritual. Yet these beliefs not only inform their understanding, they inform behaviors, which become practices. Researchers can and must create inquiries to explore these factors and should not shy away from natural and logical inferences that have unpopular or inconvenient implications. Most people, let alone students, are not secular. If researchers fail for account for this reality responsibly, they invite an equal and opposite bias of the one ostensibly avoided through the veneer of signaled empiricismWhile the JCSD does not appear to conform to any one manual of style, it does have a style guide that cautions authors from misusing words as means to communicate power and privilege, particularly when discussing various racial and ethnic groups. 


\section{Journal References}

Adebayo, B. (2008). Cognitive and non-cognitive factors: Affecting the academic performance and retention of conditionally admitted freshmen. Journal of College Admission, 15-21.

Adams, T. B., Bezner, P. T, Drabbs, M. E., Zambarano, R. J., \& Steinhardt, M. A. (2000). Conceptualization and measurement of the spiritual and psychological wellness in a college population. Journal of American College Health, 48(4), 165-173.

Aruguete, M. S. (2017). Recognizing challenges and predicting success in first-generation university students. Journal of STEM Education: Innovations and Research, 18(2).

Astin, A. W., Astin, H. S., \& Lindholm, J. A. (2011). Assessing students' spiritual and religious qualities. Journal of College Student Development, 52(1), 39-61.

Astin, H. S., \& Lindholm, J. A. (2011). Understanding the "interior" life of faculty: How important is spirituality?. In M.D. Waggoner (Ed.) Sacred and Secular Tensions in Higher Education (pp. 63-85). New York, NY: Routledge.

Astin, A.W., Astin, H. S., Lindholm, J.A, Bryant, A.N, Calderone, S., \& Szelenyi, K. (2011) The spiritual life of college students. Higher Education Research Institute.

Auerbach, R. P., Mortier, P., Bruffaerts, R., Alonso, J., Benjet, C., Cuijpers, P., ... Kessler, R. C. (in press). The WHO World Mental Health Surveys International College Student Project: Prevalence and distribution of mental disorders. Journal of Abnormal Psychology, 127, 623-638. https://doi.org/10.1037/abn0000362

Bravo, A. J., Pearson, M. R., \& Stevens, L. E. (2016). Making religiosity person-centered: A latent profile analysis of religiosity and psychological health outcomes. Personality and Individual Differences, 88, 160-169. https://doi.org/10.1016/j.paid.2015.08.049. 
Breslau, J., Lane, M., Sampson, N., \& Kessler, R. C. (2008). Mental Disorders and Subsequent Educational Attainment in a US National Sample. Journal of Psychiatric Research, 42, 708-716.

Brubacher, J. (2017). Higher education in transition: History of American colleges and universities. New York, NY: Routledge.

Bruffaerts, R., Mortier, P., Kiekens, G., Auerbach, R. P., Cuijpers, P., Demyttenaere, K.,... Kessler, R. C. (2018). Mental health problems in college freshmen: Prevalence and academic functioning. Journal of Affective Disorders, 225, 97-103. http://dx.doi.org/10.1016/j.jad.2017 .07.044

Butler, J., \& Kern, M. L. (2015). The PERMA-Profiler: A brief multidimensional measure of flourishing. Available from http://www.peggykern.org/questionnaires.html

Chickering, A. W., Dalton, J. C., \& Stamm, L. (2006). Encouraging authenticity and spirituality in higher education. San Francisco, CA: Jossey-Bass.

Chickering, A. W., \& Reisser, L. (1993). Education and identity. (2 ${ }^{\text {nd }}$ ed.). San Francisco, CA: Jossey-Bass.

Choy, S.P. (2002). Access \& persistence: Findings from 10 years of longitudinal research on students. Washington, DC: American Council on Education, Center for Policy Analysis.

Clark, W. H. (1958). How do social scientists define religion? The Journal of Social Psychology, 47(1), 143-147.

Cortina, J. M. (1993). What is coefficient alpha? An examination of theory and applications. Journal of applied psychology, 78(1), 98.

Creswell, J. W. (2013). Research design: Qualitative, quantitative, and mixed methods approaches. ( $4^{\text {th }}$ ed.). Thousand Oaks, CA: Sage. 
Daaleman, T. P., \& Frey, B. B. (2004). The spirituality index of wellbeing: A new instrument for health-related quality-of-life research. The Annals of Family Medicine, 2(5), 499-503.

Dalton, J. C., Eberhardt, J. B., Bracken, J. \& Echols, K. (2006). Inward journeys: Forms and patterns of college student spirituality. Journal of College and Character, 8, 1-22.

Davis, T. L., Kerr, B. A., \& Kurpius, S. E. R. (2003). Meaning, purpose, and religiosity in at-risk youth: The relationship between anxiety and spirituality. Journal of Psychology and Theology, 31(4), 356-365.

Diener, E. (1984). Subjective wellbeing. Psychological Bulletin, 95, 542-575

Diener, E., Lucas, R. E., \& Oishi, S. (2002). Subjective wellbeing: The science of happiness and life satisfaction. Handbook of positive psychology, 2, 187-194.

Duckworth, A. L., Peterson, C., Matthews, M. D., \& Kelly, D. R. (2007). Grit: perseverance and passion for long-term goals. Journal of Personality and Social Psychology, 92(6), 1087.

Dweck, C. S. (2008). Mindset: The new psychology of success. New York, NY: Random House

Engle, J., \& Tinto, V. (2008). Moving beyond access: College success for low-income, firstgeneration students. Washington, DC: The Pell Institute for the Study of Opportunity in Higher Education.

Fowler, F. J. (2009). Survey research methods (4th ed.). Thousand Oaks, CA: Sage.

Fowler, J.W., \& Dell, M.L. (2006). Stages of faith from infancy through adolescence: Reflections on three decades of faith development theory. In E.C. Roehlkepartain, P.E. King, L. Wagener, \& P.L. Benson (Eds.), The handbook of spiritual development in childhood and adolescence (pp. 34-45). Thousand Oaks, CA: Sage. .

Fowler JW. (1981) Stages of faith. San Francisco, CA: Harper Collins. 
Goodman, F., Disabato, D., Kashdan, T., \& Kauffman, S. (2017). Measuring wellbeing: A comparison of subjective wellbeing and PERMA. The Journal of Positive Psychology, 112. doi:10.1080/17439760.2017.1388434

HERI. (2004) The spiritual life of college students: A national study of students' search for meaning and purpose. HERI - Higher Education Research Institute. Retrieved from https://spirituality.ucla.edu/background/methodology/longitudinal-study.php

Hettler, B. (1984). Wellness: Encouraging a lifetime pursuit of excellence. Health Values: Achieving High-Level Wellness, 8(4), 13-17.

Hood Jr, R. W., Hill, P. C., \& Spilka, B. (2018). The psychology of religion: An empirical $\operatorname{approach}\left(4^{\text {th }}\right.$ ed.) New York, NY: Guilford.

Hughes, C., Stenhjem, P. H., \& Newkirk, R. (2007). Poverty, race and youth: Challenges and promising practices in education. International Journal on School Disaffection, 5(1), 2228

Katrevich, A.V. \& Aruguete, M. S. (2017). Recognizing challenges and predicting success in first-generation university students. Journal of STEM Education: Innovations and Research, 18(2).40-44.

Kitzrow, M. A. (2009). The mental health needs of today's college students: Challenges and recommendations. NASPA Journal, 46(4), 646-660.

Kosmin, Barry and Ariela Keysar. 2009. American nones: The profile of the no religion population. Hartford, CT: Program on Public Values, Trinity College.

Kuh, George D. and Robert M. Gonyea. 2006. Spirituality, liberal learning, and college student engagement. Liberal Education 92(1):40-47. 
Lippincott, J. A., \& German, N. (2007). From blue collar to ivory tower: Counseling firstgeneration, working-class students. In J. A. Lippincott \& R. B. Lippincott (Eds.), Special populations in college counseling: A handbook for mental health professionals (pp. 8998). Alexandria, VA: American Counseling Association.

Low, C. A., \& Handal, P. J. (1995). The relationship between religion and adjustment to college. Journal of College Student Development, 36, 406-412

MacKinnon, D.P., Krull, J.L., \& Lockwood, C.M. (2000). Equivalence of mediation, confounding and suppression effect. Prevention Science, 1, 173-181.

Markowitz, T. (2017, August 16). The Barriers to Success and Upward Mobility For First Generation Students And How To Fix The Problem. Retrieved from https://www.forbes.com/sites/troymarkowitz/2017/08/08/the-barriers-to-success-andupward-mobility-for-first-generation-students-and-how-to-fix-theproblem/\#1f919f7e1cb3

Martin, L. (2000). The relationship of college experiences to psychosocial outcomes in students. Journal of College Student Development, 41, 294-302.

Mattis, J. S. (2000). African American women's definitions of spirituality and religiosity. Journal of Black Psychology, 26(1), 101-122.

Miller, W. R. \& Martin J. E. (1988). Spirituality and behavioral psychology: Toward integration. In W. R. Miller and J. E. Martin (Eds.) Behavior therapy and religion: Integrating spiritual and behavioral approaches to change (13-23). Newbury Park, CA: Sage 
McCarron, G. P., \& Inkelas, K. K. (2006). The gap between educational aspirations and attainment for first-generation college students and the role of parental involvement. Journal of College Student Development, 47(5), 534-549.

Nelms, L.W., Hutchins, E., Hutchins, D., \& Pursley, R.J (2006) Spirituality and the health of college students. Journal of Religion and Health. Blanton-Peale Institute

Padgett, R. D., Johnson, M. P., \& Pascarella, E. T. (2012). First-generation undergraduate students and the impacts of the first year of college: Additional evidence. Journal of College Student Development, 53(2), 243-266.

Pargament, K. I., Sullivan, M. S., Balzer, W. K., Van Haitsma, K. S., \& Raymark, P. H. (1995). The many meanings of religiousness: A policy capturing approach. Journal of Personality, 63, 953-983.

Pargament, K. I. (2001). The psychology of religion and coping: Theory, research, practice. New York, NY: Guilford.

Parks, S. (1986). The critical years: Young adults and the search for meaning, faith, and commitment. San Francisco, CA: Harper Collins.

Parks, S. (2000). Big questions, worthy dreams: Mentoring young adults in their search for meaning, purpose, and faith. San Francisco, CA: Jossey-Bass

Pascarella, E. T., Pierson, C. T., Wolniak, G. C., and Terenzini, P. T. (2004). First Generation College Students: Additional Evidence on College Experiences and Outcomes. The Journal of Higher Education, 75(3): 249-284.

Pascarella, E.T. \& Terenzini, P.T. (2005) How college affects students. San Francisco, CA; Jossey-Bass. 
Perna, L. W. (2015). Improving college access and completion for low-income and firstgeneration students: The role of college access and success programs. Invited testimony presented to the Subcommittee on Higher Education and Workforce Training, Committee on Education and the Workforce, United States House of Representatives, Washington, DC

Reisser, L. (1995). Revisiting the seven vectors. Journal of College Student Development, 36, 505-511.

Roberts, J. H., Turner, J., \& Turner, J. (2000). The sacred and the secular university. Princeton, NJ: Princeton University Press.

Rudolph, F. (1962). The American college and university: A history. Athens, GA; University of Georgia Press.

Stewart, D. L. (2009). Perceptions of multiple identities among black college students. Journal of College Student Development, 50(3), 253-270. Retrieved from https://login.cyrano.ucmo.edu/login?url=https://search-proquestcom.cyrano.ucmo.edu/docview/195178714?accountid=6143

Straub, C. A. (1987). Women's development of autonomy and Chickering's theory. Journal of College Student Personnel, 28, 198-205.

Streib, H. (2001). Faith development theory revisited: The religious styles perspective. The International Journal for the Psychology of Religion, 11(3), 143-158.

Tebbs, J., \& Turner, S. (2005). Low-income students a caution about using data on Pell grant recipients. Change: The Magazine of Higher Learning, 37(4), 34-43. 
Terenzini, P. T, Rendon, L. L, Upcraft, M. L., Millar, S. B., Allison, K. W, Gregg, P. L., et al. (1994). The transition to college: Diverse students, diverse stories. Research in Higher Education, 35, 57-73.

Terenzini, P. T., Springer, L., Yaeger, P. M., Pascarella, E. T., \& Nora, A. (1996). Firstgeneration college students: Characteristics, experiences, and cognitive development. Research in Higher education, 37(1), 1-22.

Thayer, P. (2000). Retention of students from first-generation and low-income backgrounds. The Journal of the Council for Opportunity in Education, Washington, DC: Council for Opportunity in Education

Tinto, V. (2012). Completing college: Rethinking institutional action. Chicago, IL: University of Chicago Press.

Tinto, V. (2006). Research and practice of student retention: What next? Journal of College Student Retention: Research, Theory \& Practice, 8(1), 1-19.

Walker, K. L., \& Dixon, V. (2002). Spirituality and academic performance among African American college students. Journal of Black Psychology, 28(2), 107-121.

Wolverton, B. (2019, February 21). As Students Struggle With Stress and Depression, Colleges Act as Counselors. Retrieved from https://www.nytimes.com/2019/02/21/education/learning/mental-health-counseling-oncampus.html

Yeh, T. L. (2010). Service-learning and persistence of low-income, first-generation college students: An exploratory study. Michigan Journal of Community Service Learning, 16(2), $50-65$. 
Zinnbauer, B. J., Pargament, K. I., Cole, B., Rye, M. S., Butter, E. M., Belavich, T. G., Hipp, K. M., Scott, A. B., \& Kadar, J. L. (1997). Religion and spirituality: Unfuzzying the fuzzy. Journal for the Scientific Study of Religion, 36, 549-564. 


\section{SECTION SIX}

\section{SCHOLARLY PRACTIONER REFLECTION}


When I began this program I was a program director for a federal grant program that served $200+$ students that had just returned to its service space within our institution after a nine-month relocation due to asbestos abatement. I was a relatively new father and my wife and I were settling into that life with all of its joys and struggles. We just had our second child and I was unsure of how to manage being a father and husband, which was and remains my priority, and program director leading a program trying to get its bearings. Support to do the program was virtually unanimous from past graduates, coworkers, and supervisors. I felt I lacked the time to do it well. In response, many said there's never a good time to get your doctorate. I also felt I lacked ambition for what one was supposed to do with the degree. Like some of my peers, I did not have necessarily crave an upper administration appointment, a role, I observed, often kept leaders from their families. I was already in leadership, and had enough to do and learn.

But I missed the conversations, the readings, the arguing, and rumbling over competing theories and principles that were a fixture in my graduate degree program. I found myself reading articles for fun, thinking about their implications, remarking at impracticability of some recommendations. I reasoned that I did not need an ambition, rather, I needed to be ready to make a contribution. I was the first in my family to get a college degree, so I did not have status points to achieve in my personal sphere. But, there were opportunities in education that I felt I could contribute to, and put some skin in the game, as it were.

While I did not have an end in mind for the degree, I did have a research topic: this one. I knew and would tell the few who would listen, that I wanted to research 
student spirituality. This surprised people and worried some others. Could I conduct rigorous, quantitative research on an alternative topic like student spirituality? I'll let the reader and the committee judge those merits. My hope is that we can, as scholar practitioners, consider options that make be risky and unconventional to address problems that are monumental and specific. If not us, who? This is the drive I have accessed, as motivation has waxed and waned.

In the last three years I have been promoted, twice. I now oversee responsibilities for academic support for the entire university. More removed from students than I would like and more than I ever thought I would be, I work with a team to help support them across the student life cycle. The readings and class discussions within the cohort have been practiced. Norms? That's from Summer One. Program evaluation? Fall 2018. Dealing with team dysfunction? On-going.

I did not finish high school. I do not think about it as much as I used to, as the negative consequences of that choice have dissipated with time. In education, and in other areas of life both large and small, I have often struggled to finish what I started. In Mad Men, when Faye tells Don Draper "You only like the beginning of things," it can, at times, feel like an indictment. But, with the evidence presented in this volume, I have come to the end of section, seeing an idea through to completion. I must say, it is satisfying, and I am tired. 


\section{REFERENCES}




\section{References}

Adebayo, B. (2008). Cognitive and non-cognitive factors: Affecting the academic performance and retention of conditionally admitted freshmen. Journal of College Admission, 15-21.

Adams, T. B., Bezner, P. T, Drabbs, M. E., Zambarano, R. J., \& Steinhardt, M. A. (2000). Conceptualization and measurement of the spiritual and psychological wellness in a college population. Journal of American College Health, 48(4), 165-173.

Aruguete, M. S. (2017). Recognizing challenges and predicting success in first-generation university students. Journal of STEM Education: Innovations and Research, 18(2).

Astin, A. W., Astin, H. S., \& Lindholm, J. A. (2011). Assessing students' spiritual and religious qualities. Journal of College Student Development, 52(1), 39-61.

Astin, H. S., \& Lindholm, J. A. (2011). Understanding the "interior" life of faculty: How important is spirituality?. In M.D. Waggoner (Ed.) Sacred and Secular Tensions in Higher Education (pp. 63-85). New York, NY: Routledge.

Astin, A. W. (1993). What matters in college: Four critical years revisited. San Francisco, CA: Jossey-Bass.

Astin, A. W. (2004). Why Spirituality Deserves a Central Place in Liberal Education. Liberal education, 90(2), 34-41

Astin, A.W., Astin, H. S., Lindholm, J.A, Bryant, A.N, Calderone, S., \& Szelenyi, K. (2011) The spiritual life of college students. Higher Education Research Institute.

Auerbach, R. P., Mortier, P., Bruffaerts, R., Alonso, J., Benjet, C., Cuijpers, P., ... Kessler, R. C. (in press). The WHO World Mental Health Surveys International College Student 
Project: Prevalence and distribution of mental disorders. Journal of Abnormal Psychology, 127, 623-638. https://doi.org/10.1037/abn0000362

Bardach, E., \& Patashnik, E. M. (2015). A practical guide for policy analysis: The eightfold path to more effective problem solving. New York: Chatham

Bolman, L. G., \& Deal, T. E. (2013). Reframing organizations: Artistry, choice, and leadership. San Francisco, CA: Jossey-Bass

Baron, R. M., \& Kenny, D. A. (1986). The moderator-mediator variable distinction in social psychological research: Conceptual, strategic, and statistical considerations. Journal of Personality and Social Psychology, 51, 1173-1182

Baumeister, R. F., Vohs, K. D., Aaker, J. L., \& Garbinsky, E. N. (2013). Some key differences between a happy life and a meaningful life. The Journal of Positive Psychology, 8(6), 505-516. Doi: 10.1080/17439760.2013.830764

Bowman, N. A. (2010). The development of psychological wellbeing among first-year college students. Journal of College Student Development, 51(2), 180-200.

Bravo, A. J., Pearson, M. R., \& Stevens, L. E. (2016). Making religiosity person-centered: A latent profile analysis of religiosity and psychological health outcomes. Personality and Individual Differences, 88, 160-169. https://doi.org/10.1016/j.paid.2015.08.049.

Breslau, J., Lane, M., Sampson, N., \& Kessler, R. C. (2008). Mental Disorders and Subsequent Educational Attainment in a US National Sample. Journal of Psychiatric Research, 42, 708-716.

Brubacher, J. (2017). Higher education in transition: History of American colleges and universities. New York, NY: Routledge. 
Bruffaerts, R., Mortier, P., Kiekens, G., Auerbach, R. P., Cuijpers, P., Demyttenaere, K.,... Kessler, R. C. (2018). Mental health problems in college freshmen: Prevalence and academic functioning. Journal of Affective Disorders, 225, 97-103. http://dx.doi.org/10.1016/j.jad.2017.07.044

Bryant, A. N., Choi, J. Y., \& Yasuno, M. (2003). Understanding the religious and spiritual dimensions of students' lives in the first year of college. Journal of College Student Development, 44(6), 723-745.

Butler, J., \& Kern, M. L. (2015). The PERMA-Profiler: A brief multidimensional measure of flourishing. Available from http://www.peggykern.org/questionnaires.html

Cabrera, A. F. \& La Nasa, S. M. (2001). On the path to college: Three critical tasks facing America's disadvantaged. Research in Higher Education, 42(2), 119-150.

Chickering, A. W. (1969). Education and identity. San Francisco, CA: Jossey-Bass.

Chickering, A. W., \& Braskamp, L. A. (2009). Developing a global perspective for personal and social responsibility. Peer Review, 11, 27-30.

Chickering, A. W., Dalton, J. C., \& Stamm, L. (2006). Encouraging authenticity and spirituality in higher education. San Francisco, CA: Jossey-Bass.

Chickering, A. W., \& Reisser, L. (1993). Education and identity. (2 ${ }^{\text {nd }}$ ed.). San Francisco, CA: Jossey-Bass.

Choy, S.P. (2002). Access \& persistence: Findings from 10 years of longitudinal research on students. Washington, DC: American Council on Education, Center for Policy Analysis.

Clark, M.A., Brooks, M., Lee, S.M., Daley, L.P., Crawford, Y., \& Maxis, S. (2006). Factors influencing the educational success of minority pre-service educators. Journal of College Student Retention, 8(1), 121-135. 
Clark, W. H. (1958). How do social scientists define religion? The Journal of Social Psychology, 47(1), 143-147.

Coffey, J. K., Wray-Lake, L., Mashek, D., \& Branand, B. (2016). A multi-study examination of wellbeing theory in college and community samples. Journal of Happiness Studies, 17, $187-211$.

Cortina, J. M. (1993). What is coefficient alpha? An examination of theory and applications. Journal of applied psychology, 78(1), 98.

Covarrubias, R., \& Fryberg, S. A. (2015). Movin'on up (to college): First-generation college students' experiences with family achievement guilt. Cultural Diversity and Ethnic Minority Psychology, 21(3), 420.

Creswell, J. W. (2013). Research design: Qualitative, quantitative, and mixed methods approaches. ( $4^{\text {th }}$ ed.). Thousand Oaks, CA: Sage.

Daaleman, T. P., \& Frey, B. B. (2004). The spirituality index of wellbeing: A new instrument for health-related quality-of-life research. The Annals of Family Medicine, 2(5), 499-503.

Dalton, J. C., Eberhardt, J. B., Bracken, J. \& Echols, K. (2006). Inward journeys: Forms and patterns of college student spirituality. Journal of College and Character, 8, 1-22.

Davis, T. L., Kerr, B. A., \& Kurpius, S. E. R. (2003). Meaning, purpose, and religiosity in at-risk youth: The relationship between anxiety and spirituality. Journal of Psychology and Theology, 31(4), 356-365.

Diener, E. (1984). Subjective wellbeing. Psychological Bulletin, 95, 542-575

Diener, E., Lucas, R. E., \& Oishi, S. (2002). Subjective wellbeing: The science of happiness and life satisfaction. Handbook of positive psychology, 2, 187-194. 
Dolan, P., Layard, R., \& Metcalfe, R. (2011). Measuring subjective wellbeing for public policy: Recommendations on measures. Centre for Economic Performance, Special Paper No. $23,1-20$

Duckworth, A. L., Peterson, C., Matthews, M. D., \& Kelly, D. R. (2007). Grit: perseverance and passion for long-term goals. Journal of Personality and Social Psychology, 92(6), 1087.

Dudley, T. (1650). Harvard charter of 1650. Harvard University.

Dunn, H.L. (1961) High Level Wellness. Washington, DC: Mt. Vernon.

Dweck, C. S. (2008). Mindset: The new psychology of success. New York, NY: Random House Eitel, S.J., \& Martin, J. (2009). First generation female college students' financial literacy; Real and perceived barriers to degree completion. College Student Journal, 43, 616-630.

Engle, J., \& Tinto, V. (2008). Moving beyond access: College success for low-income, firstgeneration students. Washington, DC: The Pell Institute for the Study of Opportunity in Higher Education.

Ettling, D. (2012). Educator as change agent: Ethics of transformative learning. In E. W. Taylor \& P. Cranton (Eds.), Handbook of Transformative Learning: Theory, Research, and Practice (pp. 536- 552). San Francisco, CA: Jossey-Bass.

Federal Student Aid. (2019). Federal Pell grants. Retrieved from https://studentaid.ed.gov/sa/types/grants-scholarships/pell

Fowler, F. J. (2009). Survey research methods (4th ed.). Thousand Oaks, CA: Sage.

Fowler, J.W., \& Dell, M.L. (2006). Stages of faith from infancy through adolescence: Reflections on three decades of faith development theory. In E.C. Roehlkepartain, P.E. King, L. Wagener, \& P.L. Benson (Eds.), The handbook of spiritual development in childhood and adolescence (pp. 34-45). Thousand Oaks, CA: Sage. . 
Fowler JW. (1981) Stages of faith. San Francisco, CA: Harper Collins.

Fry, L. W. (2003). Toward a theory of spiritual leadership. The Leadership Quarterly, 14, 693 727.

Fry, L. W. (2005). Toward a theory of ethical and spiritual wellbeing, and corporate social responsibility through spiritual leadership. Positive Psychology in Business Ethics and Corporate Responsibility, 47-83.

Fry, L. W. (2009). Spiritual leadership as a model for student inner development. Journal of Leadership Studies, 3(3), 79-82.

Gilligan, C. (1977). In a different voice: Women's conceptions of self and of morality. Harvard Educational Review, 47(4), 481-517.

Goodman, F., Disabato, D., Kashdan, T., \& Kauffman, S. (2017). Measuring wellbeing: A comparison of subjective wellbeing and PERMA. The Journal of Positive Psychology, 112. doi:10.1080/17439760.2017.1388434

Greenway, K. A. (2006). The role of spirituality in purpose in life and academic engagement. Journal of College \& Character, VII(6), 1-5.

Hancock, J. (2018). Higher education takes $\$ 70$ million hit in Gov. Greitens' budget plan. The Kansas City Star. Retrieved from https://www.kansascity.com/news/politicsgovernment/article196060924.html

Hardison, K., \& Washburn, K. (2018, January 23). Greitens' proposed budget cuts higher education funding again. Retrieved from https://www.columbiamissourian.com/news/higher_education/greitens-proposed-budgetcuts-higher-education-funding-again/article_d5cec5ce-ffd3-11e7-a5e0-8f3ef7aec15f.html 
Hartocollis, A. (2017, July 9) Long after protests, students shun the University of Missouri.

Retrieved from https://www.nytimes.com/2017/07/09/us/university-of-missourienrollment-protests-fallout.html

Hayes, A. F. (2013). Introduction to mediation, moderation, and conditional process analysis: A regression-based approach. New York, NY: Guilford Press.

Hebert, T.P. (2018) An examination of high-achieving fist-generation college students from lowincome backgrounds. Gifted Child Quarterly. 62(1). 96-110

HERI. (2004) The spiritual life of college students: A national study of students' search for meaning and purpose. HERI - Higher Education Research Institute. Retrieved from https://spirituality.ucla.edu/background/methodology/longitudinal-study.php

Hettler, B. (1984). Wellness: Encouraging a lifetime pursuit of excellence. Health Values: Achieving High-Level Wellness, 8(4), 13-17.

Hood Jr, R. W., Hill, P. C., \& Spilka, B. (2018). The psychology of religion: An empirical approach (4 $4^{\text {th }}$ ed.) New York, NY: Guilford.

Hill, P. C., \& Hood, R. W. (Eds.). (1999). Measures of religiosity Birmingham, AL: Religious Education Press.

Hughes, C., Stenhjem, P. H., \& Newkirk, R. (2007). Poverty, race and youth: Challenges and promising practices in education. International Journal on School Disaffection, 5(1), 2228

Jagers, R.J., \& Smith, P. (1996). Further examination of the spirituality scale. Journal of Black Psychology, 22, 429-442.

Judd C.M., \& Kenny D.A (1981). Estimating the effects of social interventions. Cambridge University Press; New York: 1981 
Katrevich, A.V. \& Aruguete, M. S. (2017). Recognizing challenges and predicting success in first-generation university students. Journal of STEM Education: Innovations and Research, 18(2).40-44.

Kitzrow, M. A. (2009). The mental health needs of today's college students: Challenges and recommendations. NASPA Journal, 46(4), 646-660.

Khaw, D., \& Kern, M. (2014). A cross-cultural comparison of the PERMA model of wellbeing. Undergraduate Journal of Psychology at Berkeley, University of California, 8(1), 10-23.

Kosmin, Barry and Ariela Keysar. 2009. American nones: The profile of the no religion population. Hartford, CT: Program on Public Values, Trinity College.

Kuh, George D. and Robert M. Gonyea. 2006. Spirituality, liberal learning, and college student engagement. Liberal Education 92(1):40-47.

Levi, D. J. (2017). Group dynamics for teams (5 $5^{\text {th }}$ ed.). Los Angeles, CA: Sage.

Lippincott, J. A., \& German, N. (2007). From blue collar to ivory tower: Counseling firstgeneration, working-class students. In J. A. Lippincott \& R. B. Lippincott (Eds.), Special populations in college counseling: A handbook for mental health professionals (pp. 8998). Alexandria, VA: American Counseling Association.

Love, P. G. (2002). Comparing Spiritual Development and Cognitive Development. Journal of college student development, 43(3), 357-73.

Love, P., \& Talbot, D. (1999). Defining spiritual development: A missing consideration for student affairs. NASPA Journal, 37(1), 361. Retrieved from https://login.cyrano.ucmo.edu/login?url=https://search.proquest.com/docview/223532155 ?accountid=6143 
Low, C. A., \& Handal, P. J. (1995). The relationship between religion and adjustment to college. Journal of College Student Development, 36, 406-412

MacKinnon, D.P., Krull, J.L., \& Lockwood, C.M. (2000). Equivalence of mediation, confounding and suppression effect. Prevention Science, 1, 173-181.

Markowitz, T. (2017, August 16). The Barriers to Success and Upward Mobility For First Generation Students And How To Fix The Problem. Retrieved from https://www.forbes.com/sites/troymarkowitz/2017/08/08/the-barriers-to-success-andupward-mobility-for-first-generation-students-and-how-to-fix-theproblem/\#1f919f7e1cb3

Martin, L. (2000). The relationship of college experiences to psychosocial outcomes in students. Journal of College Student Development, 41, 294-302.

Martinez, I., \& Turner, S. (2015). The productivity of Pell grant spending: Enrollment versus attainment. Change, 47(5), 55-62.

Mattis, J. S. (2000). African American women's definitions of spirituality and religiosity. Journal of Black Psychology, 26(1), 101-122.

Mayol, M.H. (2012). Wellness: The Total Package. 2nd ed. Dubuque, IA: Kendall Hunt Publishing Company

Mayol M.H., Scott B.M., Schreiber J.B. (2017) Validation and use of the multidimensional wellness inventory in collegiate student-athletes and first-generation students. Am J Health Educ. 2017;48(5):338-50

M.D.H.E (2019). Admissions selectivity categories. Missouri Department of Higher Education. Retrieved from https://dhe.mo.gov/policies/admissions-selectivity.php 
Miller, W. R. \& Martin J. E. (1988). Spirituality and behavioral psychology: Toward integration. In W. R. Miller and J. E. Martin (Eds.) Behavior therapy and religion: Integrating spiritual and behavioral approaches to change (13-23). Newbury Park, CA: Sage

McCarron, G. P., \& Inkelas, K. K. (2006). The gap between educational aspirations and attainment for first-generation college students and the role of parental involvement. Journal of College Student Development, 47(5), 534-549.

McFatter, R. M. (1979). The "Use of structural equation models in interpreting regression equations including suppressor and enhancer variables," Applied Psychological Measurement, 3 (1), 123-35

Mullin C.M. (2013). Past, present, and possibilities for the future of the Pell Grant Program. Journal of Education Finance, 39 (1), 3-14.

Murphy, J. (2018, December 3). UCM Honors Three Individuals Who Devoted Their Lives to Justice Dec. 8. Retrieved from https://www.ucmo.edu/news/university-news/posts/201812-03-ucm-honors-three-individuals-who-devoted-their-lives-to-justice-dec-8.php

Nelms, L.W., Hutchins, E., Hutchins, D., \& Pursley, R.J (2006) Spirituality and the health of college students. Journal of Religion and Health. Blanton-Peale Institute

Northouse, P.G. (2010). Leadership theory and practice. 5th Ed. Thousand Oaks, CA: Sage Publications.

Padgett, R. D., Johnson, M. P., \& Pascarella, E. T. (2012). First-generation undergraduate students and the impacts of the first year of college: Additional evidence. Journal of College Student Development, 53(2), 243-266. 
Pargament, K. I., Sullivan, M. S., Balzer, W. K., Van Haitsma, K. S., \& Raymark, P. H. (1995). The many meanings of religiousness: A policy capturing approach. Journal of Personality, 63, 953-983.

Pargament, K. I. (2001). The psychology of religion and coping: Theory, research, practice. New York, NY: Guilford.

Parks, S. (1986). The critical years: Young adults and the search for meaning, faith, and commitment. San Francisco, CA: Harper Collins.

Parks, S. (2000). Big questions, worthy dreams: Mentoring young adults in their search for meaning, purpose, and faith. San Francisco, CA: Jossey-Bass

Pascarella, E. T., Pierson, C. T., Wolniak, G. C., and Terenzini, P. T. (2004). First Generation College Students: Additional Evidence on College Experiences and Outcomes. The Journal of Higher Education, 75(3): 249-284.

Pascarella, E.T. \& Terenzini, P.T. (2005) How college affects students. San Francisco, CA; Jossey-Bass.

Perry, W. G., Jr. (1970). Forms of intellectual ethical and intellectual development in the college years. New York, NY: Holt, Rinehart \& Winston.

Perna, L. W. (2015). Improving college access and completion for low-income and firstgeneration students: The role of college access and success programs. Invited testimony presented to the Subcommittee on Higher Education and Workforce Training, Committee on Education and the Workforce, United States House of Representatives, Washington, DC 
Ramos-Sánchez, L., \& Nichols, L. (2007). Self-efficacy of first-generation and non-firstgeneration college students: The relationship with academic performance and college adjustment. Journal of College Counseling, 10(1), 6-18.

Reisser, L. (1995). Revisiting the seven vectors. Journal of College Student Development, 36, $505-511$.

Rendón, L. I., Jalomo, R. E., \& Nora, A. (2000). Theoretical considerations in the study of minority student retention in higher education. In J. M. Braxton (Ed.), Reworking the student departure puzzle (pp.127-156). Nashville, TN: Vanderbilt University Press.

Roberts, J. H., Turner, J., \& Turner, J. (2000). The sacred and the secular university. Princeton, NJ: Princeton University Press.

Rudolph, F. (1962). The American college and university: A history. Athens, GA; University of Georgia Press.

Soria, K. M., \& Stebleton, M. J. (2012). First-generation students' academic engagement and retention. Teaching in Higher Education, 17(6), 673-685.

Stebleton, M. J., Soria, K. M., \& Huesman Jr, R. L. (2014). First-generation students' sense of belonging, mental health, and use of counseling services at public research universities. Journal of College Counseling, 17(1), 6-20.

Stewart, D. L. (2009). Perceptions of multiple identities among black college students. Journal of College Student Development, 50(3), 253-270. Retrieved from https://login.cyrano.ucmo.edu/login?url=https://search-proquestcom.cyrano.ucmo.edu/docview/195178714?accountid=6143

Straub, C. A. (1987). Women's development of autonomy and Chickering's theory. Journal of College Student Personnel, 28, 198-205. 
Streib, H. (2001). Faith development theory revisited: The religious styles perspective. The International Journal for the Psychology of Religion, 11(3), 143-158.

Taub, D. J. (1995). Relationship of selected factors to traditional-age undergraduate women's development of autonomy. Journal of College Student Development, 36, 141-151

Tebbs, J., \& Turner, S. (2005). Low-income students a caution about using data on Pell grant recipients. Change: The Magazine of Higher Learning, 37(4), 34-43.

Terenzini, P. T, Rendon, L. L, Upcraft, M. L., Millar, S. B., Allison, K. W, Gregg, P. L., et al. (1994). The transition to college: Diverse students, diverse stories. Research in Higher Education, 35, 57-73.

Terenzini, P. T., Springer, L., Yaeger, P. M., Pascarella, E. T., \& Nora, A. (1996). Firstgeneration college students: Characteristics, experiences, and cognitive development. Research in Higher education, 37(1), 1-22.

Thayer, P. (2000). Retention of students from first-generation and low-income backgrounds. The Journal of the Council for Opportunity in Education, Washington, DC: Council for Opportunity in Education

Tinto, V. (2012). Completing college: Rethinking institutional action. Chicago, IL: University of Chicago Press.

Tinto, V. (2006). Research and practice of student retention: What next? Journal of College Student Retention: Research, Theory \& Practice, 8(1), 1-19.

Trockel, M. T., Barnes, M. D., \& Egget, D. L. (2000). Health-related variables and academic performance among first-year college students: implications for sleep and other behaviors. Journal of American College Health, 49(3), 125-131. 
University of Central Missouri. (2019). UCM's History. Retrieved from https://www.ucmo.edu/about/fast-facts/ucm-history/index.php

University of Central Missouri. (2019). Factbook 2018. Retrieved from https://www.ucmo.edu/offices/university-analytics-and-institutional$\underline{\text { research/factbook.pdf }}$

University of Central Missouri Enrollment Management. (2019). Enrollment Update. Internal enrollment report. unpublished

University of Central Missouri Office of University Analytics and Institutional Research. (2019). Retention Data. Internal retention report. Unpublished

U. S. Department of Education. (1996). Application for grants under the student support services program. Washington, DC: Author

Walker, K. L., \& Dixon, V. (2002). Spirituality and academic performance among African American college students. Journal of Black Psychology, 28(2), 107-121.

Williams, R., Smiley, E., Davis, R., \& Lamb, T. (2018). The Predictability of Cognitive and Non-cognitive Factors on the Retention Rate among Freshmen College Students. The Journal of Negro Education, 87(3), 326-337.

Wolverton, B. (2019, February 21). As Students Struggle With Stress and Depression, Colleges Act as Counselors. Retrieved from https://www.nytimes.com/2019/02/21/education/learning/mental-health-counseling-oncampus.html

Yeh, T. L. (2010). Service-learning and persistence of low-income, first-generation college students: An exploratory study. Michigan Journal of Community Service Learning, 16(2), $50-65$. 
Zinnbauer, B. J., Pargament, K. I., Cole, B., Rye, M. S., Butter, E. M., Belavich, T. G., Hipp, K. M., Scott, A. B., \& Kadar, J. L. (1997). Religion and spirituality: Unfuzzying the fuzzy. Journal for the Scientific Study of Religion, 36, 549-564.

Zinnbauer, B. J., Pargament, K. I., \& Scott, A. B. (1999). The emerging meanings of religiousness and spirituality: Problems and prospects. Journal of Personality, 67(6), 889-919.

Zinnbauer, B. J., \& Pargament, K. I. (1998). Spiritual conversion: A study of religious change among college students. Journal for the Scientific Study of Religion, 161-180 
APPENDIX 


\section{APPENDIX A}

\section{Institutional Review Board}

University of Missouri-Columbia

FWA Number: 0002876

IRB Registration Numbers: 00000731, 00009014
482 McReynolds Hall

Columbia, MO 65211

573-882-3181

irb@missouri.edu

October 24, 2019

Principal Investigator: Christopher Beggs (MU-Student)

Department: Educational Leadership-EDD

Your IRB Application to project entitled Spirituality and Wellbeing in First-Generation and LowIncome College Students was reviewed and approved by the MU Institutional Review Board according to the terms and conditions described below:

IRB Project Number

IRB Review Number

Initial Application Approval Date

IRB Expiration Date

Level of Review

Project Status

Exempt Categories (Revised Common

Rule)

Risk Level
2017809

254887

October 24, 2019

October 24, 2020

Exempt

Active - Exempt

45 CFR 46.104d(2)

Minimal Risk

The principal investigator (PI) is responsible for all aspects and conduct of this study. The PI must comply with the following conditions of the approval:

1. No subjects may be involved in any study procedure prior to the IRB approval date or after the expiration date.

2. All changes must be IRB approved prior to implementation utilizing the Exempt Amendment Form.

3. The Annual Exempt Form must be submitted to the IRB for review and approval at least 30 days prior to the project expiration date to keep the study active or to close it.

4. Maintain all research records for a period of seven years from the project completion date.

If you are offering subject payments and would like more information about research participant payments, please click here to view the MU Business Policy and Procedure:

http://bppm.missouri.edu/chapter2/2_250.html

If you have any questions or concerns, please contact the MU IRB Office at 573-882-3181 or email to muresearchirb@missouri.edu.

Thank you,

MU Institutional Review Board 


\section{Appendix B}

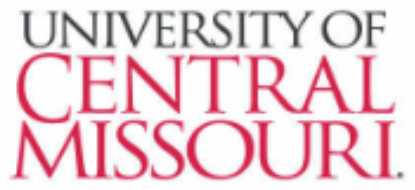

LEARNING TO A GREATER DEGREE
UCM Research Compllance Committees Administration 102 Warrensburg, MO 64093 Office: $660-543-8562$ researchreview@ucmo.edu

External Protocol Review

$10 / 24 / 2019$

Protocol Number: 1543

Dear Chris Beggs:

Your research project, 'Splrituality and Wellbeing in Flrst-Generation and Low-Income Students', was approved by the University of Central Missouri Human Subjects Review Committee (IRB) on 10/24/2019. You may collect data for thie project until 10/24/2020.

If an adverse event (such as harm to a research participant) occurs during your project, you must IMMEDIATELY stop the research unless stopping the research would cause more harm to the participant. If an adverse event occurs during your project, notify the committee IMMEDIATELY at researchreview@ucmo.edu.

The following will help to guide you. Please refer to this letter often during your project.

- If you wish to make changes to your study, submit an "Amendment" to the IRB committee. You may not implement changes to your study without prior approval of the UCM Human Subjects Review Committee.

- If the nature or status of the risks of participating in this research project change, submit an "Amendment" to the IRB committee. You may not implement changes to your study without prior approval of the UCM Human Subjects Review Committee.

- Near your expiration date $(10 / 24 / 2020)$ for collecting data, if you have not finished collecting data:

1. submit your project application to the IRB committee (include any revisions and/or amendments approved since you submitted your application initially)

AND

2. submit a "Renewal Report" to the IRB committee.

- When you have completed your collection of data, please submit the "Final Report" to the IRB committee.

If your protocol contained a consent form and the consent form was approved, you will receive an additional e-mail. The e-mail will contain a copy of your consent form with an approval stamp in the top right corner. Do not begin data collection until you receive a copy of your consent form with an approval stamp. Note: One year after your protocol's approval date, a request for renewal $O R$ a final project report is required.

Resources: https://www.ucmo.edu/offices/sponsored-programs-and-research-integrity/forms-andresources/index.php

If you have any questions, please feel free to contact me at researchreview@ucmo.edu.

Sincerely,

Institutional Review Board

Equal Education and Ėmployment Opportunity 


\section{Appendix C}

Survey

\section{Informed Consent}

\section{Start of Block: SURVEY INSTRUCTION}

\section{Start of Block: Informed Consent}

\section{Q1 Welcome to the Student Experience Survey}

We are interested in understanding student, spirituality, wellbeing, and academic performance. You will be presented with information relevant to spirituality, wellbeing, and academic performance and asked to answer some questions about it. Please be assured that your responses will be kept completely confidential.

The study should take you around 10-15 minutes to complete, and you will have an opportunity to be entered to win either a pair of headphones or \$XX Amazon Gift Card your participation. Ys vour participation in this research is voluntary. You have the right to withdraw at any point during the study, for any reason, and without any prejudice. If you would like to contact the Principal Investigator in the study to discuss this research, please email Chris Beggs at crb6fc@mail.missouri.edu or the faculty advisor Dr. Barbara Martin at bmartin@ucmo.eduistep

By clicking the button below, you acknowledge that your participation in the study is voluntary, you are 18 years of age, and that you are aware that you may choose to terminate your participation in the study at any time and for any reason.

Please note that this survey will be best displayed on a laptop or desktop computer. Some features may be less compatible for use on a mobile device.

I consent, begin the study (1)

I do not consent, I do not wish to participate (2) 
Q28 Which best describes you?

Male (1)

Female (2)

Please write the best description (3)

Q3 Did one or more of your biological parents earn a bachelor's degree?

Yes (1)

I'm not sure (2)

No (3)

Q4 Do you receive a Pell grant?

Yes (1)

I'm not sure (2)

No (3)

Q5 Which best describes you?

Freshman (1)

Sophomore (2)

Junior (3)

Senior (4)

Graduate (5)

I am not a student (6) 


\section{Start of Block: Block 2}

Q6 Since starting college have you: (Mark all that apply)

Discussed religion/spirituality with friends (1)

Worked on or off campus (2)

Attended an extracurricular event (3)

Studied abroad (4)

Joined a fraternity or sorority (5)

Met with an advisor (6)

Debated a political issue (7)

Discussed religion/spirituality in class (8)

Used the student recreational center (9) 
Q7 For the activities listed below, please indicate how often you engaged in each since starting college

Participating in a Frequently (1) Occasionally (2) Not at all (3) student organization

(1)

Attending a religious service (2)

Volunteering (3)

Attending athletic events (4)

Getting help from a tutor (5)

Getting help from a faculty member (6) Getting assistance from financial aid staff (7)

Q8 Compared to when you first started college, how would you now describe your (mark one for each item) 


Much
Stronger (1) $\begin{aligned} & \text { Stronger (2) No change Weaker (4) } \\ & \text { Knowledge of } \\ & \text { financial aid } \\ & \text { (1) } \\ & \text { Ability to } \\ & \text { navigate } \\ & \text { campus (2) } \\ & \text { Confidence in } \\ & \text { sharing ideas } \\ & \text { (3) } \\ & \text { Spirituality (4) } \\ & \text { Understandin } \\ & \text { g of national } \\ & \text { issues (5) } \\ & \text { Knowledge of } \\ & \text { future career } \\ & \text { opportunities } \\ & \text { (6) }\end{aligned}$

Q9 How often have your faculty provided you with (mark one for each item)

Study guides to help Frequently (1) Occasionally (2) Not at all (3) for exam (1) Help during office hours (2)

Recommendations for internships or employment (3) Advice or general mentoring (4)

Encouragement to discuss religious/spiritual matters (5) 
Q10 Please indicate the importance to you personally of each of the following (mark one for each item)

\section{Essential (1)}

Getting hired in one's preferred field upon graduation (1) Studying for a career that I find personally satisfying (2) Meeting new people on campus (3) Graduating with a little debt as possible (4)

Getting leadership experience as a student (5) Integrating spirituality into my life (6) Setting a good example for my family (7) Getting a high GPA (8)

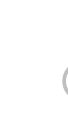

\section{Very Important}

(2)

Somewhat

Important (3)

Not Important

(4)
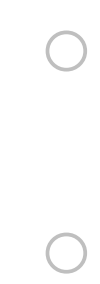

$\bigcirc$ 
Q11 Please indicate your agreement with each of the following statements: (mark one for each item)

Agree Strongly

(1)

As much as

possible we

should try to get

along (1)

Anyone can be

successful in

college if they try

hard enough (2)

We are all

spiritual beings

(3)

Everything

happens for a

reason (4)

Most people are

good (5)

Life is a gift (6)

Difficult times

can make

someone

stronger (7)

People are

products of their

circumstances

(8)

I know someone

I can turn to for

spiritual

guidance (9)
Agree
Disagree
Disagree
Somewhat (2)
Somewhat (3)
Strongly (4) 
Q13 Since beginning college, please indicate how often you have: (mark one for each item) Frequently (1) Occasionally (2) Not at All (3)

Participated in volunteer work or service learning (1)

Felt overwhelmed (2)

Had disagreements with loved ones (3)

Visited home (4)

Questioned your religious/spiritual beliefs (5)

Talked to friends who do not attend this college (6) Changed your mind about a previously held belief (7) Attended a class/workshop or retreat on matters related to spirituality (8) 
Q14 My spiritual/religious beliefs: (mark one for each item)

$\begin{array}{llll}\text { Agree Strongly } & \text { Agree } & \text { Disagree } & \text { Disagree } \\ (1) & \text { Somewhat (2) } & \text { Somewhat (3) } & \text { Strongly (4) }\end{array}$

Have helped me develop my identity (1)

Are one of the most important things in my life

(2)

Give meaning/purpos

e to my life (3) Help define the goals I set for myself (4)

Provide me with strength, support, and guidance (5) Lie behind my whole approach to life (6)

Q15.

\begin{tabular}{lllllllllll} 
Never & \multicolumn{1}{c}{ Always } \\
& $\begin{array}{lllllllllll} & & & & & & \\
& 1 & 2 & 3 & 4 & 5 & 6 & 7 & 8 & 9 & 10\end{array}$
\end{tabular}


How much of the time do you feel you are making progress towards accomplishing your goals? ()

How often do you become absorbed in what you are doing? ()

In general, how often do you feel joyful? ()

In general, how often do you feel anxious? ()

How often do you achieve the important goals you have set for yourself? ()
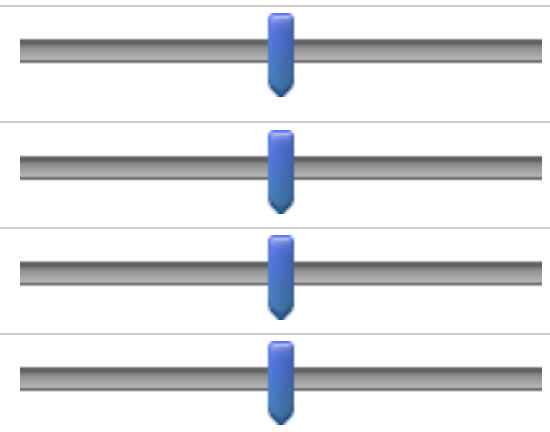

Q16.

Terrible Excellent

$\begin{array}{lllllllllll}0 & 1 & 2 & 3 & 4 & 5 & 6 & 7 & 8 & 9 & 10\end{array}$

In general, how would you say your health is? ()

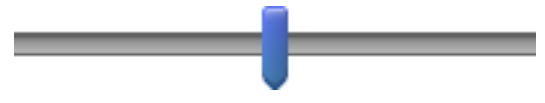

Q17.

Not at All Completely

$\begin{array}{lllllllllll}0 & 1 & 2 & 3 & 4 & 5 & 6 & 7 & 8 & 9 & 10\end{array}$


In general, to what extent do you lead a purposeful and meaningful life? ()

To what extent do you receive help and support from others when you need it? ()

In general, to what extent do you feel that what you do in your life is valuable and worthwhile? ()

In general, to what extent do you feel excited and interested in things? ()

How lonely do you feel in your daily life? ()

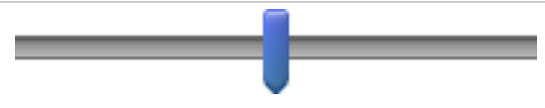

\section{End of Block: Block 2}

\section{Start of Block: Block 5}

Q18.

Not at all Completely

$\begin{array}{lllllllllll}0 & 1 & 2 & 3 & 4 & 5 & 6 & 7 & 8 & 9 & 10\end{array}$

How satisfied are you with your current physical health? ()

\section{End of Block: Block 5}

\section{Start of Block: Block 6}

Q19.

Never Always

$\begin{array}{lllllllllll}0 & 1 & 2 & 3 & 4 & 5 & 6 & 7 & 8 & 9 & 10\end{array}$




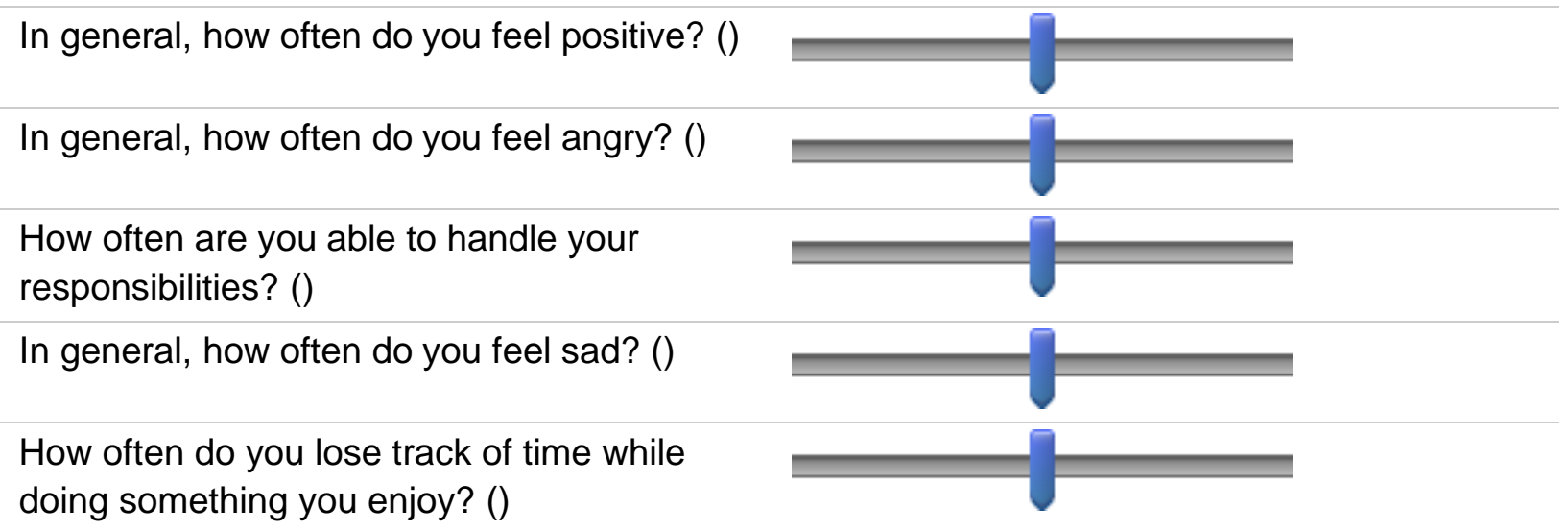

Q20 .

Terrible Excellent

$\begin{array}{lllllllllll}0 & 1 & 2 & 3 & 4 & 5 & 6 & 7 & 8 & 9 & 10\end{array}$

Compared to others of your same age and sex, how is your health? ()

Q21.

Not at All Completely

$\begin{array}{lllllllllll}0 & 1 & 2 & 3 & 4 & 5 & 6 & 7 & 8 & 9 & 10\end{array}$ 
To what extent do you feel loved? ()

To what extent do you generally feel you have a sense of direction in your life? ()

How satisfied are you with your personal relationships? ()

In general, to what extent do you feel contented? ()

\section{End of Block: Block 7}

\section{Start of Block: Block 8}

Q22.

Not at all Completely

$\begin{array}{lllllllllll}0 & 1 & 2 & 3 & 4 & 5 & 6 & 7 & 8 & 9 & 10\end{array}$

Taking all things together, how happy would you say you are? ()

\section{End of Block: Block 8}

\section{Start of Block: Block 3}

Q23 My last semester GPA was:

Q25 My best estimate of my cumulative GPA is: 
Q26 The following best describes me:

I am currently a student in good academic standing (1)

I am currently on academic probation (2)

I am unsure (3)

End of Block: Block 3

Start of Block: Block 4 


\section{Appendix D}

Permission to Adapt and Use the College Student Beliefs and Values Survey

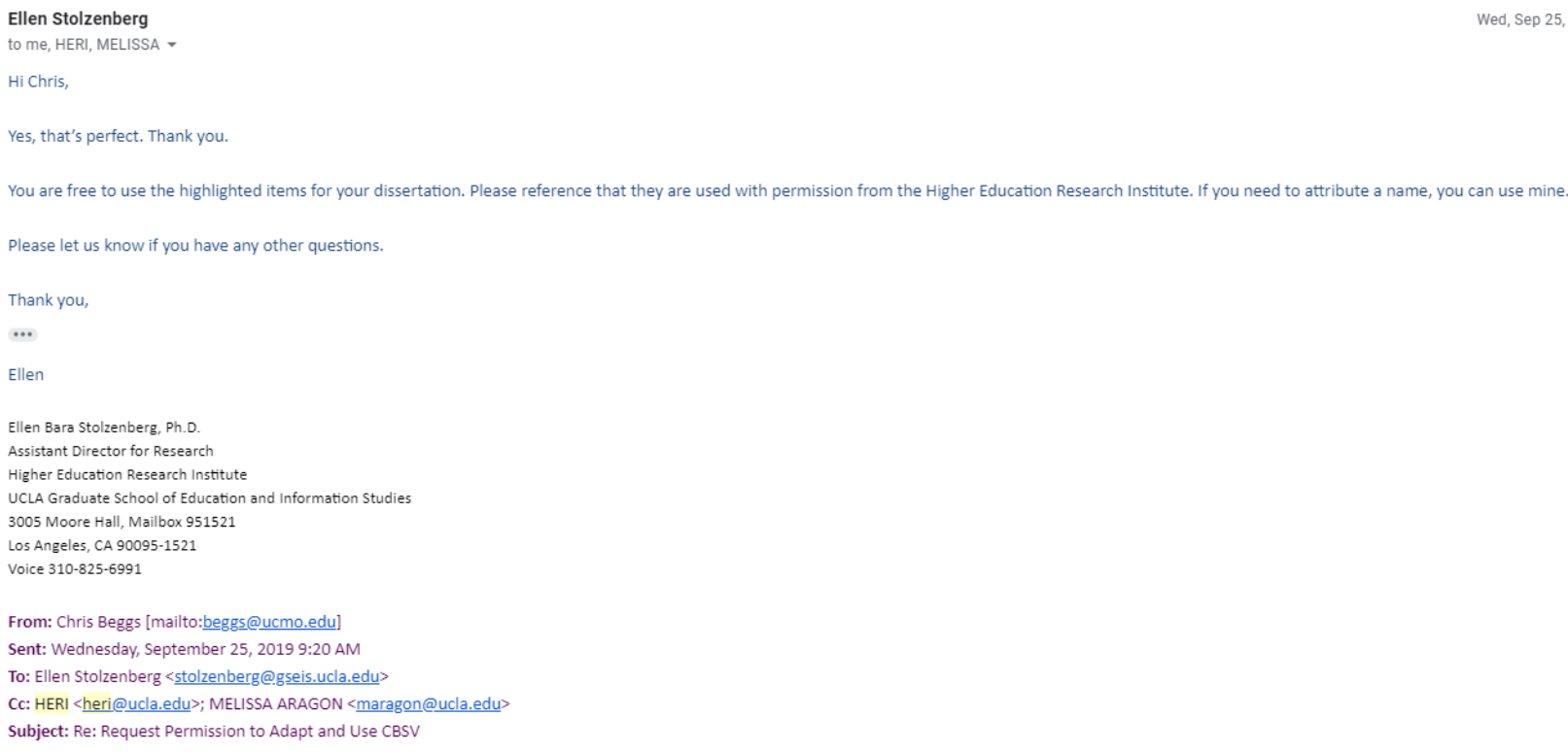




\section{Appendix E}

Permission to Use the PERMA-Profiler

You are welcome to use the measure for noncommercial research or assessment purposes, giving credit as noted below. There is no cost involved in using the measure for these purposes.

Before using the measure, please read through this document, and register by completing this form.

Please cite the measure as:

Butler, J., \& Kern, M. L. (2015). The PERMA-Profiler: A brief multidimensional measure of flourishing. Available from http://www.peggykern.org/questionnaires.html 


\section{VITA}

Chris Beggs is from Kansas City, Missouri. He is the son of Jeanette and Walter Johnston. He earned his General Educational Development (GED) certification from the State of Missouri. In 2007, he earned a bachelors degree in education and in 2012 he earned a masters degree in college student personnel administration, both from the University of Central Missouri. In 2020, he earned a doctorate in educational leadership and policy analysis from the University of Missouri- Columbia.

Chris has spent most of his career in higher education helping first-generation and lowincome students flourish in college and earn bachelors degrees. Starting as a graduate assistant in the campus diversity office, Chris then went on to be an advisor in the federal grant program, TRIO-Student Support Services. Promoted to director in 2015, Chris led the program to improved outcomes for first-generation, low-income, and disability-challenged students. In 2018, Chris was given an interim assignment, in addition to other duties, as the director of the university's learning center and its services, known as the Learning Commons. In 2019, Chris was promoted as the Executive Director of Academic Support Services, charged with providing leadership to campus-wide support of enrolled students, now also including Title III programs and services such as freshman seminar, scaling corequisite courses, creation of active learning classrooms, and gateway course redesign as well as the creation of first year programs. Next he hopes to help lead a conversation in implementation of spiritual development and support interventions for students in public universities.

Chris currently resides in Kansas City, Missouri. 